\title{
Genetische und agronomische Charakterisierung von Raps-Mutanten mit gesteigertem Ölsäuregehalt
}

\author{
Dissertation \\ zur Erlangung des Doktorgrades \\ der Fakultät für Agrarwissenschaften \\ der Georg-August-Universität Göttingen
}

\author{
vorgelegt von \\ Maria Kahlmeyer \\ geboren in Leinefelde
}

Göttingen, September 2009 
D 7

1. Referentin/Referent:

2. Korreferentin/Korreferent:

Tag der mündlichen Prüfung
Prof. Dr. H. C. Becker

Prof. Dr. E. Pawelzik

19.11.2009 


\section{Abkürzungsverzeichnis}

$\begin{array}{ll}\text { A } & \text { Adenin } \\ \text { ACP } & \text { Acyl-Carrier-Protein } \\ \text { ATP } & \text { Adenosintriphosphat } \\ \text { C } & \text { Cytosin } \\ \text { CoA } & \text { Coenzym A } \\ \text { DAG } & \text { Diacylglycerin } \\ \text { DNA } & \text { Desoxyribonukleinsäure } \\ \text { EMS } & \text { Ethylmethansulfonat } \\ \text { ER } & \text { Endoplasmatisches Retikulum } \\ \text { FAD } & \text { fatty acid desaturase (Fettsäure-Desaturase) } \\ \text { G } & \text { Guanin } \\ \text { HO } & \text { high oleic } \text { (Hoch-Ölsäure) } \\ \text { MUFA } & \text { monounsaturated fatty acid (einfach ungesättigte Fettsäure) } \\ \text { PCR } & \text { polymerase chain reaction (Polymerase-Kettenreaktion) } \\ \text { PUFA } & \text { polyunsaturated fatty acid (mehrfach ungesättigte Fettsäure) } \\ \text { RNA } & \text { Ribonukleinsäure } \\ \text { T } & \text { Thymin } \\ \text { TAG } & \text { Triacylglycerin }\end{array}$

$\begin{array}{llll}\text { A } & \text { Alanin } & \text { L } & \text { Leucin } \\ \text { R } & \text { Arginin } & \text { K } & \text { Lysin } \\ \text { N } & \text { Asparagin } & \text { M } & \text { Methionin } \\ \text { D } & \text { Asparaginsäure } & \text { F } & \text { Phenylalanin } \\ \text { C } & \text { Cystein } & \text { P } & \text { Prolin } \\ \text { Q } & \text { Glutamin } & \text { S } & \text { Serin } \\ \text { E } & \text { Glutaminsäure } & \text { T } & \text { Threonin } \\ \text { G } & \text { Glycin } & \text { W } & \text { Tryptophan } \\ \text { H } & \text { Histidin } & \text { Y } & \text { Tyrosin } \\ \text { I } & \text { Isoleucin } & \text { V } & \text { Valin }\end{array}$

Fettsäuren werden im Text auch in Zahlenform abgekürzt. Dabei wird die Anzahl der Kohlenstoffatome in der Fettsäure durch die Zahl vor dem Doppelpunkt und die Anzahl der Doppelbindungen durch die Zahl nach dem Doppelpunkt angegeben. So steht z.B. C18:1 für Ölsäure. 


\section{Inhaltsverzeichnis}

1. Allgemeine Einleitung und Problemstellung.............................................................1

1.1 Der Raps und seine Entwicklung zur Nutzpflanze........................................

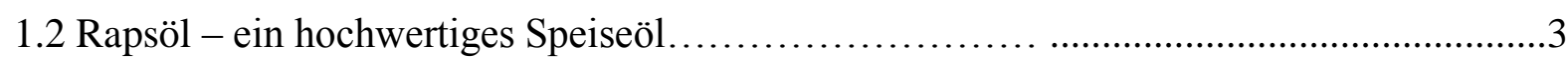

1.3 Rapsöl als Futtermittel und nachwachsender Rostoff.............................................5

1.4 Züchtungsfortschritte und Anforderungen an moderne Rapssorten.................................6

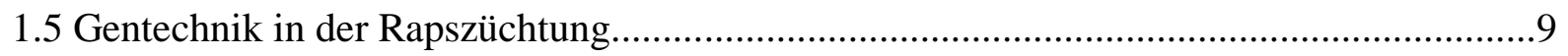

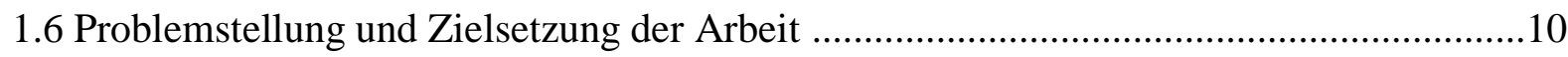

2. Fettsäuremuster und agronomische Eigenschaften der Mutanten ...............................12

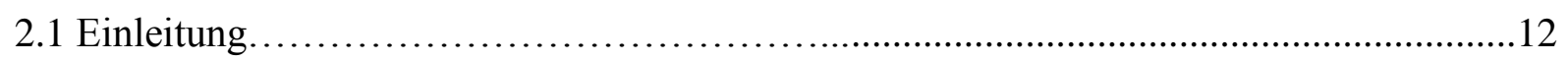

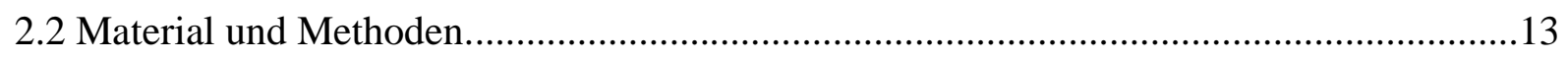

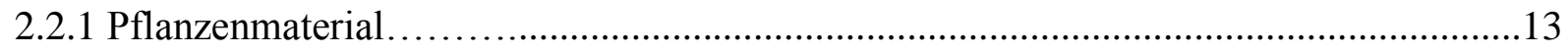

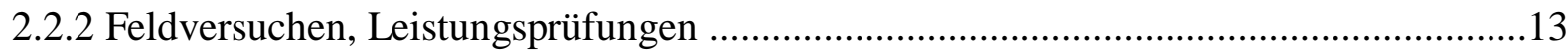

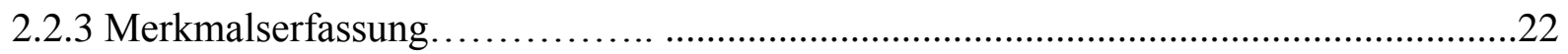

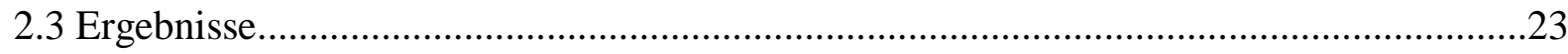

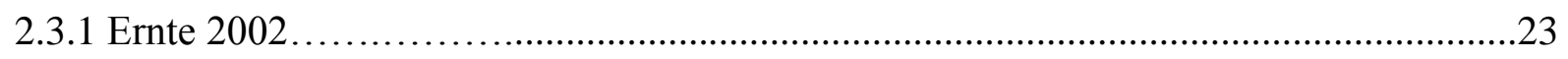

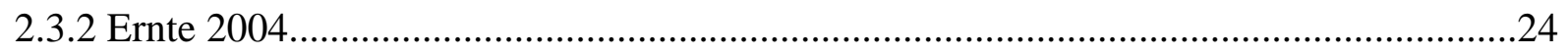

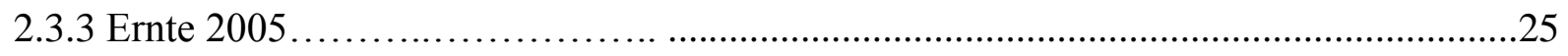

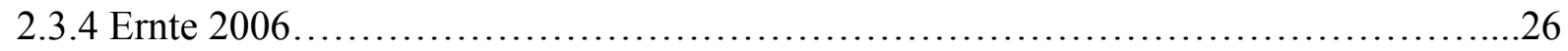

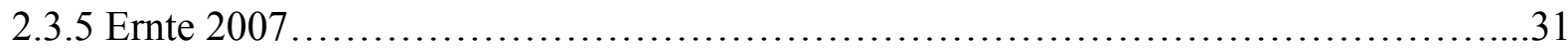

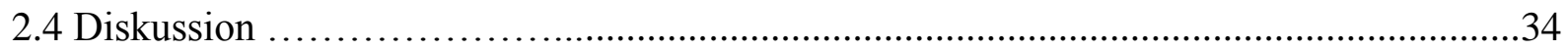

3. Genetische Analyse der Mutanten in Kreuzungen....................................................38

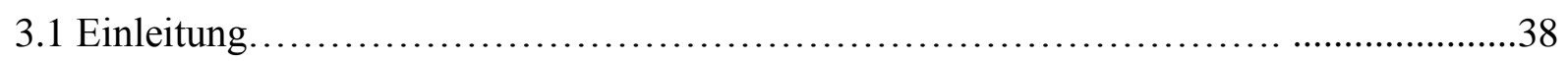

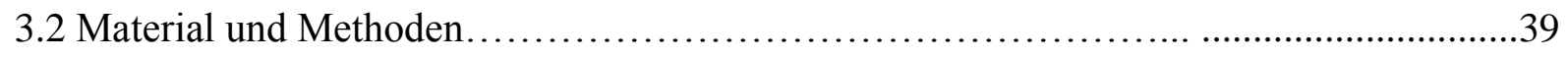

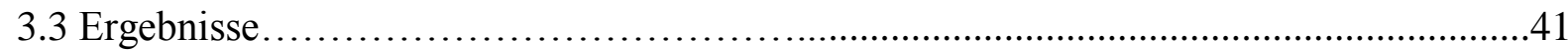

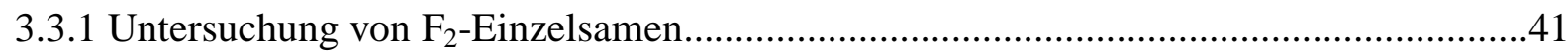

3.3.2 Fettsäuremuster vom Erntegut der $\mathrm{F}_{2}$-Pflanzen.............................................................44

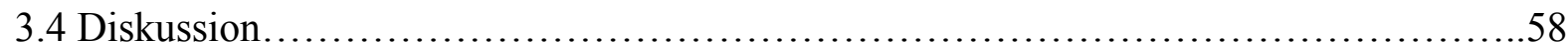


4. Charakterisierung der Mutanten durch DNA-Analysen............................61

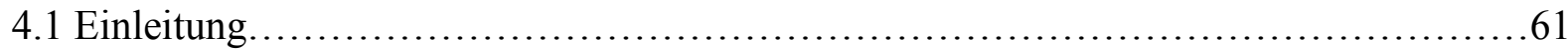

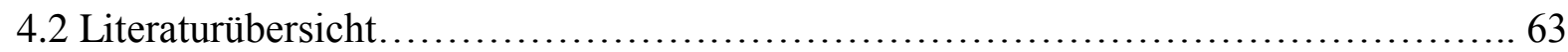

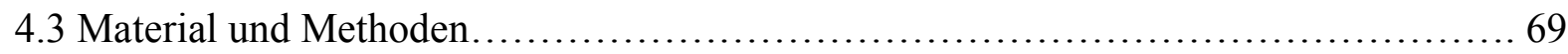

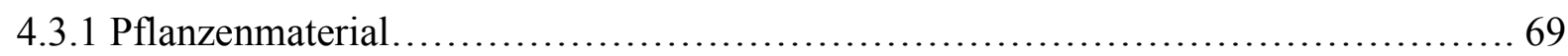

4.3.2 DNA-Isolation........................................................... 69

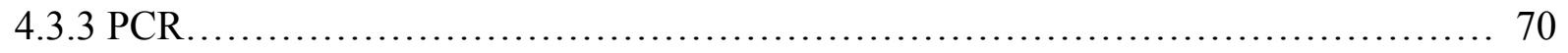

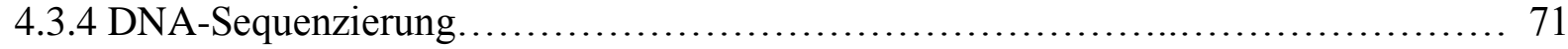

4.3.5 Sequenzanalyse............................................................. 71

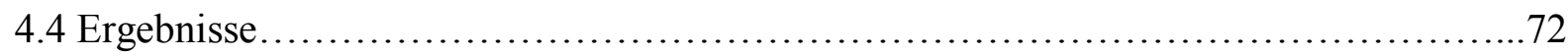

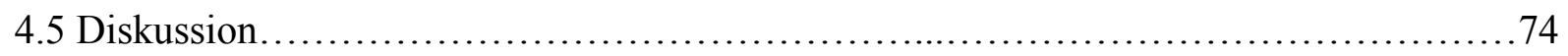

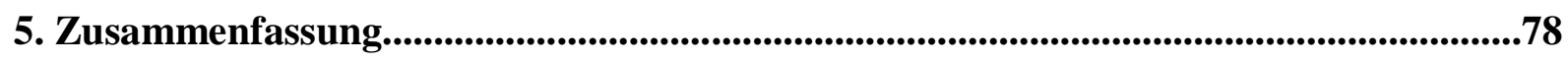

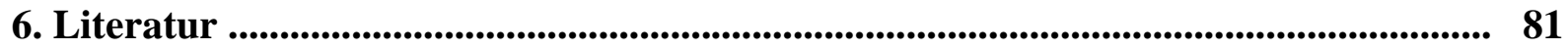

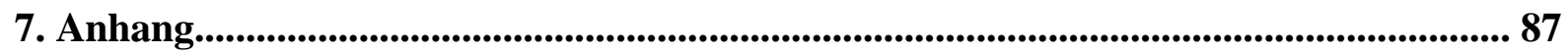




\section{Allgemeine Einleitung und Problemstellung}

\subsection{Der Raps und seine Entwicklung zur Nutzpflanze}

Raps (Brassica napus L.) ist eine zwischen 50 und 150 Zentimetern hohe, krautige Pflanzenart aus der Familie der Kreuzblütengewächse (Brassicaceae). Der traubige Blütenstand enthält bis zu 60 gelbe Einzelblüten, die bevorzugt von Bienen aber auch von Hummeln und Schwebfliegen bestäubt werden (Fremdbefruchtung), sich darüber hinaus auch selbst bestäuben können (Selbstbefruchtung bzw. Selbstung) (Heyland et al 2006; Treu and Emberlin 2000). Ihr wirtschaftlich interessanter Bestandteil sind die in Schoten zu jeweils 12 bis 20 aufgereihten schwarzbraunen Samenkörner. Sie haben einen Durchmesser von 1,5 bis 3,0 mm und einen Ölgehalt von etwa $40 \%$ der Trockenmasse sowie einen Proteinanteil, der bis zu $25 \%$ betragen kann (Kuhn 2008). Zusammen mit dem verwandten Rübsen (Brassica rapa) stellt Brassica napus die bedeutendste einheimische und weltweit an zweiter Stelle rangierende Ölpflanze dar. Je nach Vegetationsdauer und Anbauperiode unterscheidet man den einjährigen Sommerraps ( $f$. аппиа) und die überwinternde Form, den zweijährigen Winterraps (f. biennis). Ersterer wird wegen der geringeren Erträge in Deutschland allerdings kaum noch angebaut.

Brassica napus ist ein allopolyploider bzw. amphidiploider Bastard - Genom: AACC, $\mathrm{n}=19$ der aus einer sexuellen Kreuzung vom Rübsen (B. rapa) - Genom: AA - mit dem Gemüsekohl (B. oleracea) - Genom: CC - entstanden ist. Von seinen 38 Chromosomen stammen 20 vom Rübsen und 18 vom Kohl. Nach Raymer (2002) ist es durchaus denkbar, dass der Raps, von dem bisher keine eigene Wildform gefunden wurde, rein zufällig bei der gemeinsamen Kultivierung der beiden Elternpflanzen entstanden sein könnte. Als Entstehungsgebiet spricht viel für den mediterranen Raum, als Zeitpunkt käme der Beginn des späten Mittelalters in Betracht (Raymer 2002). Als gut gesichert gilt, dass Raps seit dem 14. Jahrhundert systematisch angebaut und als Lieferant für Lampenöl genutzt wurde (Kempken und Kempken 2006). Mit Beginn der industriellen Revolution in der zweiten Hälfte des 18. Jahrhunderts stieg der Bedarf an Gleit- und Schmiermitteln - und damit auch an Rapsöl beträchtlich an. Bemühungen zur verstärkten Nutzung bei der Herstellung von Margarine während des ersten und zweiten Weltkrieges blieben aber wegen des zu hohen Gehaltes an Bitterstoffen und Säuren ebenso wenig erfolgreich wie die Verwendung des in den Ölmühlen anfallenden Rapskuchens bzw. -schrotes als Futtermittel. Hinzu kamen die von der Erucasäure (C22:1) und den Senfölverbindungen ausgehenden und zumindest in 
Rattenversuchen nachgewiesenen gesundheitlichen Gefährdungen (Vles 1974). Erstere verursachte eine Verfettung des Herzmuskels, Läsionen und Herzfunktionsstörungen, letztere eine Vergrößerung des Thymus.

Die um 1960 gestarteten und besonders intensiven Anstrengungen der Pflanzenzüchter in Kanada zeitigten nach einer Reihe kleinerer Fortschritte bei der Verbesserung der Ölqualität (Downey et al. 1969) 1974 einen ersten großen Erfolg. Durch konventionelle Kreuzungsversuche war es gelungen, eine Rapssorte mit signifikant erniedrigten Anteilen an Erucasäure und Glucosinolaten auf den Markt zu bringen Sie trug den Namen Tower und war die erste „double low“-Sorte (Colton and Potter 1999, Stringam et al. 2003). Seit 1978 wird diese Varietät unter dem eingetragenen Handelsnamen Canola, abgeleitet von , canadian oil, low a acid“, geführt und als „eine von kanadischen Züchtern kreierte Rapspflanze, deren Samen weniger als $2 \%$ Erucasäure (C22:1) und deren Schrot weniger als 30 Mikromol an Glucosinolaten per Gramm luftgetrockneten, ölfreien Mehls enthält“, definiert (Shahidi 1990). Angefangen hatte alles mit der Entdeckung von C22:1-low-Mutanten in einer deutschen Sommerrapssorte namens Liho im Jahre 1959 (Stefansson et al. 1961).

Etwa zeitgleich mit der Markteinführung von Canola gelang auch den deutschen Züchtern die angestrebte Qualitätsverbesserung der Ölpflanze Brassica napus. Der Gehalt an Erucasäure konnte durch einen Austausch mit der ebenfalls einfach ungesättigten Ölsäure fast auf Null reduziert und der Wert als Speiseöl dadurch deutlich gesteigert wird. Diese Varietät erhielt die Bezeichnung 0-Raps und unter dem Handelsnamen Lesira 1973 seine Erstzulassung durch das Deutsche Bundessortenamt (Jentsch 2009). Gut neun Jahre später konnte man einen weiteren Zuchterfolg verbuchen. Beim 0-Raps war es gelungen, den Glucosinolatgehalt auf $10 \%$ des Ausgangswertes zu senken und auch die zweite störende Komponente auf 25 Mikromol pro Gramm Trockenmasse zu drücken (Rapsmagazin 2009). Damit stand eine neue Sorte mit „Canola-Qualität“ als 00-Raps mit nahezu idealem Fettmuster für die menschliche Ernährung zum Anbau bereit (Becker 1993). Er wurde 1981 unter dem Namen Librador erstmals zugelassen (Jentsch 2009). Bis 1974 betrug die Gesamtanbaufläche für Raps in Deutschland ca. 100000 Hektar und etwa $70 \%$ der Ernte wurde als technisches Öl verarbeitet. Durch die Entwicklung und Zulassung des 00-Raps änderte sich die Situation drastisch. Die Größe der Anbaufläche stieg sprunghaft an und erreichte schon 1993 einen Umfang von 1 Million und 2007 von 1,5 Millionen Hektar (Lehmann et al. 2008). Auch das Verwendungsspektrum änderte sich zu Gunsten der Nahrungsmittelherstellung. 


\subsection{Rapsöl - ein hochwertiges Speiseöl}

Dank der züchterischen Erfolge in der zweiten Hälfte des vergangenen Jahrhunderts (siehe Teil 1 der Einleitung) konnten mit Canola in Kanada und Librador in Deutschland zwei Rapsvarietäten entwickelt werden, deren Öle praktisch frei von Erucasäure und Glucosinolaten sind und die demzufolge beide $\mathrm{zu}$ den „Doppelnullsorten“ (00-Sorten) gehören. Aus ernährungsphysiologischer Sicht gelten ihre Öle als besonders wertvoll und dem der Oliven mindestens vergleichbar (Trautwein und Erbersdobler 1998). Rapssamen enthalten bis zu $45 \%$ Rohfett, dessen prozentuale Zusammensetzung (bei Winterraps der 00-Qualität) der nachfolgenden Auflistung (nach Jentsch 2009) zu entnehmen ist:

$\begin{array}{lc}\text { Ölsäure (einfach ungesättigt) } & -51-70 \% \\ \text { Linolsäure (mehrfach ungesättigt) } & -15-30 \% \\ \text { Linolensäure (mehrfach ungesättigt) } & -5-14 \% \\ \text { Palmitinsäure (gesättigt) } & -2,5-7 \% \\ \text { Gadoleinsäure (einfach ungesättigt) } & -0,1-4,3 \% \\ \text { Stearinsäure (gesättigt) } & -0,8-3,0 \% \\ \text { Erucasäure (einfach ungesättigt) } & -\mathrm{NN}-2,0 \% \\ \text { Arachinsäure (gesättigt) } & -0,2-1,2 \%\end{array}$

Das ergibt eine Verteilung (pro $100 \mathrm{ml}$ Rapsöl) von 7 bis 8 Gramm gesättigter, 65 Gramm einfach ungesättigter und 27 bis 28 Gramm mehrfach ungesättigte Fettsäuren. Letztere setzen sich aus ca. 18 Gramm Linolsäure und ca. 9 Gramm Alpha-Linolensäure zusammen. Legt man die Empfehlungen der Deutschen Gesellschaft für Ernährung (DGE) e. V. zugrunde, dann handelt es sich dabei um eine aus ernährungsphysiologischer Sicht nahezu optimale Mischung (Haberberger 2009). Der Anteil an gesättigten Fettsäuren ist relativ gering, an ungesättigten vergleichsweise hoch und an Linolsäure ausreichend. Hinzu kommt der hohe Gehalt an Alpha-Linolensäure und das günstige Verhältnis der beiden Letztgenannten zueinander. Den Essgewohnheiten des durchschnittlichen Mitteleuropäers entsprechend enthält unsere Nahrung einen gewissen Überschuss an Linolsäure. Schon eineinhalb Esslöffel Rapsöl täglich reichen aus, um dieses Missverhältnis zu korrigieren (Haberberger 2009). Im Rahmen einer Vollwertkost ist vor allem kaltgepresstes, natives Rapsöl zu empfehlen (AID 1997).

Innerhalb der einzelnen Fettsäuren dominiert die Ölsäure mit einem Anteil von durchschnittlich $60 \%$. Sie wird auch als Oleinsäure oder auch Omega-9-Fettsäure bezeichnet 
und ist eine einfach ungesättigte, mit Glycerin veresterte Fettsäure, Summenformel: $\mathrm{C}_{18} \mathrm{H}_{34} \mathrm{O}_{2}$, die in fast allen pflanzlichen und tierischen Fetten zu finden ist (Kunau 1976). Sie liegt in den Pflanzen zu $100 \%$ in der cis-Konfiguration vor und ist in dieser Form ein für die Gesundheit des Konsumenten wertvolles, wenn auch nicht essentielles, Nahrungsmittel. Beim Prozess der Härtung (Hydrierung) oder bei der Hitzebehandlung während der Raffination kommt es aber zur Entstehung sogenannter TFA (trans fatty acid). Das sind ungesättigte Fettsäuren, die mindestens eine Doppelbindung in trans-Figuration aufweisen (Müller 2008). Aus der Ölsäure (C18:1 c9) entsteht Elaidinsäure (C18:1 t9), und diese stellt von einer bestimmten Konzentration an ein gesundheitliches Risiko dar, indem sie zum Anstieg des SerumLDL(low density lipoproteine)-Cholesterins und gleichzeitig zum Absinken des SerumHDL(high density lipoproteine)-Cholesterins führt. Die dadurch verursachte Ablagerung von Cholesterin in den Blutgefäßen kann auf lange Sicht arteriosklerotische Veränderungen und koronare Herzerkrankungen hervorrufen (Mensink 2005).

Die Linolsäure ist eine ungesättigte Fettsäure. Sie hat die Summenformel $\mathrm{C}_{18} \mathrm{H}_{32} \mathrm{O}_{2}$ und ist der wichtigste Vertreter der Omega-6-Fettsäurefamilie. Linolsäure ist essentiell, d. h. sie muss dem menschlichen Organismus mit der Nahrung zugeführt werden. Als cis-Isomer in der Ölpflanze vorliegend ist sie für den Menschen gesundheitsfördernd. Sie setzt den Serumcholesterinspiegel herab und dient zum Aufbau von Phosphatiden und Prostaglandinen. (Müller 2008). In zu hohen Konzentrationen neigt sie allerdings zur Thrombose- und Entzündungsförderung und sollte nach einer Empfehlung von Colombani et al. (2008) stets zusammen mit der Omega-3-Fettsäure im Verhältnis 5:1 aufgenommen werden. Auch die Linolsäure kann infolge technischer Verfahren in eine gesundheitsgefährdende transKonfiguration übergehen (Mensink 2005).

Die Alpha-Linolensäure ist eine dreifach ungesättigte Fettsäure der Omega-3Fettsäurefamilie. Sie hat die Summenformel $\mathrm{C}_{18} \mathrm{H}_{30} \mathrm{O}_{2}$ und ist für den Menschen als cisIsomer ein essentieller Nährstoff. Sie dient vor allem als Ausgangsmaterial für den Aufbau von entzündungshemmenden Eicosanoiden, senkt den Gehalt von Triglyceriden im Blut und wirkt einer Arterioskleroseentstehung entgegen (Müller 2008, Hahn und Ströhl 2004). Auch Alpha-Linolensäure kann durch entsprechende Bearbeitungsprozesse zum trans-Isomer mit gesundheitsgefährdenden Eigenschaften werden (Mensink 2005). 
Palmitinsäure und Stearinsäure gehören zu den am häufigsten in pflanzlichen und vor allem in tierischen Fetten vorkommenden gesättigten Fettsäuren. Sie haben keine Doppelbindungen zwischen C-Atomen und sind außer als Energielieferant ernährungsphysiologisch eher störende Bestandteile im Pflanzenöl. Sie steigern den Serum-LDL-Cholesterin-Spiegel und damit das Risiko für koronare Herzkrankheiten, senken die Insulinempfindlichkeit und erhöhen das Diabetes-Risiko (Colombani et al. 2008). Der mit ca. $6 \%$ nur geringe Anteil vgl. Olivenöl mit $14 \%$ und Sonnenblumenöl mit $12 \%$ - ist ein Qualitätsmerkmal des Rapsöls.

\subsection{Rapsöl als Futtermittel und nachwachsender Rohstoff}

Mit dem Aufstieg des Rapsöls zu einem hochwertigen Speiseöl infolge der Züchtung von Canola in Kanada und den 00-Sorten in Europa ging auch eine Verbesserung als Futtermittel einher. Je nach angewandtem Verfahren zur Ölgewinnung fallen zwei Arten von hochwertigen Futtermitteln an - Rapskuchen und Rapsextraktionsschrot (RES).

Rapskuchen entsteht als Nebenprodukt bei der mechanischen Kaltpressung von Rapssaat in der Ölmühle. Bei einer durchschnittlichen Ausbeute von $70 \%$ bleiben $30 \%$ des Ausgangsmaterials in der Pressmasse zurück. Dieser Rapskuchen enthält in Abhängigkeit vom Pressgrad 10-20 \% Rohfett, 25-35 \% Rohprotein und 7-13\% Rohfasern (Spiekers und Südekum 2004). Obwohl mittlerweile fast ausschließlich 00-Raps - also erucasäurefreie und glucosinolatarme Sorten - auf dem Markt sind, dürfen die noch immer vorhandenen Glucosinolatgehalte nicht außer Acht gelassen werden. Das Glucosinolat verbleibt im Rapskuchen und macht 12-14 mmol/kg aus. Um eine gute Mastleistung zu erreichen, sollte das Glucosinolat eine Menge von 1,5 mmol/kg im Futter (Wiederkäuer tolerieren $5 \mathrm{mmol} / \mathrm{kg}$ ) aber nicht überschreiten. Höhere Dosierungen vermindern die Futteraufnahme und beeinträchtigen die Gesundheit der Tiere. Die Zufütterung mit Rapskuchen ist demzufolge auf etwa $10 \%$ zu begrenzen (Sommer 2006). Ein interessanter Befund wurde von Gerlach (2007) publiziert. Rinder, Schweine und Mastgeflügel speichern die aus dem Rapskuchen aufgenommene Omega-3-Fettsäure im Muskelfleisch und geben sie auf diese Weise an den Konsumenten weiter.

Rapsextraktionsschrot (RES) fällt bei der Extraktion des Öls aus der Rapssaat mithilfe von Lösungsmitteln an. Es enthält bezogen auf 1000 Gramm Trockenmasse 391 g Rohprotein, 24 g Rohfett, 133 g Rohfaser, 29 g Stärke, 91 g Zucker und 8,4 mmol/kg Glucosinolat, liegt also bezüglich des Fett- und Glucosinolatgehaltes deutlich unter dem des Rapskuchens und kann 
demzufolge dem Viehfutter in größeren Mengen beigemischt werden (Weiß und Schöne 2008). In Deutschland wurden 2007/08 rund 3 Mio. Tonnen RES in der Tierhaltung eingesetzt.

Die zunehmende Erweiterung der Nutzungspalette für Rapsöl ist aber keineswegs auf die Nahrungs- und Futtermittel (Food-Bereich) begrenzt. Rapsöl wird in steigendem Maße auch als Bioenergie-Träger (Biodiesel) und von der chemischen und pharmazeutischen Industrie als wichtiger Rohstoff (Non-Food-Bereich) für zahlreiche Produkte genutzt.

Biodiesel ist ein dem mineralischen Diesel vergleichbarer biosynthetischer Kraftstoff, der durch Umesterung von langkettigen, aus tierischen oder pflanzlichen Fetten stammenden Fettsäuren, gewonnen wird (Biodiesel 2008). Er wird in Deutschland zu $80 \%$ aus Rapsöl hergestellt (VDB 2008), in diesem Fall durch Umsetzung des Rapsöls mit Methanol produziert und als Rapsdiesel bzw. Rapsmethylester (RME) bezeichnet. Er kommt als Reinkraftstoff oder als Beimischung zum konventionellen Diesel in entsprechend adaptierten Dieselmotoren zum Einsatz. Darüber hinaus findet RME auch Verwendung als Treibstoff in Pflanzenöl-Blockheizkraftwerken und als Brennstoff in speziellen Ölheizungen (Agrarmärkte 2007). Das beim Umesterungsprozess anfallende Glycerin kann ebenfalls als Bioenergieträger dienen oder zu Futtermittel verarbeitet werden. Die Biodieselproduktion ist im letzten Jahrzehnt enorm angestiegen. Allein in Deutschland wuchs die Jahresleistung von 50000 Tonnen im Jahre 1998 auf 2,3 Millionen Tonnen in 2005 und 4,8 Millionen in 2007.

Produkte der chemischen und pharmazeutischen Industrie, die aus Rapsöl bzw. dessen einzelnen Inhaltsstoffen hergestellt werden, reichen von Maschinenölen, Gleit- und Schmierstoffen über Plastikstoffe wie z. B. Folien, Linoleum u. ä., bis hin zur Verwendung als Grundstoff bei der Herstellung von Farben, Lacken, Waschmitteln, Seifen und Kosmetika (Agrarmärkte 2007). Allein für die technische Verwertung der Erucasäure (C22:1) und deren Abkömmlinge wurden bisher mehr als 1000 Anwendungspatente vergeben (Mietkiewska et al. 2004).

\subsection{Züchtungsfortschritte und Anforderungen an moderne Rapssorten}

Nach Jentsch (2009) besteht der Züchtungsfortschritt bei landwirtschaftlichen Kulturen in der Verbesserung des Bestehenden entsprechend der Zuchtziele bei neuen Sorten. Dazu gehört aber auch die stetige Regeneration des vorhandenen Bewährten wie

- Erhalt bzw. Verbesserung positiver agrotechnischer Eigenschaften 
- Sicherung von Ertrag und Ertragsstabilität

- Erhöhung bzw. Erhalt der Widerstandsfähigkeit gegenüber Krankheiten und Schädlingsbefall.

Diese Anforderungen gelten auch bei der Zucht neuer Rapssorten, sind aber durch einen wesentlichen Punkt, nämlich das Anstreben eines hohen Gesamtölgehaltes und Änderungen im Fettsäurespektrum entsprechend den Bedürfnissen der verarbeitenden Industrie, zu ergänzen. Das gilt für den Food- ebenso wie für den Non-Food-Bereich. Dabei verlangt vor allem der industrielle Verbraucher Öle mit möglichst hohem Anteil einer bestimmten Fettsäure, da diese eine ökonomischere Ausbeute und ein einheitlicheres Endprodukt erwarten lässt.

Die Erucasäure $\left(\mathrm{C}_{21} \mathrm{H}_{41}-\mathrm{COOH}\right)$ ist eine einfach ungesättigte Fettsäure, die wegen ihrer ungünstigen Begleiterscheinungen im Speiserapsöl ein qualitätsmindernder Bestandteil, in vielen technischen Ölen hingegen ein wünschenswerter Faktor ist. Sie wird u. a. zur Herstellung von Schmiermitteln, Weichmachern für Textilien, Polymeren für die PlastikBranche, Oberflächenbeschichtungen und Pharmazeutika benötigt (Scarth and Tang 2006). Im Samen einer normalen Brassica-napus-Pflanze nimmt die C22:1 $45 \%$ des Gesamtfettes ein. Das ist schon ein relativ großer Anteil, entspricht aber nicht den Anforderungen der Industrie. Um wirtschaftlich produzieren und mit dem Petroleum konkurrieren zu können, erwarten sie vom Pflanzenzüchter die HEAR (high erucic acid rapeseed) oder noch lieber die SHEAR (super high erucic acid rapeseed) mit einem C22:1-Gehalt von $80 \%$. Letzteres ist, wenn überhaupt, nur mit gentechnischen Maßnahmen denkbar. HEAR-Sorten sind aber seit etwa 10 Jahren auf dem Markt (Scarth and Tang 2006). Die C22:1-Anteile der zugelassenen Varietäten liegen zwischen 55 und $60 \%$. Über einen mit konventionellen Züchtungsmethoden erreichten bisherigen Höchstwert von 61,5 \% berichteten Schröder-Pontoppidan et al. (1999). Die stark forcierten gentechnischen Experimente zur Schaffung von SHEAR-Sorten haben bisher noch keine durchschlagenden Erfolge gezeitigt (Scarth and Tang 2006).

Ein weiteres und zum großen Teil auch schon realisiertes Ziel der aktuellen Rapszüchtung ist die Entwicklung von Pflanzen mit einem hohen Ölsäureanteil im Samenkorn. Solche higholeic-Rapsöle, kurz HO-Öle, enthalten züchtungsbedingt einen besonders hohen Anteil einfach ungesättigter Ölsäure und sind deshalb sowohl für die Nahrungs- und Futtermittelherstellung als auch für die oleochemische Industrie von besonderem Interesse. Letztere wünscht einen Ölsäureanteil von über $90 \%$ und würde durch die Verwendung dieses 
nahezu homogenen Ausgangsmaterials besonders ökonomisch produzieren können (Töpfer et al. 1995). Durch das Einkreuzen natürlich entstandener Mutanten, gefolgt von Selbstbefruchtung und wiederholten Selektionen haben Vilkki und Tanhuanpää (1995) eine Varietät von Brassica napus kreieren können, die über einen C18:1-Anteil von 85 bis $90 \%$ verfügte. Auch Rücker und Röbbelen (1995) sowie Schierholt und Becker (1999), die die Mutationsintensität durch den Einsatz von Ethylmethansulfonat künstlich steigerten, konnten mit 80 bis $86 \%$ an C18:1 beachtliche Erfolge erzielen.

Die Alpha-Linolensäure, Kurzbezeichnung C18:3, zeigt bezüglich Nutzen und Verwertbarkeit zwei verschiedene Gesichter. Einerseits ist diese dreifach ungesättigte Fettsäure z. B. ein essentieller Nährstoff als Ausgangsmaterial für den Aufbau entzündungsregulierender Eicosanoide (Müller 2008; Hahn und Ströhl 2004), andererseits ist sie als mehrfach ungesättigte Fettsäure besonders empfindlich gegenüber Oxidationen (Lauridsen et al. 1999). Die Oxidationsrate ist 25mal höher als die der Ölsäure (Fried und Lühs 1999), führt an der Luft rasch zur Verkürzung der Haltbarkeitsdauer und zur Wertminderung. Diesen Veränderungen kann man zwar durch den Prozess der Fetthärtung entgegenwirken, jedoch muss man dann ein weiteres Problem in Kauf nehmen - der Bildung von trans-Isomeren mit all ihren nachteiligen gesundheitlichen Effekten, z. B. der möglichen Förderung arteriosklerotischer Erkrankungen des Blutgefäßsystems (Mensink 2005). Aufgrund dieser Erkenntnisse ergab sich die Aufgabe für den Züchter, eine Rapssorte mit Canola- bzw. 00Qualität aber niedriger Alpha-Linolensäure-Konzentration zu kreieren. Im Jahre 1987 wurde unter dem Namen Stellar die erste „low-linolenic“-Sommerrapssorte in Kanada zugelassen (Scarth et al. 1988). Der Anteil an C18:3 ist bei dieser Varietät auf $3 \%$ gegenüber sonst $9 \%$ reduziert.

In Europa haben die Franzosen 2004 als erste eine sogenannte Holli-Rapssorte (Holli leitet sich von der englischen Bezeichnung „high oleic, low linolenic acid“ ab, erfolgreich auf den Markt gebracht (Lehmann et al. 2008). Die Vistive-Holli-Sorte Splendor ist ein Winterraps mit folgendem, nahezu idealem Fettsäurespektrum: Ölsäure 75-78 \%, Linolsäure 12-13 \% und Alpha-Linolensäure 2,2-3,3 \%. Die Gesamtheit der gesättigten Fettsäuren bleibt unter $7 \%$. Das Rapssamenöl ist oxidations- und hitzestabil, frei von trans-Fettsäuren und geschmacksneutral. Allerdings ließ der Samenertrag zunächst noch zu wünschen übrig, konnte aber durch kontinuierliche Züchtungsbemühungen deutlich gesteigert werden. Die aktuellen Vistive-Holli-Sorten „V140 OL“ und „V141 OL“ liegen nur noch 5 \% unter dem 
der Vergleichssorte und sollen sich durch Züchtung von Hybriden mit Holli-Qualität noch verbessern lassen (Lehmann et al. 2008). Von Versuchen, eine Rapspflanze ohne AlphaLinolensäure zu züchten, sollte man Abstand nehmen, da C18:3 eine essentielle Rolle für Wachstum und Reproduktion der Pflanze spielt, ein Fehlen also zu einer Beeinträchtigung ihrer normalen Entwicklung führen muss (Hugly et al. 1989).

\subsection{Gentechnik in der Rapszüchtung}

Neben den konventionellen Methoden der Rapszüchtung, die im Wesentlichen auf Kreuzungsexperimenten mit natürlich auftretenden oder künstlich induzierten Mutanten basieren, hat die Anwendung gentechnischer Verfahren in den vergangenen zwei Jahrzehnten zunehmend an Bedeutung gewonnen. Dabei verfolgen Forschung und praktische Umsetzung zwei generelle Ziele:

1. Die Übertragung von Herbizidtoleranz-Genen in leistungsstarke Rapssorten.

2. Die gerichtete Änderung (Qualität und Quantität) von Inhaltsstoffen des Rapssamens.

Der Einsatz moderner, nur über eine geringe selektive Wirksamkeit verfügender Herbizide, verlangt den Schutz der Kulturpflanzen. Diese Forderung konnte durch die Anwendung gentechnischer Methoden erfüllt werden. Aus resistenten Bakterien konnten die dafür zuständigen Gene isoliert, in ihren Expressionssignalen verändert und erfolgreich in das Genom der Rapspflanze übertragen werden (Saedler 2004). Erfolgreich heißt, die Pflanze wurde nicht mehr vom Herbizid geschädigt, sie zeigte sich diesem Wirkstoff gegenüber tolerant.

Schon 1995 kamen die ersten beiden HT (,herbicide tolerance“)-Rapssorten in Kanada auf den Markt, die transgene Canola-Varietät Roundup Ready mit einer Toleranz für Glycophysat und Liberty Link mit einer Toleranz gegenüber Glufosinat. Nur kurze Zeit später folgte Navigator, eine Varietät, die das Herbizid Bromoxynil toleriert (Stringam et al. 2003). 1996 erfolgte in Kanada und den USA die erste Aussaat (Green 2009). Mittlerweile sind weltweit mehr als 5,5 Millionen Hektar mit transgenem Raps bestellt, davon in Kanada $87 \%$ der gesamten Rapsanbaufläche und in den USA 82 \% (Transgen 2009).

Der Wert eines Rapsöls wird durch Qualität und Quantität seiner Inhaltsstoffe bestimmt und an den Bedürfnissen des jeweiligen Verbrauchers gemessen. Das zweite große Ziel der Gentechniker besteht daher in der Transformation von Genen, die aus ganz unterschiedlichen 
Organismen wie niederen Pflanzen, Hefen, Bakterien, Säugetieren stammen und regulierend in den Biosyntheseweg z. B. von einzelnen Fettsäuren eingreifen (Scarth und Tang 2006). Beispielhaft seien hier die Versuche zur Reduzierung der gesättigten Fettsäuren im Rapskorn genannt. Aufgrund des Fehlens von entsprechenden Mangelmutanten in den einkreuzungsfähigen Brassica-Arten stößt der konventionelle Pflanzenzüchter an Grenzen der Machbarkeit. Mithilfe gentechnischer Maßnahmen gelang es Dehesh (2004), die Grenze zu überwinden und den Anteil von ursprünglich $6 \%$ gesättigter Fettsäuren auf $3,4 \%$ zu reduzieren. Das gelang ihm durch Insertion von Fremdgenen für Enzyme, die an der Biosynthese der Fettsäuren beteiligt sind.

Mit hoher Intensität wird auch an zielgerichteter Steigerung oder Reduktion anderer Ölkomponenten im Rapssamen geforscht, um in naher Zukunft Rapssorten zur Aussaat zu bringen, die nach den Bedürfnissen der Verbraucher „,maßgeschneidert“ sind. Dabei wird die konventionelle Züchtung vor allem in Europa, wo der Anbau von GM-Raps nicht erlaubt ist, genau so gefragt sein, wie der Einsatz gentechnischer Maßnahmen.

\subsection{Problemstellung und Zielsetzung der Arbeit}

Die hier vorgelegte Arbeit versteht sich als Weiterführung eines von Rücker und Röbbelen im Jahre 1991 am Institut für Pflanzenbau und Pflanzenzüchtung der Universität Göttingen initiierten Forschungsprojektes. Ziel dieses Forschungsvorhabens ist es,

- durch Behandlung mit Ethylmethansulfonat (EMS) bei der Rapssorte Wotan Mutationen auszulösen

- die so entstandenen Genotypen zu selektieren und zu charakterisieren

- durch Anpassung dieses so erarbeiteten Materials an das Niveau des ,normalen“ Sortenspektrums neue Hochölsäure- bzw. Hochölsäure/NiedriglinolensäureRapssorten zu züchten (Schierholt und Becker 2001).

Die Aufgabenstellungen für die eigenen Untersuchungen ergaben sich vor allem aus dem zuletzt genannten Schwerpunkt. Sie bestanden im Wesentlichen

- in der Fortsetzung der Suche nach neuen Mutanten, die im Unterschied zu den 
bisher von Schierholt gefundenen über bessere agronomische Eigenschaften verfügen

- in der Charakterisierung der neuen Mutanten bezüglich des Fettsäuremusters und der agronomischen Merkmale

- in weiterführenden Kreuzungsexperimenten, die zum einen die Chance zur

Auffindung neuer und bezüglich des Fettsäurespektrums günstigerer Kombinationen bieten und durch die Kreuzung mit bekannte Mutanten Aufschlüsse über die Lokalisation der für die Mutationen zuständigen Gene zu erhalten

- in DNA-Analysen zum direkten Vergleich mit bekannten DNA-Sequenzen der Ausgangssorte Wotan und der bereits beschriebenen Mutante 19661.

Entsprechend dieser Schwerpunkte ist die Arbeit im folgenden in 3 Abschnitte unterteilt:

1. Fettsäuremuster und agronomische Eigenschaften der Mutanten

2. Genetische Analyse der Mutanten in Kreuzungen

3. Charakterisierung der Mutanten durch DNA-Analysen 


\section{Fettsäuremuster und agronomische Eigenschaften der Mutan- ten}

\subsection{Einleitung}

Bereits in den 70er Jahren wurden chemische Mutationsauslösungen im Raps erfolgreich eingesetzt, um bestimmte Zuchtziele, z.B. eine Veränderung in der Zusammensetzung der Inhaltsstoffe, zu erreichen (Rakow, 1973). Diesem Ziel diente auch ein 1991 gestarteter Versuch der Arbeitsgruppe um Prof. Röbbelen, Universität Göttingen, bei dem Samen der Rapssorte Wotan mit der Mutationen auslösenden Substanz EMS (Ethylmethansulfonat) behandelt wurden. Das so behandelte Saatgut $\left(M_{1}\right)$ wurde im Jahre 1992 im Feld ausgesät und ca. 20000 offen abgeblühte Pflanzen geerntet und auf Fettsäurezusammensetzung untersucht (Rücker und Röbbelen 1995). In dem Material dieser $\mathrm{M}_{1}$-Generation ließen sich Mutanten mit einem erhöhten Ölsäuregehalt identifizieren. Die Werte lagen bei einem Anteil von 75-80 \% und damit deutlich über den bei Wotan ermittelten Durchschnittswerten von 60-65\%. Leider erwiesen sich diese Mutanten als schwach im Wuchs und niedrig im Kornertrag. Auch waren alle Mutationen im selben Gen lokalisiert (Schierholt 2000). Die Samen der geernteten $\mathrm{M}_{1^{-}}$ Pflanzen wurden als Ausgangsmaterial für die vorliegende Arbeit verwendet. Aus ihnen wurde die $\mathrm{M}_{2}$-Generation angezogen, um auch Mutanten erkennen zu können, die nur homozygot einen Effekt zeigen.

Ziel des Versuches war es deshalb, zunächst in der $\mathrm{M}_{2}$-Generation des EMS-behandelten Rapses nach neuen Mutanten zu suchen, im Hinblick auf folgende Merkmale der Samenqualität:

- Sinapingehalt

- Phytingehalt

- Ölgehalt

- Proteingehalt

- Glucosinolatgehalt

- erhöhter Ölsäuregehalt

Da schon einmal Genotypen mit dem letztgenannten Zuchtziel gefunden wurden, sollte der Schwerpunkt auf dieses Merkmal gelegt werden. Es sollten zum einen Mutanten mit besseren 
Eigenschaften bezüglich agronomischer Merkmale identifiziert werden, zum anderen sollte untersucht werden, ob Mutanten in mehreren Genloci aufgetreten waren.

Die schon vorher in der $\mathrm{M}_{1}$-Generation gefundenen und beschriebenen Genotypen (Rücker und Röbbelen 1995, Schierholt 2000) - sie werden in dieser Arbeit als „alte Mutanten“ bezeichnet - wurden zu Vergleichszwecken mitgeführt.

Die von uns aufgrund eines erhöhten Ölsäuregehaltes neu in der $\mathrm{M}_{2}$-Generation selektierten Mutanten wurden zusammen mit den ,alten Mutanten“ und der Ausgangssorte Wotan mehrjährig an zwei verschiedenen Orten angebaut und geselbstet, um sie bezüglich des Fettsäuremusters sowie der o.g. agronomischen Merkmale wie Kornertrag, Blühbeginn, Blühdauer und Pflanzenlänge sicher charakterisieren zu können.

\subsection{Material und Methoden}

\subsubsection{Pflanzenmaterial}

Das Ausgangsmaterial für diese Arbeit stammt aus einen Versuch, der 1991 von Prof. Röbbelen in Göttingen begonnen wurde. Damals wurde Winterraps der Sorte Wotan mit $2 \%$ EMS (Ethylmethansulfonat) behandelt, um Mutationen auszulösen. Die so behandelten Samen wurden ausgesät, über 20.000 offen abgeblühte $\mathrm{M}_{1}$-Pflanzen geerntet und am Erntegut die Fettsäurezusammensetzung mittels NIRS und GC analysiert. Aus diesem Experiment stammen die ,alten Mutanten', die in die laufenden Untersuchungen mit einbezogen wurden. Als Grundlage der vorliegenden Arbeit wurde eine Mischung von je zwei $\mathrm{M}_{2}$-Samen aus 19.625 Samentüten (Samen der $\mathrm{M}_{1}$-Pflanze) hergestellt.

\subsubsection{Feldversuche, Leistungsprüfungen}

\section{Ernte 2002}

Am 26.08.2001 wurde diese Mischung am Standort Kalteneber auf einer Fläche von 1,41 ha ausgedrillt. Die Aussaat erfolgte in Blöcken (16m x 220m) mit einem jeweiligen Abstand von 0,50 m, damit der Bestand zur Beobachtung begehbar blieb.

Der Standort Kalteneber liegt im Eichsfeldkreis im nordwestlichen Thüringen. Die Flächen befinden sich in der Außenstelle des Bundessortenamtes Hannover, Prüfstelle Kalteneber. Der Standort ist ein tiefgründiger Berglehm- und Bergtonstandort, mit der Hauptbodenform 
Lößkerf-Parabraunerde als Muschelkalkverwitterungsboden. Der Boden besteht aus Lehmton mit einer Ackerzahl von 45, einem Feinerdeanteil von 29,5\% und einem Humusgehalt von 3,2 \%. Die Höhenlage des Standortes beträgt $475 \mathrm{~m}$, die durchschnittliche Jahrestemperatur $7,5^{\circ} \mathrm{C}$ und der langjährige mittlere Niederschlag $725 \mathrm{~mm}$.

Die Wetterdaten für das erste Versuchsjahr sind in Abb. 2.1 dargestellt.

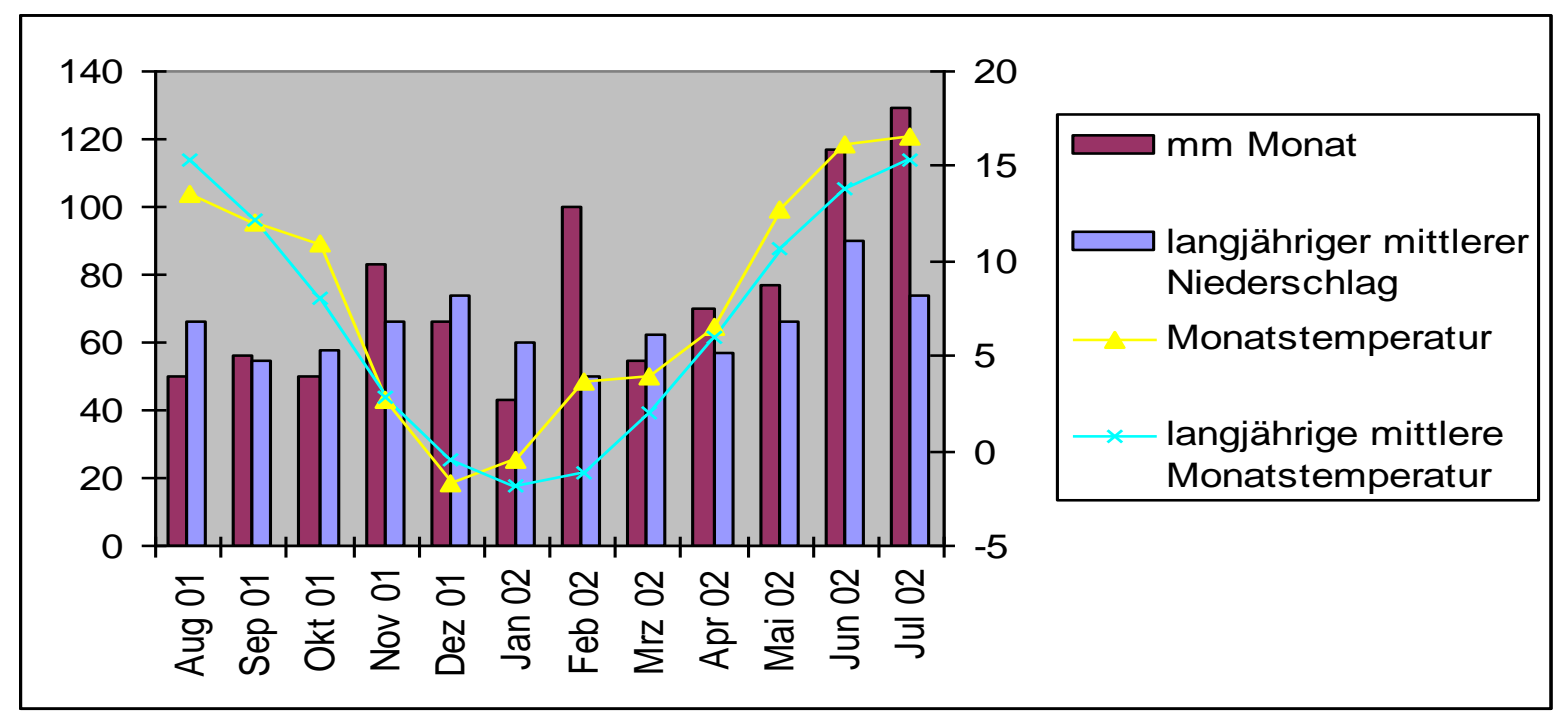

Abb.2.1 Wetterdaten August 2001 bis Juli 2002; Wetterstation Flinsberg (ca 2 km östlich vom Versuchsstandort Kalteneber)

Folgende Pflanzenschutz und Düngungsmaßnahmen wurden auf der Fläche durchgeführt:

28.08.01 100 1/ha AHL und $2 \mathrm{~kg} / \mathrm{ha}$ Metarex Schneckenkorn

24.09.01 0,1 1/ha Fastac (Erdflöhe)

15.02.02 $220 \mathrm{~kg} \mathrm{KAS}(=60 \mathrm{~kg} \mathrm{~N})$

29.03.02 0,1 1/ha Fastac, 1,0 1/ha Lontrel

05.04. $02 \quad 3,0 \mathrm{~kg} / \mathrm{ha}$ Pradone Kombi (Klatschmohn)

Vom 15. bis 21.8. 2002 wurden 4550 Einzelpflanzen geerntet und deren Samen anschließend mit NIRS auf Öl-, Protein-, GSL-, Sinapin- und Phytingehalt und die Fettsäurezusammensetzung untersucht.

Am 4.9.2002 wurde die gleiche Mischung von $\mathrm{F}_{2}$-Samen wie im August 2001 erneut ausgesät, die Pflanzen winterten aber aus. 


\section{Ernte 2004}

Die $\mathrm{M}_{3}$-Samen aus der Ernte 2002 wurden nach den Ergebnissen der NIRS-Untersuchung und im Hinblick auf interessante Merkmale wie Ölsäuregehalt, Sinapingehalt und Phytingehalt ausgewählt. Am 15.08.2003 wurden in Kalteneber 45 Parzellen (1,20 m x 14 m) mit diesen Genotypen angebaut.

Die angebauten Parzellen wurden folgendermaßen behandelt:

18.08.03 1,0 1/ha Butisan

02.09.03 1,5 1/ha Butisan top; 0,5 1/ha Gallant super; 0,1 1/ha Fastac

16.03.04 230 1/ha AHL $(83 \mathrm{~kg} \mathrm{~N})$

31.03.04 0,1 1/ha Fastac; 0,5 1/ha Folicur; 0,8 1/ha Fusilade; 1,0 kg/ha Foliarel

28.04.04 170 1/ha AHL $(61 \mathrm{kgN})$

12.05.04 0,5 1/ha Cantus; 0,075 1/ha Karate Zeon; 50 1/ha AHL (18kg N)

Die Wetterdaten für das Jahr 2003/2004 Standort Kalteneber sind in Abb. 2.2 dargestellt:

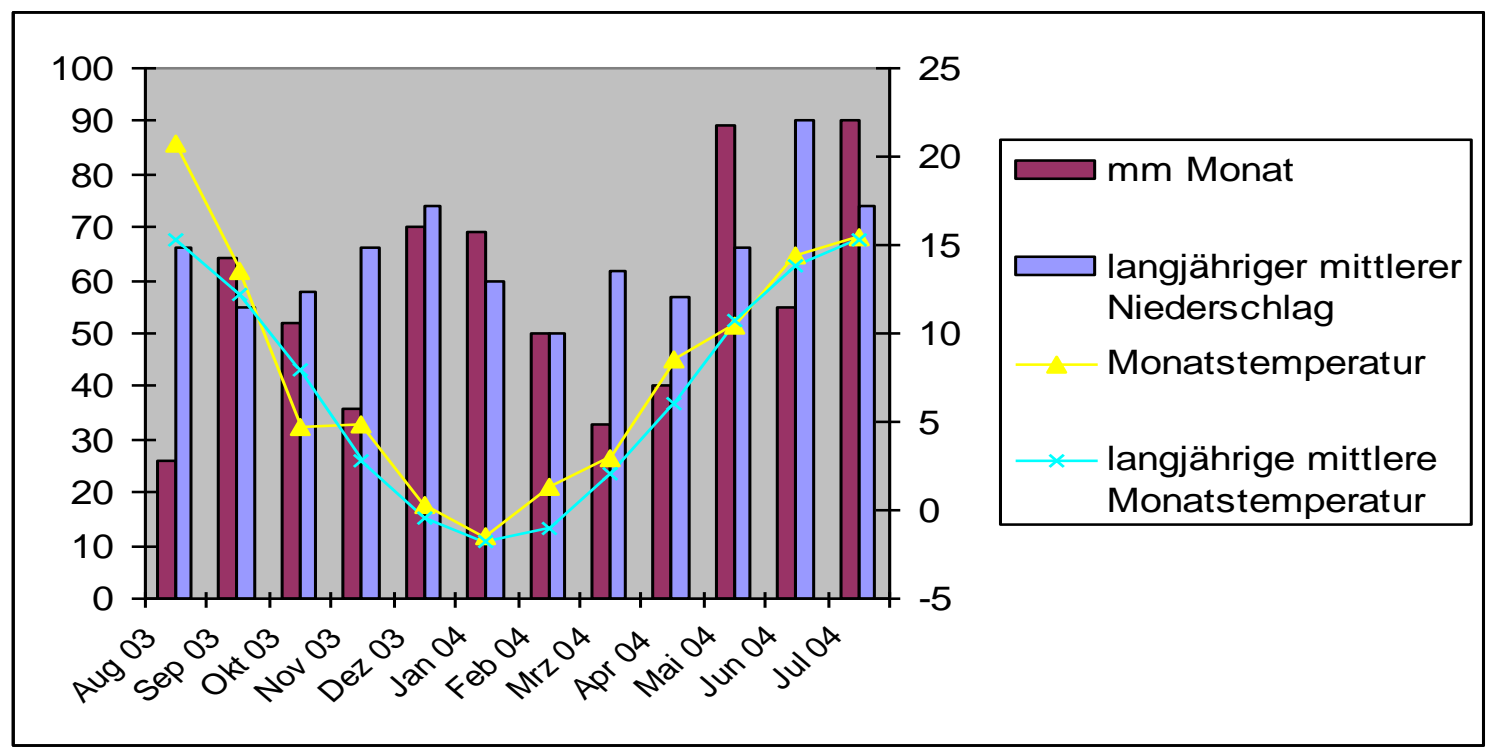

Abb. 2.2: Wetterdaten Kalteneber August 2003 bis Juli 2004; Wetterstation Flinsberg

In Göttingen wurden ebenfalls 62 interessante Genotypen in zwei Wiederholungen zum Beobachtungsanbau ausgesät. Die Versuche erfolgten auf dem Reinshof. Der Reinshof ist ein Versuchsgut der Georg-August-Universität und liegt südlich von Göttingen. Der Standort besteht zu ca. $80 \%$ aus Auenböden (Lehme bis tonige Lehme), aus Schwemmlöß und zu ca. $20 \%$ aus Grießerden (aus Löß). Die durchschnittliche Ackerzahl beträgt 83 BP. Der Reinshof liegt $150 \mathrm{~m}$ über NN und der langjährige Durchschnitt an Niederschlägen beträgt $645 \mathrm{~mm}$, die recht gleichmäßig verteilt sind (Abb2.3). Die mittlere Jahrestemperatur beträgt $8,7^{\circ} \mathrm{C}$ und die mittlere Luftfeuchtigkeit $77,3 \%$. 


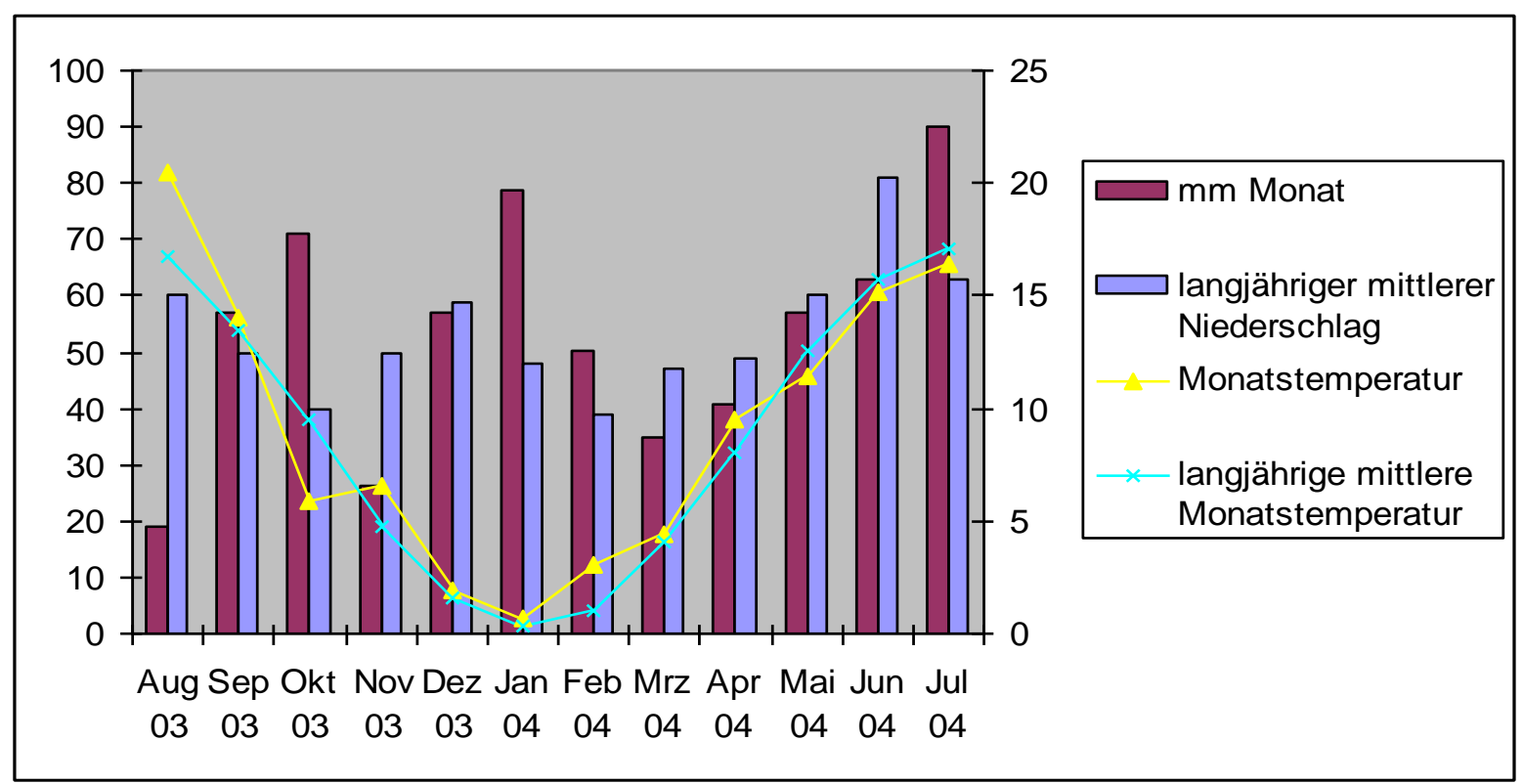

Abb. 2.3: Wetterdaten August 2003 bis Juli 2004 Standort Göttingen (Wetterstation Göttingen)

\section{Ernte 2005}

Nach der Ernte 2004 fiel die Entscheidung, nur noch mit den Genotypen weiterzuarbeiten, die einen hohen Ölsäuregehalt aufwiesen.

Am Standort Kalteneber wurden acht dieser auffälligen Genotypen aus dem Erntejahr 2004 mit höherem Ölsäuregehalt weiter geprüft. Als Vergleich wurde die Sorte Wotan (Ausgangssorte) mit angebaut. Die Aussaat erfolgte am 23.08.2004 mit 100 Körnern/qm in zwei Wiederholungen. Die Parzellen $\left(12 \mathrm{~m}^{2}\right)$ wurden folgendermaßen behandelt:

Pflanzenschutz
10.09.04 1,5 1/ha Butisan
14.09.04 0,15 1/ha Sumicidin alpha
24.03.05 $330 \mathrm{~kg} / \mathrm{ha}$ Thomaskali $14+14+8+4$
21.03.05 4,5 dt/ha KAS $(120 \mathrm{~kg} \mathrm{~N})$
22.04.05 $3 \mathrm{dt} / \mathrm{ha}$ KAS $(80 \mathrm{~kg} \mathrm{~N}), 20 \mathrm{~kg}$ Bittersalz
28.04.05 0,1 1/ha Fastac SC

Die Wetterdaten für Kalteneber sahen in dem Jahr folgendermaßen aus (Abb. 2.4). 


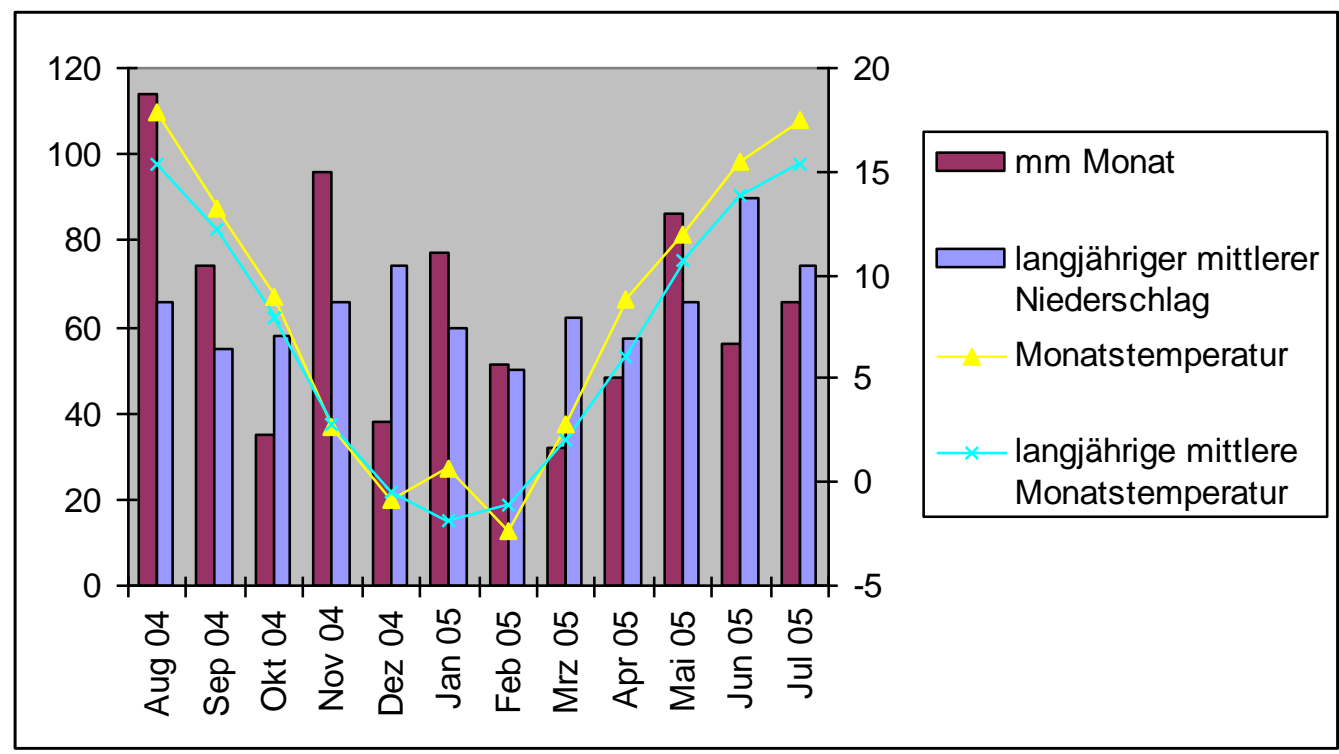

Abb. 2.4 Wetterdaten August 2004 bis Juli 2005; Wetterstation Flinsberg

Auch in Göttingen wurden diese 8 Genotypen und Wotan als Beobachtungsanbau (in Parzellen $\mathrm{zu} 1,9 \mathrm{~m}^{2}$ ) in zwei Wiederholungen ins Feld gestellt. Zum Vergleich wurden außerdem 8 ,alte Mutanten“ aus dem vorhergehenden Versuch von Antje Schierholt (Schierholt 2000) angebaut (Tab. 2.1).

Tab.2.1: Nummerierung alter und neuer Mutanten

\begin{tabular}{|c|c|c|c|}
\hline Nr. & Bezeichnung & Nr. & Bezeichnung \\
\hline 1 & "alte Mutante" 19574 & 10 & Mu10 \\
\hline 2 & "alte Mutante" 19517/1944 & 11 & Mu11 \\
\hline 3 & "alte Mutante" 19517/499 & 12 & Mu12 \\
\hline 4 & "alte Mutante" 19566 & 13 & $\mathrm{Mu} 13$ \\
\hline 5 & "alte Mutante" 19646 & 14 & $\mathrm{Mu} 14$ \\
\hline 6 & "alte Mutante" 19661 & 15 & $\mathrm{Mu} 15$ \\
\hline 7 & "alte Mutante" 19684 & 16 & $\mathrm{Mu16}$ \\
\hline 8 & "alte Mutante" 19782 & 17 & Mu17 \\
\hline 9 & Wotan alt & 18 & Wotan neu \\
\hline
\end{tabular}

Das Saatgut mit der Bezeichnung „Wotan alt“ stammt aus der Absaat 1998, d.h. das Saatgut war schon 6 Jahre alt. Das Saatgut für „Wotan neu“ war NPZ-Saatgut (Norddeutsche Pflanzenzucht) aus dem Jahr 1999. Sowohl in Kalteneber als auch in Göttingen wurden Selbstungen dieser Genotypen im Feld durchgeführt.

In der Abbildung 2.5 sind die Wetterdaten für das Jahr 2004/2005 in Göttingen dargestellt. 


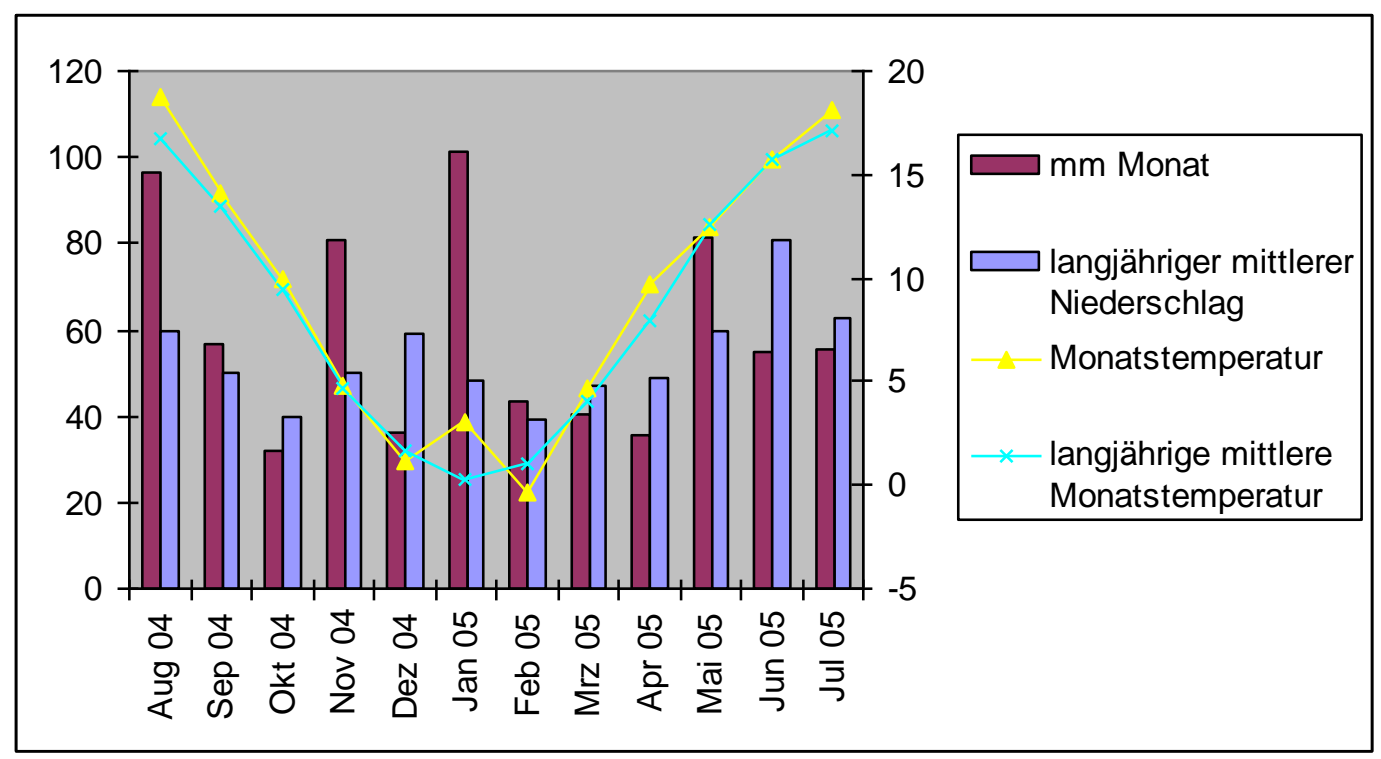

Abb. 2.5 Wetterdaten August 2004 bis Juli 2005 Standort Göttingen

\section{Ernte 2006}

Mit der Aussaat 2005 wurden an beiden Standorten Leistungsprüfungen angelegt.

In Kalteneber wurden am 29.8.2005 in Parzellen mit einer Größe von jeweils $12 \mathrm{~m}^{2}$ mit 18 Genotypen (siehe Tabelle 2.1) in zwei Wiederholungen ausgesät:

Die Genotypen der Nummern 1 bis 9 stammen aus einem älteren Versuch (Schierholt et al 2001). Die Nummern 10 bis 17 sind die selektierten Genotypen der vorigen Jahre. Als Vergleich mit „,normalem“ Ölsäuregehalt diente wiederum die Sorte Wotan.

Die Parzellen in Kalteneber wurden folgendermaßen behandelt:

Pflanzenschutz:
30.08.05 3,0 1/ha Nimbus
22.09.05 0,1 1/ha Fastac
17.10.05 $\quad 0,5 \mathrm{~kg} / \mathrm{ha}$ Cantus
27.04.06 0,1 1/ha Fastac
06.05.06 0,75 1/ha Karate Zeon; 0,5 kg/ha Cantus
15.05.06 0,8 1/ha Harvesan
24.05.06 0,8 1/ha Harvesan 
Düngung:

04.04.06 $100 \mathrm{~kg} / \mathrm{ha}$ KAS $(27 \mathrm{~kg} \mathrm{~N})$

06.04.06 $300 \mathrm{~kg} / \mathrm{ha}$ Thomaskali $\left(8 \mathrm{P}_{2} \mathrm{O}_{5}+15 \mathrm{~K}_{2} \mathrm{O}+6 \mathrm{KMgO}\right)$

$27.04 .06 \quad 20 \mathrm{~kg} / \mathrm{ha}$ Bittersalz

08.05.06 $60 \mathrm{~kg} / \mathrm{ha} \operatorname{KAS}(16 \mathrm{~kg} \mathrm{~N})$

Während der Vegetationszeit wurden Merkmale wie Bestand vor und nach Winter, Blühbeginn, Blühende, Pflanzenlänge und Parzellenerträge beobachtet.

Die Wetteraufzeichnungen im Erntejahr 2006 ergaben folgende Daten (Abb.2.6):

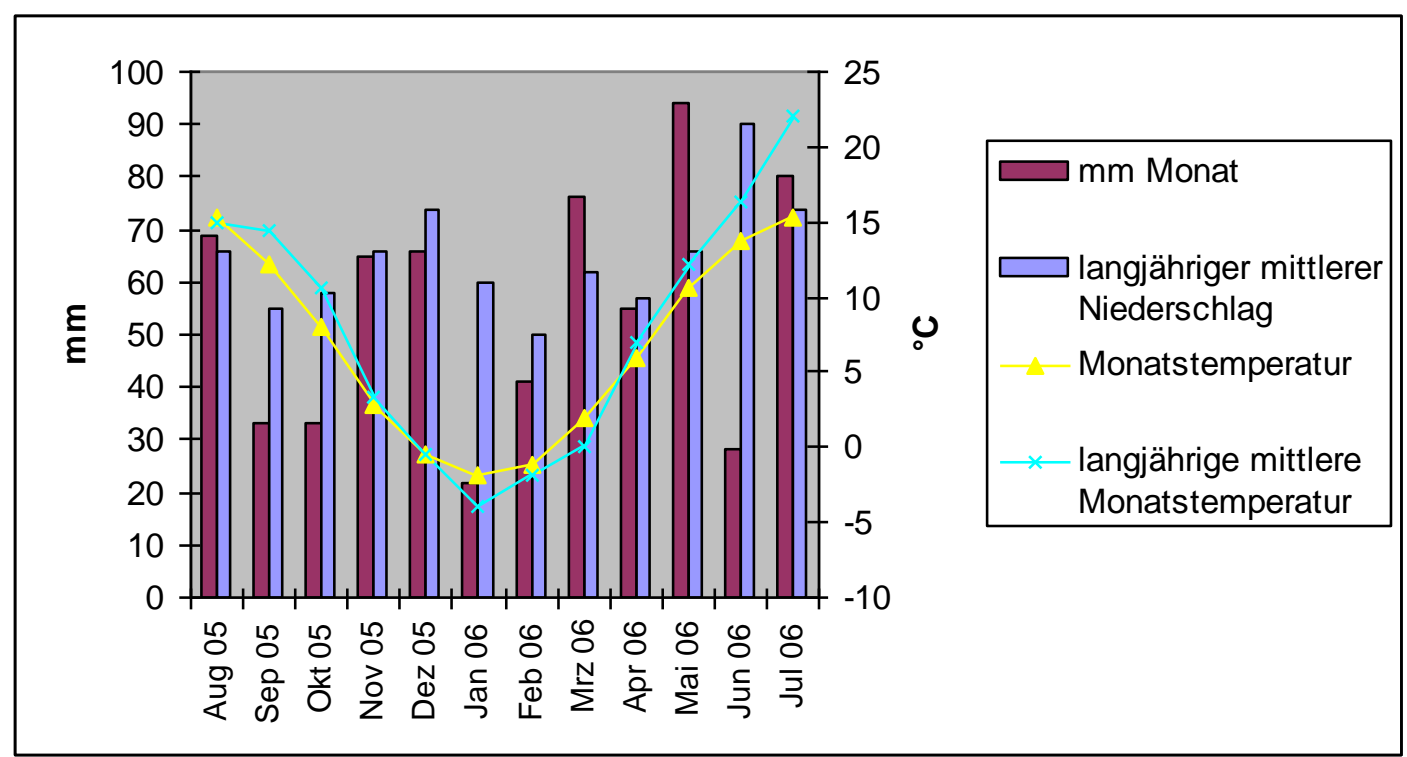

Abb. 2.6: Wetterdaten August 2005 bis Juli 2006; Wetterstation Flinsberg

Auf dem Reinshof bei Göttingen wurden ebenfalls Leistungsprüfungen in zwei Wiederholungen angelegt. Die Parzellengröße betrug 11,25 m², die Aussaat erfolgte am 29.08 2005 und der Drusch der Parzellen am 19.07.2006.

Die Pflanzenschutz- und Düngungsmaßnahmen sind nachfolgend genannt:

$\begin{array}{ll}\text { 15.09.2005 } & 2 \text { 1/ha Butisan top } \\ \text { 24.04.2006 } & 0,15 \mathrm{~kg} / \mathrm{ha} \text { Trafo WG } \\ \text { 13.07.2006 } & 4 \mathrm{l} / \mathrm{ha} \text { Reglone } \\ 29.03 .2006 & 85 \mathrm{~kg} / \mathrm{ha} \mathrm{N} \text { und } 42 \mathrm{~kg} / \mathrm{ha} \mathrm{S} \text { aus SSA und KAS } \\ 28.04 .2006 & 90 \mathrm{~kg} / \mathrm{ha} \mathrm{N} \text { aus KAS }\end{array}$


Während der Vegetationszeit wurden Merkmale wie Bestand vor und nach Winter, Blühbeginn, Blühende, Pflanzenlänge und Parzellenerträge beobachtet. Die Wetterdaten für das Erntejahr 2006 sind in Abb. 2.7 dargestellt.

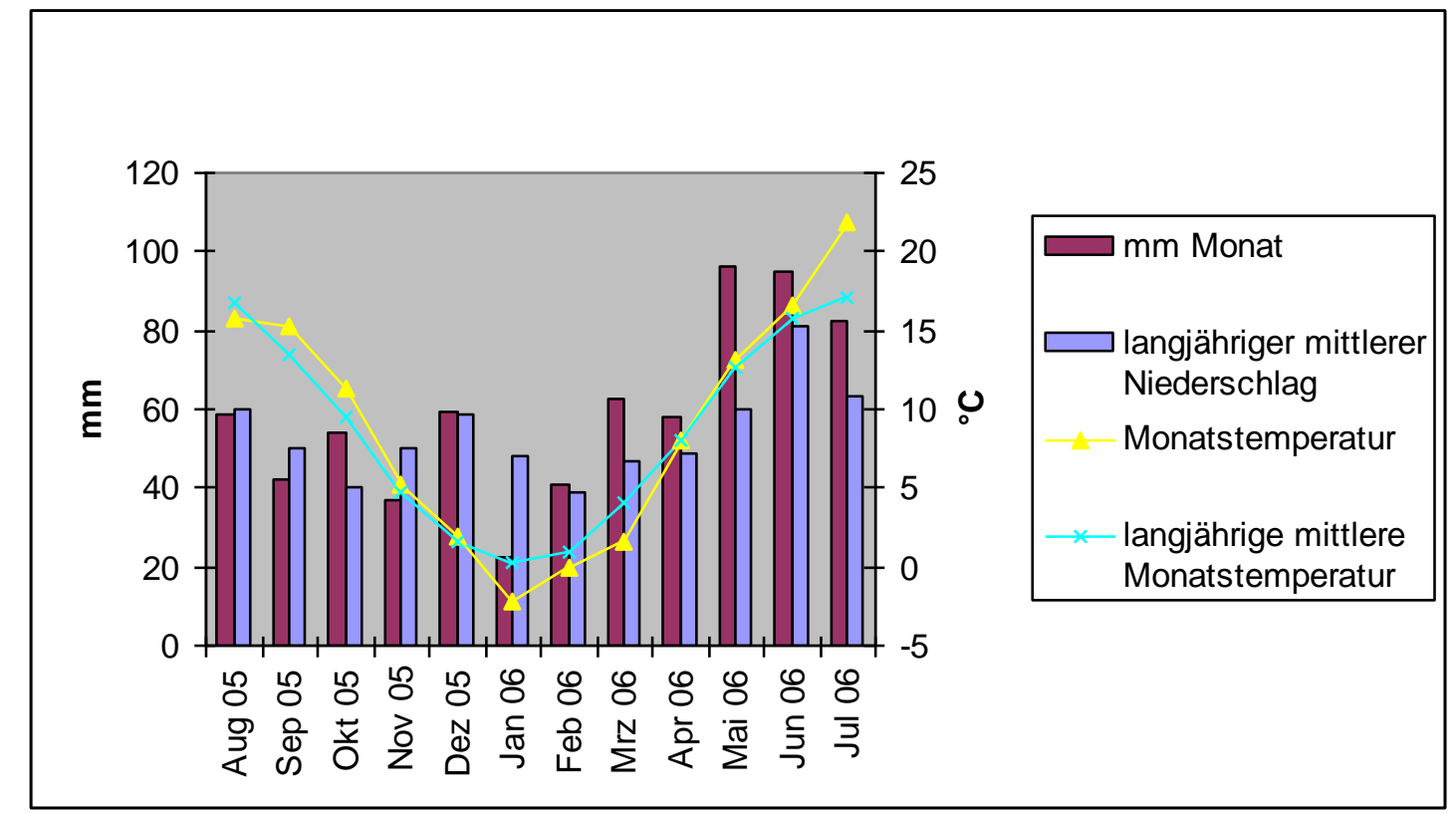

Abb. 2.7: Wetterdaten August 2005 bis Juli 2006 Standort Göttingen

\section{Ernte 2007}

Zur Aussaat 2006 wurden erneut auf beiden bereits beschriebenen Standorten Leistungsprüfungen durchgeführt.

Auf dem Reinshof bei Göttingen wurden wie im Jahr zuvor die 18 bereits beschriebenen Genotypen in zwei Wiederholungen angebaut. Die Aussaat erfolgte am 02.09.2006 in Parzellen mit der Größe von 11,25 m².

Pflanzenschutz:

$\begin{array}{ll}\text { 29.09.2006 } & \text { 2 1/ha Butisan top } \\ \text { 09.10.2006 } & 0,151 / \text { ha Karate } \\ \text { 02.04.2007 } & \text { 0,075 1/ha Karate zeon } \\ \text { 03.07.2007 } & \text { 2 1/ha Round up }\end{array}$

Düngung:

$\begin{array}{ll}\text { 14.03.2007 } & 42 \mathrm{~kg} / \mathrm{ha} \mathrm{N} \text { aus SSA } \\ \text { 20.03.2007 } & 54 \mathrm{~kg} / \mathrm{ha} \mathrm{N} \text { aus KAS } \\ 04.04 .2007 & 81 \mathrm{~kg} / \mathrm{ha} \mathrm{N} \text { aus KAS }\end{array}$


Auf dem Standort Göttingen herrschten im Jahr 2006/2007 folgende Wetterbedingungen vor (Abb.2.8).

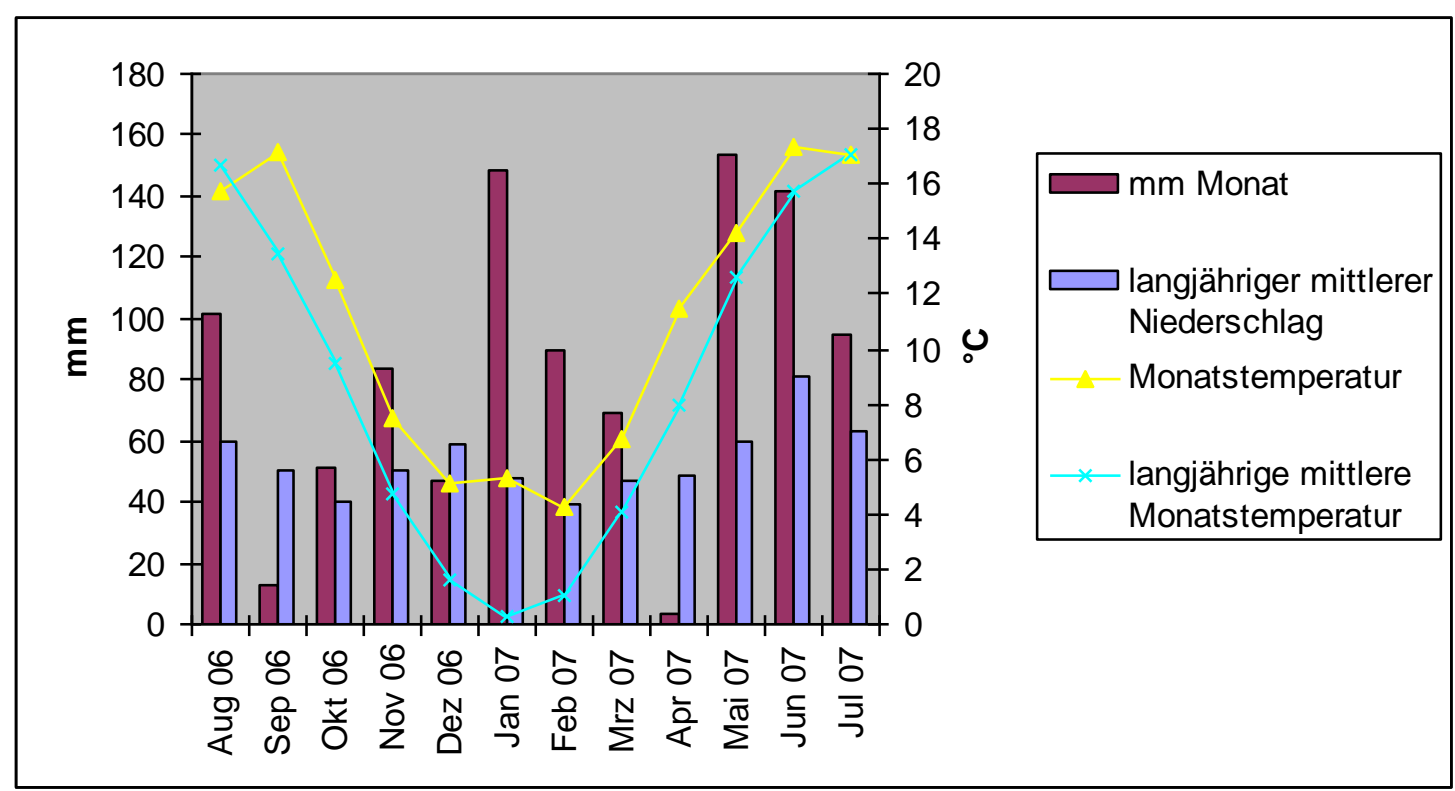

Abb. 2.8 Wetterdaten August 2006 bis Juli 2007 Standort Göttingen

Die Aussaat in Kalteneber erfolgte am 01.09.2006 in zwei Wiederholungen auf Parzellen mit der Größe von $12 \mathrm{~m}^{2}$. Da nicht mehr genug Saatgut der ,alten Mutanten“ vorhanden war, konnten am Standort Kalteneber nur die „,neuen Mutanten“ und Wotan zur Leistungsprüfung angebaut werden.

Pflanzenschutz:

04.09.2006 2,5 1/ha Nimbus

20.09.2006 1,5 1/ha Butisan top

18.09.2006 0,075 1/ha Karate Zeon

23.03.2007 $0,15 \mathrm{~kg} / \mathrm{ha}$ Trafo WG

26.04.2007 0,075 1/ha Fastac SC

22.05.2007 0,075 17ha Fastac SC

Düngung:

Grunddünger: $300 \mathrm{~kg} / \mathrm{ha}$ Thomaskali $12+15+3$

14.03.2007 $100 \mathrm{~kg} / \mathrm{ha}$ KAS $(27 \mathrm{~kg} \mathrm{~N})$

16.04.2007 $70 \mathrm{~kg} / \mathrm{ha}$ KAS $(20 \mathrm{~kg} \mathrm{~N})$

Für das Erntejahr 2007 sind die Wetterdaten für den Standort Kalteneber in der Abb. 2.9 wiedergegeben. 


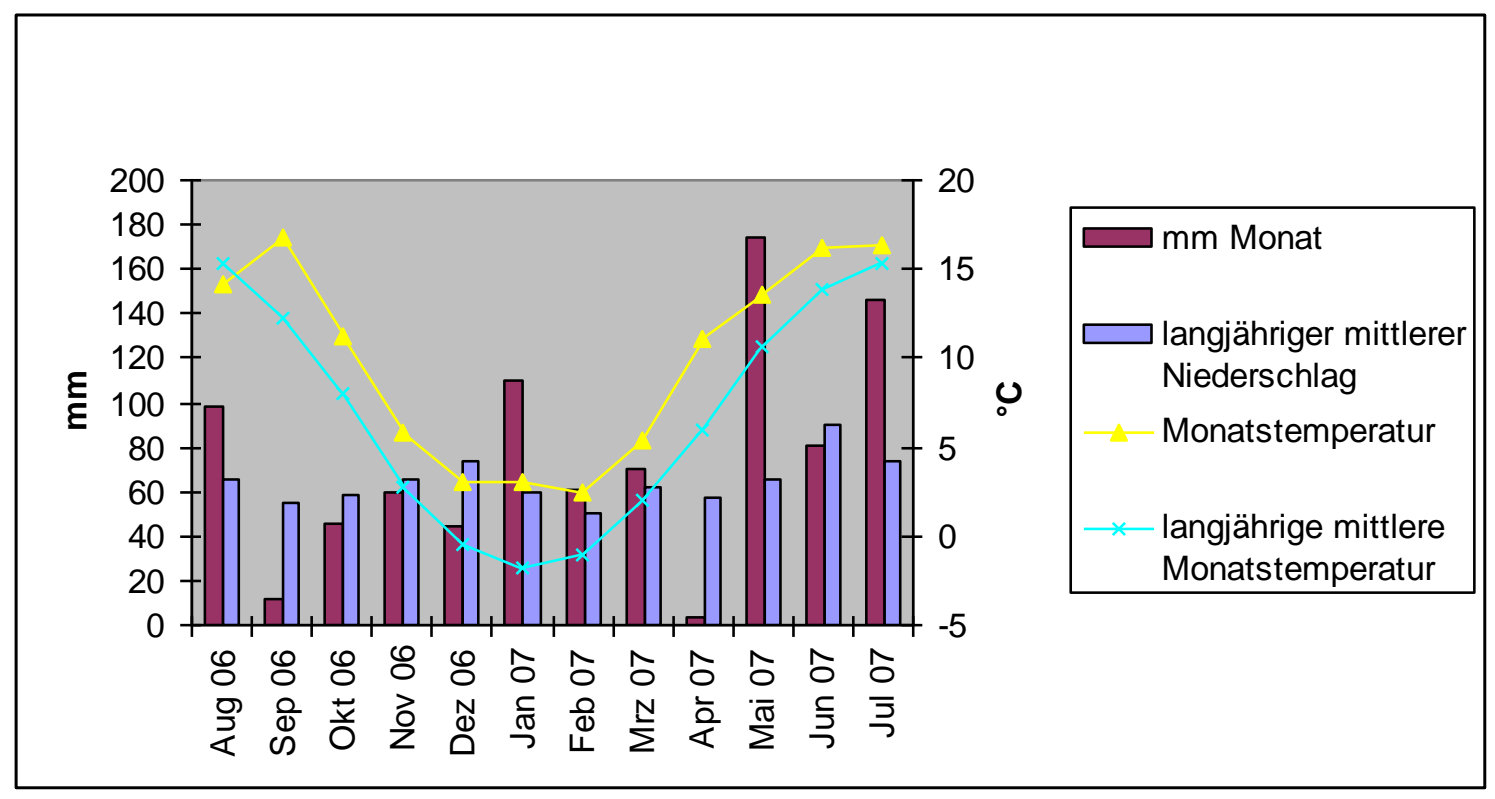

Abb. 2.9: Wetterdaten August 2006 bis Juli 2007; Wetterstation Flinsberg

\subsubsection{Merkmalserfassung}

Die Untersuchung der geernteten Samen erfolgte zunächst mittels Nah-Infrarot-ReflektionsSpektroskopie (NIRS) nach Velasco et al. (1999) mittels einer Kalibrierung nach Tillmann (2003). Damit konnte zunächst eine große Menge an Proben in relativ kurzer Zeit im Hinblick auf verschiedene Qualitätsmerkmale untersucht werden. Mit der NIRS wurde der Ölgehalt, der Ölsäuregehalt und der Linolensäuregehalt bestimmt, weiterhin wurde der Protein-, Glucosinolat-, Phytin- und Sianpin-Gehalt gemessen. Die angegebenen Ölgehalte sind bezogen auf $9 \%$ Feuchtegehalt der Samen. Der Linolsäuregehalt wurde nicht gemessen, da keine ausreichend genaue Methode zur Bestimmung der Linolsäurewerte mittels NIRS verfügbar war. Der Nachteil der NIRS-Analyse liegt in der geringeren Präzision.

Eine genauere Ermittlung der Zusammensetzung des Fettsäuremusters erfolgte mittels Gaschromatographie (GC) nach Thies (1971). Mit dieser Methode wurde der Ölsäuregehalt, der Linolsäure und der Linolensäuregehalt bestimmt. Die GC-Analytik erfasst die komplette Fettsäurezusammensetzung in einem Analysengang.

Die statistische Verrechnung, d.h. die Ermittlung der Mittelwerte, Varianzkomponenten und der F-Test, wurde mittels PLABSTAT-ANOVA (Utz 2001) durchgeführt. 


\subsection{Ergebnisse}

\subsubsection{Ernte 2002}

Die 2002 geernteten 4550 Einzelpflanzen wurden zunächst alle mit NIRS untersucht und im Hinblick auf folgende Merkmale betrachtet:

- Fettsäuremuster

- Proteingehalt

- Ölgehalt

- Glucosinolatgehalt

- Sinapingehalt

- Phytingehalt

Ergebnisse, die auf einen veränderten Gehalt einzelner dieser Inhaltsstoffe hinwiesen, wurden durch eine zweite NIRS-Messung abgesichert. Das Ergebnis lässt sich wie folgt zusammenfassen:

- bei der Zusammensetzung des Fettsäuremusters konnten in der zweiten NIRSMessung einige hohe Werte an Ölsäure bestätigt werden

- $\quad$ es wurden keine Genotypen mit einen auffällig niedrigen Sinapingehalt (unter $5 \mathrm{mg} / \mathrm{g}$ im Samen) gefunden

- die Phytingehalte zeigten nur eine geringe Variation

- es gab keine auffälligen Werte beim Protein-, Öl- und Glucosinolatgehalt.

Die bezüglich des Fettsäuremusters auffälligen Proben wurden mit GC nachgemessen und brachten folgende Ergebnisse (Tabelle 2.2)

Tab 2.2 Fettsäuregehalte in \% der NIRS- und GC-Messung

\begin{tabular}{|c|c|c|c|c|c|}
\hline \multirow{2}{*}{ Nr } & \multicolumn{2}{|c|}{ NIRS } & \multicolumn{3}{c|}{ GC } \\
\cline { 2 - 6 } & $\mathbf{C ~ 1 8 : 1}$ & $\mathbf{C ~ 1 8 : 3}$ & $\mathbf{C ~ 1 8 : 1}$ & $\mathbf{C ~ 1 8 : 2}$ & $\mathbf{C} \mathbf{1 8 : 3}$ \\
\hline Mu10 & $\mathbf{7 9 , 5}$ & 8,1 & $\mathbf{7 2 , 4}$ & 11,4 & 7,2 \\
\hline Mu11 & $\mathbf{7 8 , 0}$ & 8,6 & $\mathbf{7 0 , 0}$ & 13,8 & 6,4 \\
\hline Mu12 & $\mathbf{8 1 , 4}$ & 8,1 & $\mathbf{7 1 , 9}$ & 11,7 & 7,3 \\
\hline Mu13 & $\mathbf{7 7 , 9}$ & 8,6 & $\mathbf{7 2 , 7}$ & 11,3 & 6,9 \\
\hline Mu14 & $\mathbf{7 7 , 9}$ & 10,9 & $\mathbf{6 6 , 6}$ & 16,7 & 7,7 \\
\hline Mu15 & $\mathbf{7 7 , 9}$ & 12,4 & $\mathbf{6 7 , 2}$ & 15,0 & 7,7 \\
\hline Mu16 & $\mathbf{8 3 , 9}$ & 7,9 & $\mathbf{7 5 , 4}$ & 9,3 & 6,7 \\
\hline Mu17 & & & $\mathbf{7 1 , 5}$ & 9,8 & 6,7 \\
\hline
\end{tabular}


Die bei der GC-Untersuchung gefundenen Gehalte von $66 \%$ bis $75 \%$ Ölsäure lagen zwar unter den NIRS-Messwerten, aber noch deutlich über den Vergleichswerten vom Wotan, die mit $60 \%$ Ölsäuregehalt ermittelt wurden.

\subsubsection{Ernte 2004}

Zur Ernte 2004 wurden in Kalteneber und auf dem Reinshof die nach der Ernte 2002 ausgewähltem Genotypen zur Beobachtung angebaut. Die geselbsteten Pflanzen auf dem Reinshof wurden alle mit NIRS gemessen. Bei den Proben mit erhöhten Werten an Ölsäure erfolgte zur Bestätigung dieser Resultate eine Messung mit GC (Tab. 2.3).

Tab. 2.3: Ernte 2004 (Selbstungen); Standort Reinshof; NIRS-Messung Ölsäuregehalt (\%); GC-Messung Ölsäure-, Linolsäure, Linolensäuregehalt

\begin{tabular}{|c|c|c|c|c|}
\hline \multirow{2}{*}{$\begin{array}{c}\text { Probe- } \\
\text { Nr. }\end{array}$} & \multirow{2}{*}{$\begin{array}{c}\text { NIRS } \\
\text { C18:1 \% }\end{array}$} & \multicolumn{3}{|c|}{ GC } \\
\hline & & C18:1 \% & C 18:2\% & C 18:3\% \\
\hline Mu10 & 76,2 & 70,4 & 12,6 & 8,3 \\
\hline Mu11 & 74,3 & 66,6 & 16,2 & 8,8 \\
\hline Mu12 & 74,1 & 68,4 & 13,2 & 10,2 \\
\hline Mu13 & 72,1 & 69,2 & 12,8 & 10,4 \\
\hline Mu14 & 67,3 & 61,0 & 23,8 & 6,9 \\
\hline Mu15 & 72,9 & 66,4 & 16,3 & 8,7 \\
\hline Mu16 & 71,0 & 63,3 & 16,5 & 12,3 \\
\hline Mu17 & 72,2 & 63,9 & 16,3 & 12,1 \\
\hline Wotan & & 58,4 & 20,7 & 12,7 \\
\hline $\begin{array}{l}\text { GD 5\% } \\
\text { F-Test }\end{array}$ & & $\begin{array}{c}8,1 \\
1,36\end{array}$ & $\begin{array}{l}7,2 \\
2,4\end{array}$ & $\begin{array}{c}3,1 \\
4,91 *\end{array}$ \\
\hline
\end{tabular}

Die mit der NIRS-Analyse ermittelten Werte liegen - messtechnisch bedingt - durchweg höher als die der genaueren GC-Messung, aber das Verhältnis der Messwerte zu einander stimmt weitgehend überein.

Die Ergebnisse der GC-Untersuchung zeigen bei den Mu10, Mu11, Mu12, Mu13 und Mu15 deutlich erhöhte Werte gegenüber der Ausgangssorte Wotan, deren Ölsäuregehalt bei 58,4 \% liegt.

In der Tabelle 2.3 sind neben dem Ölsäuregehalt noch die Linol- und die Linolensäuregehalte angegeben. Alle Proben (außer Mu14) mit erhöhtem Ölsäuregehalt zeigen im Vergleich zu Wotan niedrigere Werte bei der Linolsäure. Die Linolensäure hingegen liegt zwischen 8,3\% 
(Mu10) und 12,7\% (Wotan), d.h. nicht alle Werte sind signifikant niedriger als die von

Wotan. Eine Ausnahme bildet die Mu14, die einen hohen C 18:2 Wert aufweist.

\subsubsection{Ernte 2005}

Zur Ernte 2005 liegen nur NIRS-Messergebnisse des Standortes Reinshof vor. In der Tabelle 2.4 sind die Öl-, Ölsäure- und Linolensäuregehalte dargestellt.

Tab 2.4: Öl- Ölsäure- und Linolensäuregehalte, NIRS-Messung, Ernte Reinshof, 2005

\begin{tabular}{|l|l|l|l|}
\hline & Ölgehalt \% & C18:1 \% & C18:3 \% \\
\hline alteMu 19574 & 44,6 & 75,1 & 7,0 \\
\hline alteMu 19517/1944 & 43,9 & 76,2 & 7,4 \\
\hline alteMu 19517/499 & 42,3 & 75,0 & 7,8 \\
\hline alteMu 19566 & 38,1 & 71,3 & 7,1 \\
\hline alteMu 19646 & 43,6 & 71,3 & 8,0 \\
\hline alteMu 19661 & 42,6 & 75,9 & 6,5 \\
\hline alteMu 19684 & 42,5 & 73,7 & 8,2 \\
\hline alteMu 19782 & 39,2 & 79,3 & 4,9 \\
\hline Wotan alt & 43,2 & 61,9 & 10,1 \\
\hline Mu10 & 47,3 & 68,3 & 9,3 \\
\hline Mu11 & 47,9 & 66,9 & 8,6 \\
\hline Mu12 & 45,5 & 70,1 & 9,2 \\
\hline Mu13 & 42,5 & 68,8 & 7,2 \\
\hline Mu14 & 47,5 & 65,5 & 8,7 \\
\hline Mu15 & 43,2 & 61,9 & 10,0 \\
\hline Mu16 & 45,7 & 72,8 & 7,6 \\
\hline Mu17 & 46,3 & 70,6 & 8,2 \\
\hline Wotan neu & 44,7 & 61,1 & 9,7 \\
\hline GD 5\% & 4,0 & 4,0 & 1,4 \\
\hline F-Test & $3,91 * *$ & $15,6 * *$ & $8,02 * *$ \\
\hline
\end{tabular}

Die Ölgehalte der „,alten Mutanten“ liegen zwischen 38,1 \% und 44,6 \%. Wotan weist einen Ölgehalt von 43,2 \% bzw. 44,7 \% auf. Die neuen Mutanten liegen mit 42,5\% bis 47,9\% höher im Ölgehalt. Die Ölsäuregehalte der ,alten Mutanten“ liegen mit Werten von 71,3 \% 79,3\% deutlich und signifikant über dem Wert von Wotan (61,9\% bzw. 61,1\%). Die neuen Mutanten zeigen mit Werten von 65,5\% bis 72,8 \% (außer Mu15) nicht ganz so hohe Werte wie die ,alten Mutanten“, sie liegen aber ebenfalls signifikant über den Wotan-Werten.

Auch bei den Linolensäuregehalten sind signifikante Unterschiede zwischen Wotan und den „alten Mutanten“ sowie zwischen Wotan und den neuen Mutanten festzustellen. 
Am Standort Kalteneber wurden die Parzellenerträge zur Ernte 2005 (Abb. 2.10) ermittelt.

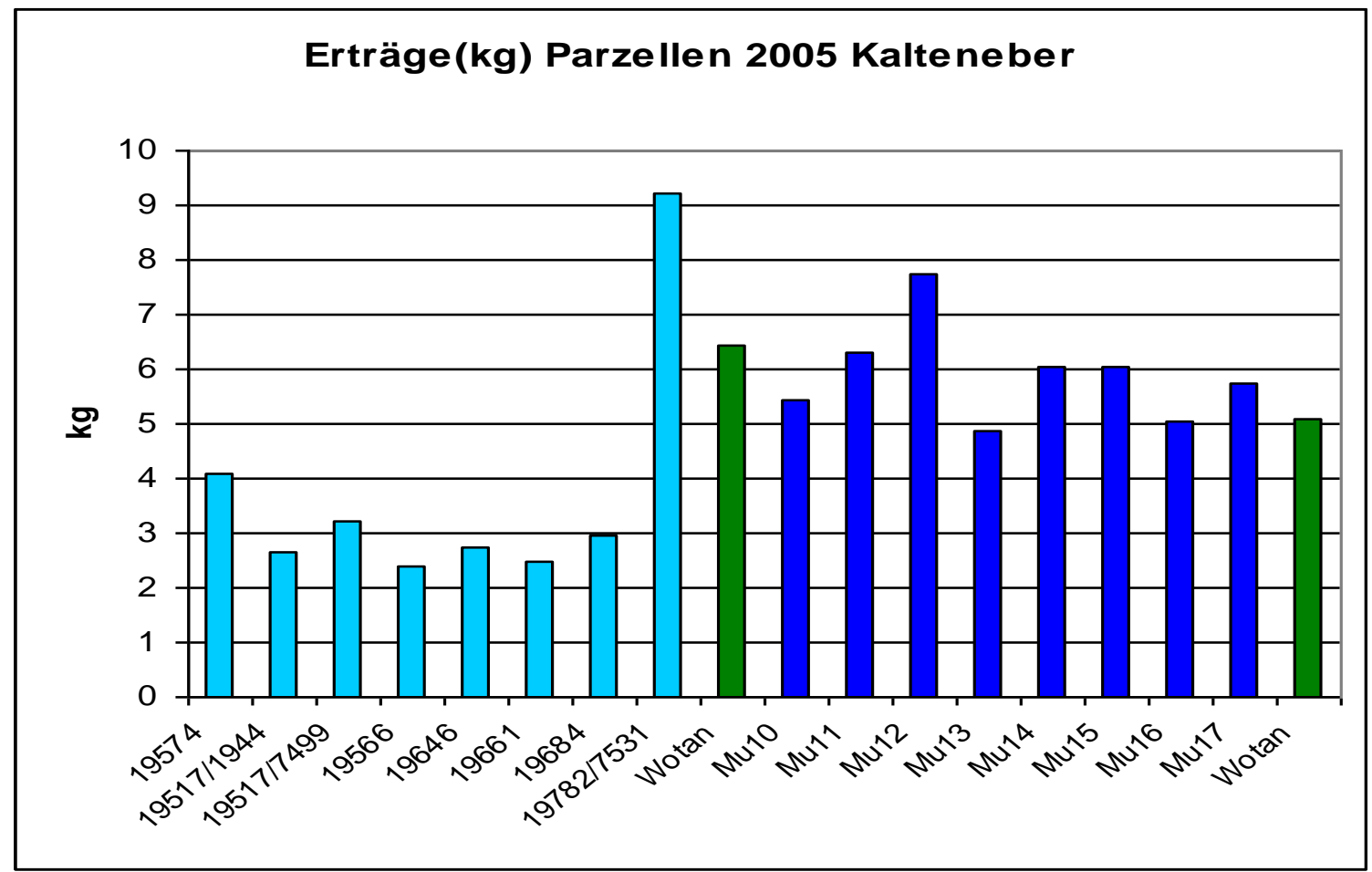

Abb. 2.10 Parzellenerträge Kalteneber 2005 in kg

Aus dem Diagramm ist ersichtlich, dass die Kornerträge der , alten Mutanten' (mit Ausnahme einer Mutante) signifikant geringer sind als die von Wotan und den neuen Mutanten. Das heißt, die neu gefundenen Genotypen zeigen bei höherem Ölsäuregehalt gleiche Erträge wie Wotan.

\subsubsection{Ernte 2006}

Zur Ernte 2006 wurden wieder alte und neue Mutanten im Vergleich mit Wotan angebaut. In der Tabelle 2.5 sind die NIRS-Messergebnisse aus Kalteneber für Ölgehalt, Ölsäuregehalt und Linolensäuregehalt dargestellt.

Hinsichtlich der Ölgehalte gibt es zwar signifikante Unterschiede zwischen den einzelnen Genotypen, d. h. die Werte schwanken zwischen 39,1\% Ölgehalt bei der alten Mutante 19661 und 44,45 Ölgehalt bei der neuen Mutante 11, aber es gibt keine signifikanten Unterschiede zwischen Wotan und den Mutanten. 
Tab. 2.5: NIRS Messergebnisse Leistungsprüfung 2006 Kalteneber

\begin{tabular}{|c|c|c|c|}
\hline & Ölgehalt \% & C18:1 \% & C18:3 \% \\
\hline alteMu 19574 & $\mathbf{4 2 , 1}$ & $\mathbf{7 5 , 4}$ & $\mathbf{6 , 5}$ \\
\hline alteMu 19517/1944 & $\mathbf{4 2 , 5}$ & $\mathbf{7 6 , 4}$ & $\mathbf{8 , 0}$ \\
\hline alteMu 19517/7499 & $\mathbf{4 1 , 1}$ & $\mathbf{7 5 , 4}$ & $\mathbf{7 , 7}$ \\
\hline alteMu 19566 & $\mathbf{3 9 , 4}$ & $\mathbf{7 2 , 4}$ & $\mathbf{9 , 0}$ \\
\hline alteMu 19646 & $\mathbf{4 1 , 5}$ & $\mathbf{7 2 , 7}$ & $\mathbf{7 , 6}$ \\
\hline alteMu 19661 & $\mathbf{3 9 , 1}$ & $\mathbf{7 5 , 0}$ & $\mathbf{8 , 1}$ \\
\hline alteMu 10684 & $\mathbf{4 0 , 7}$ & $\mathbf{7 5 , 0}$ & $\mathbf{8 , 4}$ \\
\hline alteMu 19782/7531 & $\mathbf{4 2 , 2}$ & $\mathbf{7 8 , 1}$ & $\mathbf{7 , 6}$ \\
\hline Wotan alt & $\mathbf{4 1 , 6}$ & $\mathbf{6 7 , 2}$ & $\mathbf{8 , 9}$ \\
\hline Mu10 & $\mathbf{4 3 , 5}$ & $\mathbf{7 1 , 9}$ & $\mathbf{7 , 9}$ \\
\hline Mu11 & $\mathbf{4 4 , 4}$ & $\mathbf{7 1 , 3}$ & $\mathbf{7 , 4}$ \\
\hline Mu12 & $\mathbf{4 2 , 2}$ & $\mathbf{7 8 , 5}$ & $\mathbf{7 , 3}$ \\
\hline Mu13 & $\mathbf{4 0 , 4}$ & $\mathbf{7 4 , 8}$ & $\mathbf{7 , 8}$ \\
\hline Mu14 & $\mathbf{4 1 , 5}$ & $\mathbf{6 6 , 3}$ & $\mathbf{8 , 6}$ \\
\hline Mu15 & $\mathbf{4 3 , 6}$ & $\mathbf{6 4 , 0}$ & $\mathbf{9 , 3}$ \\
\hline Mu16 & $\mathbf{4 1 , 1}$ & $\mathbf{7 0 , 3}$ & $\mathbf{8 , 8}$ \\
\hline Mu17 & $\mathbf{4 2 , 1}$ & $\mathbf{7 3 , 2}$ & $\mathbf{7 , 5}$ \\
\hline Wotan neu & $\mathbf{4 2 , 0}$ & $\mathbf{6 6 , 0}$ & $\mathbf{8 , 6}$ \\
\hline GD 5\% & 2,1 & 4,4 & 2,1 \\
F-Test & $3,53 * *$ & $8,31 * *$ & 1,05 \\
\hline
\end{tabular}

Bei den Ölsäuregehalten zeigen die alten Mutanten wieder deutlich höhere Werte als Wotan. Bei den neuen Mutanten sind bis auf die Mu 14 und 15 ebenfalls signifikant höhere Werte zu erkennen. Bezüglich des Linolensäuregehaltes gibt es keine signifikanten Unterschiede. Genauere Ergebnisse der einzelnen Fettsäureanteile bringen die Untersuchungen mittels GC. Sie sind der folgenden Tabelle 2.6 zu entnehmen.

Die GC-Ergebnisse bestätigen, dass die Ölsäuregehalte der ,alten Mutanten“ mit Werten von $71,5 \%$ bis $77,4 \%$ signifikant höher sind als die Werte von Wotan $(65,6 \%)$. Für die neuen Mutanten wird ebenfalls belegt, dass die Werte außer bei Mu14 und Mu15 mit 67,6 \% $74,2 \%$ höher sind als die bei Wotan.

Ebenso ist ersichtlich, dass die Genotypen mit den höchsten Ölsäuregehalten die niedrigsten Linolsäuregehalte aufweisen, wie die Mutante 17 mit einem Ölsäuregehalt von 74,2 \% und einem Linolsäuregehalt von 8,9 \% deutlich erkennen lässt. Bei den Linolensäuregehalten sind keine Unterschiede zwischen Wotan und den einzelnen Genotypen zu verzeichnen, aber insgesamt ist eine signifikante Variation zu beobachten. 
Tab.2.6: GC Untersuchungen Leistungsprüfung 2006 Kalteneber

\begin{tabular}{|c|c|c|c|}
\hline & C 18:1 \% & C 18:2 \% & C 18:3 \% \\
\hline alteMu 19574 & 73,0 & 9,1 & 7,3 \\
\hline alteMu 19517/1944 & 74,8 & 8,6 & 7,5 \\
\hline alteMu 19517/7499 & 77,4 & 5,9 & 6,7 \\
\hline alteMu 19566 & 71,5 & 11,1 & 7,6 \\
\hline alteMu 19646 & 71,7 & 10,4 & 8,7 \\
\hline alteMu 19661 & 74,6 & 8,4 & 7,5 \\
\hline alteMu 10684 & 74,4 & 8,4 & 8,0 \\
\hline alteMu 19782/7531 & 77,0 & 7,0 & 6,8 \\
\hline Wotan alt & 65,6 & 16,4 & 8,6 \\
\hline Mu10 & 69,3 & 12,8 & 8,6 \\
\hline Mu11 & 67,6 & 15,3 & 7,6 \\
\hline Mu12 & 74,2 & 9,3 & 7,9 \\
\hline Mu13 & 73,2 & 10,1 & 7,6 \\
\hline Mu14 & 66,1 & 17,4 & 6,9 \\
\hline Mu15 & 64,1 & 17,8 & 8,5 \\
\hline Mu16 & 70,6 & 12,9 & 7,4 \\
\hline Mu17 & 74,2 & 8,9 & 7,9 \\
\hline Wotan neu & 65,2 & 18,5 & 7,9 \\
\hline 2,8 & 2,1 & 0,73 & \\
\hline $19,99 * *$ & $31,77 * *$ & $6,27 * *$ & \\
\hline
\end{tabular}

Um die agronomischen Merkmale wie Blühverhalten, Pflanzenlänge und Erträge zu ermitteln, wurden im Jahr 2006 ebenfalls Leistungsprüfungen an beiden Standorten durchgeführt.

In der folgenden Tabelle (Tab. 2.7) sind Blühbeginn, Blühdauer und die Pflanzenlänge zu Blüte dargestellt.

Der Blühbeginn am Standort Kalteneber erfolgte aufgrund der Höhenlage deutlich später als in Göttingen. Die ,alten Mutanten“ blühten später und waren im Wuchs auch deutlich kleiner als Wotan. Die neuen Mutanten waren in ihrem Blühverhalten und in ihrem Wuchs der Vergleichssorte Wotan ähnlich, d.h. obwohl die einzelnen Genotypen einen erhöhten Ölsäuregehalt aufwiesen, unterschieden sie sich bei der Blüte und in der Pflanzenlänge kaum vom Wotan 
Tab. 2.7: Blühbeginn, Blühdauer und Wuchshöhe an beide Standorte, Leistungsprüfung 2006

\begin{tabular}{|c|c|c|c|c|c|c|}
\hline & \multicolumn{2}{|c|}{$\begin{array}{c}\text { Blühbeginn Tage im } \\
\text { Mai }\end{array}$} & \multicolumn{2}{|c|}{ Blühdauer } & \multicolumn{2}{|c|}{ Pflanzenlänge } \\
\hline & Göttingen & Kalteneber & Göttingen & Kalteneber & Göttingen & Kalteneber \\
\hline alte Mu19574 & 9 & 18 & 34 & 31 & 150 & 133 \\
\hline alte Mu19517/1944 & 10 & 17 & 38 & 32 & 158 & 138 \\
\hline alte Mu19517/499 & 8 & 20 & 36 & 35 & 135 & 135 \\
\hline alte $\mathrm{Mu} 19566$ & 9 & 20 & 40 & 35 & 125 & 128 \\
\hline alte $\mathrm{Mu} 19646$ & 8 & 18 & 34 & 31 & 145 & 125 \\
\hline alte Mu19661 & 10 & 18 & 36 & 33 & 145 & 143 \\
\hline alte Mu19684 & 9 & 20 & 36 & 34 & 143 & 128 \\
\hline alte $\mathrm{Mu} 19782$ & 10 & 17 & 37 & 34 & 155 & 145 \\
\hline Mittel & 9 & 18 & 36 & 33 & 144 & 134 \\
\hline Wotan & 8 & 15 & 33 & 31 & 158 & 150 \\
\hline Mu10 & 8 & 15 & 34 & 32 & 158 & 138 \\
\hline Mu11 & 9 & 15 & 37 & 34 & 143 & 153 \\
\hline Mu12 & 8 & 17 & 36 & 33 & 158 & 158 \\
\hline Mu13 & 9 & 16 & 36 & 33 & 150 & 140 \\
\hline Mu14 & 9 & 16 & 35 & 36 & 155 & 158 \\
\hline Mu15 & 7 & 17 & 34 & 34 & 153 & 148 \\
\hline Mu16 & 8 & 16 & 35 & 33 & 145 & 155 \\
\hline Mu17 & 8 & 16 & 36 & 32 & 150 & 143 \\
\hline Mittel & 8 & 16 & 35 & 33 & 151 & 149 \\
\hline Wotan & 7 & 16 & 32 & 31 & 158 & 145 \\
\hline GD5\% & 0,8 & 1,31 & 1,88 & 2,2 & 10,2 & 13,25 \\
\hline F-Test & $10,6 * *$ & $13,61 * *$ & $9,07 * *$ & $4,75^{* *}$ & $6,81 * *$ & $5,27 * *$ \\
\hline
\end{tabular}

.Sowohl in Göttingen als auch in Kalteneber waren die neuen Mutanten rein optisch besser, die Pflanzen waren größer und kräftiger sowie im Wuchs stabiler. Die alten Mutanten waren überwiegend kleiner und schwach wüchsig (Abb 2.11).

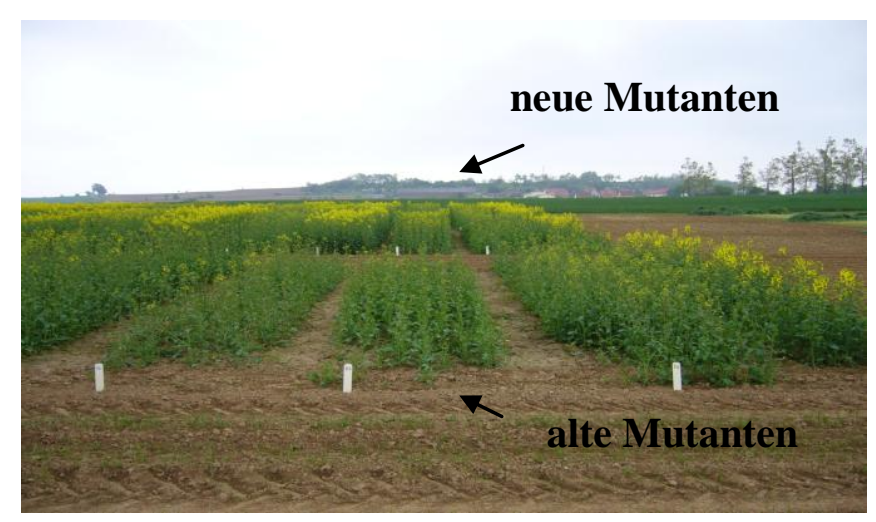

Abb 2.11 Leistungsprüfung 2006 Kalteneber 
In den Abb. 2.12 und 2.13 sind die Parzellenerträge an beiden Orten dargestellt.

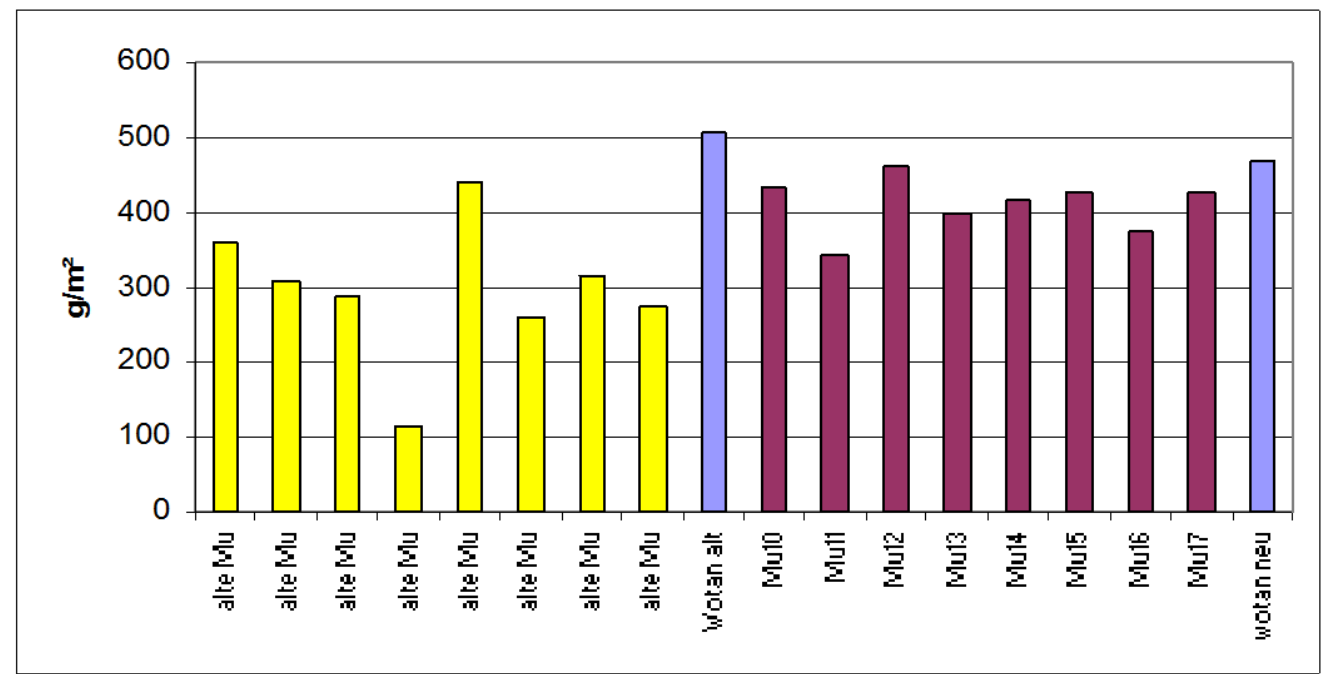

Abb. 2.12 Parzellenerträge kg/m² Leistungsprüfung 2006 Standort Göttingen

Am Standort Göttingen wiesen die neuen Mutanten durchweg stabilere und höhere Erträge auf. Die Parzellenerträge lagen alle im Bereich der Werte von Wotan.

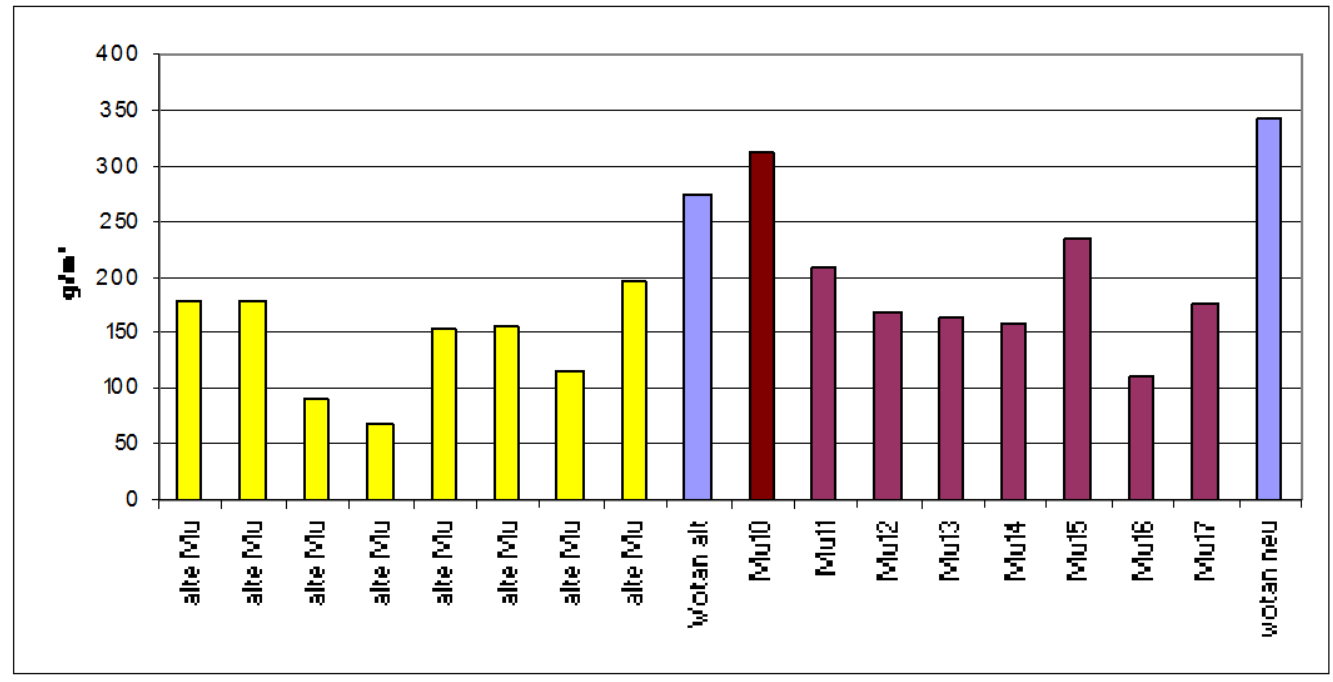

Abb. 2.13 Parzellenerträge $\mathrm{kg} / \mathrm{m}^{2}$ Leistungsprüfung 2006 Standort Kalteneber

In Kalteneber war der Bestand kurz vor der Ernte stark mit Phoma lingam befallen, ein Umstand, der sich negativ auf die Parzellenerträge auswirkte. Trotzdem lagen die Erträge derneuen Mutanten mit einem Mittelwert von $191 \mathrm{~g} / \mathrm{m}^{2}$ noch signifikant über denen der ,alten Mutanten“"(143 g/m²). 


\subsubsection{Ernte 2007}

Zur Ernte 2007 wurden wieder die neuen Mutanten angebaut. Da das Saatgut der ,alten Mutanten“ begrenzt war, konnten nur in Göttingen einige ,alte Mutanten“ zu Vergleichszwecken ausgesät werden. Als Vergleich wurde in diesem Jahr zusätzlich auch die konventionelle Sorte Express angebaut. Im Folgender Tabelle (Tab. 2.8) sind die NIRSErgebnisse beider Standorte dargestellt.

Tab. 2.8: NIRS-Werte Leistungsprüfung 2007 (beide Standorte)

\begin{tabular}{|c|c|c|c|c|c|c|}
\hline & \multicolumn{2}{|c|}{ Ölgehalt \% } & \multicolumn{2}{c|}{ C 18:1 \% } & \multicolumn{2}{c|}{ C 18:3 \% } \\
\hline & Göttingen & Kalteneber & Göttingen & Kalteneber & Göttingen & Kalteneber \\
\hline alte Mu 19574 & 42,0 & & 69,6 & & 8,7 & \\
\hline alte Mu 19517/1944 & 42,0 & & 67,8 & & 8,6 & \\
\hline alte Mu 19517/499 & 40,8 & & 74,1 & & 8,2 & \\
\hline alte Mu 19566 & 40,7 & & 68,1 & & 9,1 & \\
\hline alte Mu 19646 & 40,3 & & 69,1 & & 8,5 & \\
\hline Express & 41,2 & & 60,9 & & 11,8 & \\
\hline Wotan alt & 41,8 & & 61,9 & & 11,3 & \\
\hline Mu10 & 40,6 & 47,7 & 63,0 & 72,9 & 10,5 & 9,9 \\
\hline Mu11 & 41,6 & 45,3 & 64,1 & 67,9 & 10,4 & 10,5 \\
\hline Mu12 & 41,5 & 44,9 & $(56,9)$ & 71,3 & 12,7 & 9,7 \\
\hline Mu13 & 40,4 & 43,5 & 64,1 & 70,0 & 9,1 & 8,1 \\
\hline Mu14 & 41,3 & 45,5 & 61,6 & 64,7 & 10,6 & 11,7 \\
\hline Mu15 & 42,1 & 46,3 & 61,6 & 61,1 & 11,0 & 13,4 \\
\hline Mu16 & 43,0 & 46,4 & 68,9 & 70,2 & 9,3 & 11,5 \\
\hline Mu17 & 41,3 & 44,9 & 61,8 & 70,1 & 11,8 & 8,9 \\
\hline Wotan neu & 41,0 & 44,1 & 60,8 & 63,0 & 11,5 & 11,9 \\
\hline GD 5\% & 1,46 & 1,47 & 1,62 & 2,87 & 0,57 & 1,81 \\
\hline F-Test & $2,22+$ & $8,05 * *$ & $69,06 * *$ & $21,21 * *$ & $56,96 * *$ & $8,82^{* *} *$ \\
\hline
\end{tabular}

Beim Ölgehalt sind in Göttingen keine wesentlichen Unterschiede zwischen ,alten Mutanten“, neuen Mutanten und Wotan zu verzeichnen.

Der Ölsäuregehalt der „,alten Mutanten“ ist im Vergleich zu Wotan stark erhöht. Bei den neuen Mutanten fallen besonders Mu10, Mu12, Mu16 und Mu17 mit erhöhten Werten auf. Mu12 hat mit einem Wert von 56,9 in Göttingen nur einen relativ geringen Ölsäuregehalt. In diesem Fall lag wahrscheinlich ein Aussaatfehler vor.

Auch diese Proben wurden mit der genaueren GC-Analyse untersucht (Tab. 2.9). 
Tab. 2.9: GC-Werte Göttingen LP 2007

\begin{tabular}{|c|c|c|c|}
\hline & C 18:1 \% & C 18:2 \% & C 18:3 \% \\
\hline alte Mu 19574 & 74,2 & 9,2 & 7,2 \\
\hline alte Mu 19517/1944 & 73,9 & 10,3 & 6,6 \\
\hline alte Mu 19517/499 & 77,8 & 6,0 & 5,3 \\
\hline alte Mu 19566 & 72,4 & 10,9 & 7,3 \\
\hline alte Mu 19646 & 71,9 & 10,8 & 6,8 \\
\hline Express & 61,8 & 18,9 & 8,1 \\
\hline Wotan alt & 66,2 & 16,8 & 7,2 \\
\hline Mu10 & 67,5 & 15,2 & 7,5 \\
\hline Mu11 & 66,0 & 16,5 & 6,9 \\
\hline Mu12 & 58,9 & 22,0 & 9,0 \\
\hline Mu13 & 69,2 & 14,3 & 6,2 \\
\hline Mu14 & 64,6 & 18,2 & 6,2 \\
\hline Mu15 & 64,2 & 17,5 & 8,2 \\
\hline Mu16 & 73,7 & 9,9 & 7,3 \\
\hline Mu17 & 62,8 & 19,7 & 8,0 \\
\hline Wotan neu & 59,3 & 19,6 & 8,4 \\
\hline GD 5\% & 3,3 & 1,6 & 1,1 \\
\hline F-Test & F** 26,27 & F**78,25 & F**6,43
\end{tabular}

Die Ergebnisse bestätigen, dass die „alten Mutanten“ mit Werten von 71,9 \% - 77,8\% Ölsäuregehalt gegenüber den konventionellen Sorten Wotan und Express stark erhöhte Werte aufweisen. Aber auch die neuen Mutanten lassen mit Werten von 62,8 \% - 73,7\% gegenüber Wotan signifikant erhöhte Werte erkennen. Die Mutante 12 hat aus dem schon vermuteten Grund (Aussaatfehler) einen geringeren Wert.

Die GC-Untersuchungsergebnisse (Tab. 2.10) beider Orte bestätigen die hohen Ölsäuregehalte bei den Mutanten 10, 11, 12, 13, 16 und 17. Die Mutanten 14 und 15 liegen zwar auch höher, die Differenz lässt sich statistisch aber nicht absichern. 
Tab. 2.10: GC-Werte der Ernte 2007 beider Standorte

\begin{tabular}{|c|c|c|c|c|c|c|c|c|c|}
\hline & \multicolumn{3}{|c|}{ C 18:1 \% } & \multicolumn{3}{c|}{ C 18:2 \% } & \multicolumn{3}{c|}{ C 18:3 \% } \\
& G0̈ & Ka & Mittel & G0̈ & Ka & Mittel & Gö & Ka & Mittel \\
\hline Mu10 & 67,5 & 73,8 & 70,6 & 15,2 & 9,0 & 12,1 & 7,5 & 8,3 & 7,9 \\
\hline Mu11 & 66,0 & 67,8 & 66,9 & 16,5 & 14,8 & 15,7 & 6,9 & 7,9 & 7,4 \\
\hline Mu12 & $(58,9)$ & 73,0 & $(66,0)$ & $(22,0)$ & 9,9 & $(15,9)$ & $(9,0)$ & 8,7 & $(8,8)$ \\
\hline Mu13 & 69,2 & 72,7 & 70,9 & 14,3 & 10,6 & 12,4 & 6,2 & 7,8 & 7,0 \\
\hline Mu14 & 64,6 & 62,9 & 63,7 & 18,2 & 17,6 & 17,9 & 6,2 & 8,7 & 7,4 \\
\hline Mu15 & 64,2 & 62,9 & 63,6 & 17,5 & 17,5 & 17,5 & 8,2 & 10,4 & 9,3 \\
\hline Mu16 & 73,7 & 68,1 & 70,9 & 9,9 & 14,1 & 12,0 & 7,3 & 9,3 & 8,3 \\
\hline Mu17 & 62,8 & 73,4 & 68,1 & 19,7 & 8,9 & 14,3 & 8,0 & 8,7 & 8,4 \\
\hline Wotan & 59,3 & 62,5 & 60,9 & 19,6 & 17,9 & 18,8 & 8,4 & 9,9 & 9,1 \\
\hline GD 5\%
\end{tabular}

Im Rahmen der Leistungsprüfung wurden auch Blühbeginn und Wuchshöhe bestimmt. Die Ergebnisse finden sich in der Tabelle 2.11.

Tab. 2.11: Blühbeginn und Pflanzenlänge Leistungsprüfung 2007 Blüte

\begin{tabular}{|c|c|c|c|c|}
\hline & \multicolumn{3}{|c|}{ Blühbeginn Tage im April } & \multicolumn{2}{|c|}{ Pflanzenlänge } \\
\hline & Göttingen & Kalteneber & Göttingen & Kalteneber \\
\hline alte Mu 19574 & 14 & & 145 & \\
\hline alte Mu 19517/1944 & 16 & & 148 & \\
\hline alte Mu 19517/499 & 17 & & 135 & \\
\hline alte Mu 19566 & 15 & & 138 & \\
\hline alte Mu 19646 & 18 & & 143 & \\
\hline Mittel & 16 & & 141 & \\
\hline Express & 11 & & 138 & \\
\hline Wotan alt & 15 & & 150 & \\
\hline Mu10 & 14 & 24 & 138 & 145 \\
\hline Mu11 & 15 & 25 & 155 & 153 \\
\hline Mu12 & 13 & 25 & 155 & 150 \\
\hline Mu13 & 15 & 26 & 135 & 148 \\
\hline Mu14 & 15 & 26 & 148 & 150 \\
\hline Mu15 & 15 & 27 & 143 & 150 \\
\hline Mu16 & 16 & 26 & 145 & 155 \\
\hline Mu17 & 16 & 25 & 150 & 150 \\
\hline Mittel & 15 & 25 & 146 & 150 \\
\hline Wotan neu & 12 & 24 & 157 & 158 \\
\hline GD 5\% & 0,96 & 2,37 & 13,6 & 16,02 \\
\hline F-Test & $35,78 *$ & 3,08 & $2,75 *$ & 0,58 \\
\hline
\end{tabular}


Die ,alten Mutanten“ blühten deutlich später als Wotan, Express und die neuen Mutanten. Die Pflanzenlänge zeigte keine signifikanten Unterschiede. Express ist eine kleinwüchsige, standfeste Sorte, Wotan hingegen ist mit 150 bis $157 \mathrm{~cm}$ deutlich größer. Aber auch die Mutanten erreichten Längen von 138 bis $155 \mathrm{~cm}$, waren aber alle kürzer als Wotan.

In der letzten Grafik (Abb. 2.14) dieses Abschnittes sind die Parzellenerträge dargestellt. Die „alten Mutanten“ liegen dabei signifikant unter denen von Wotan, Express und den neuen Mutanten. Die neuen Mutanten hingegen finden sich alle im Bereich von Wotan und Express. Insgesamt waren in diesem Jahr die Parzellenerträge in Kalteneber etwas besser.

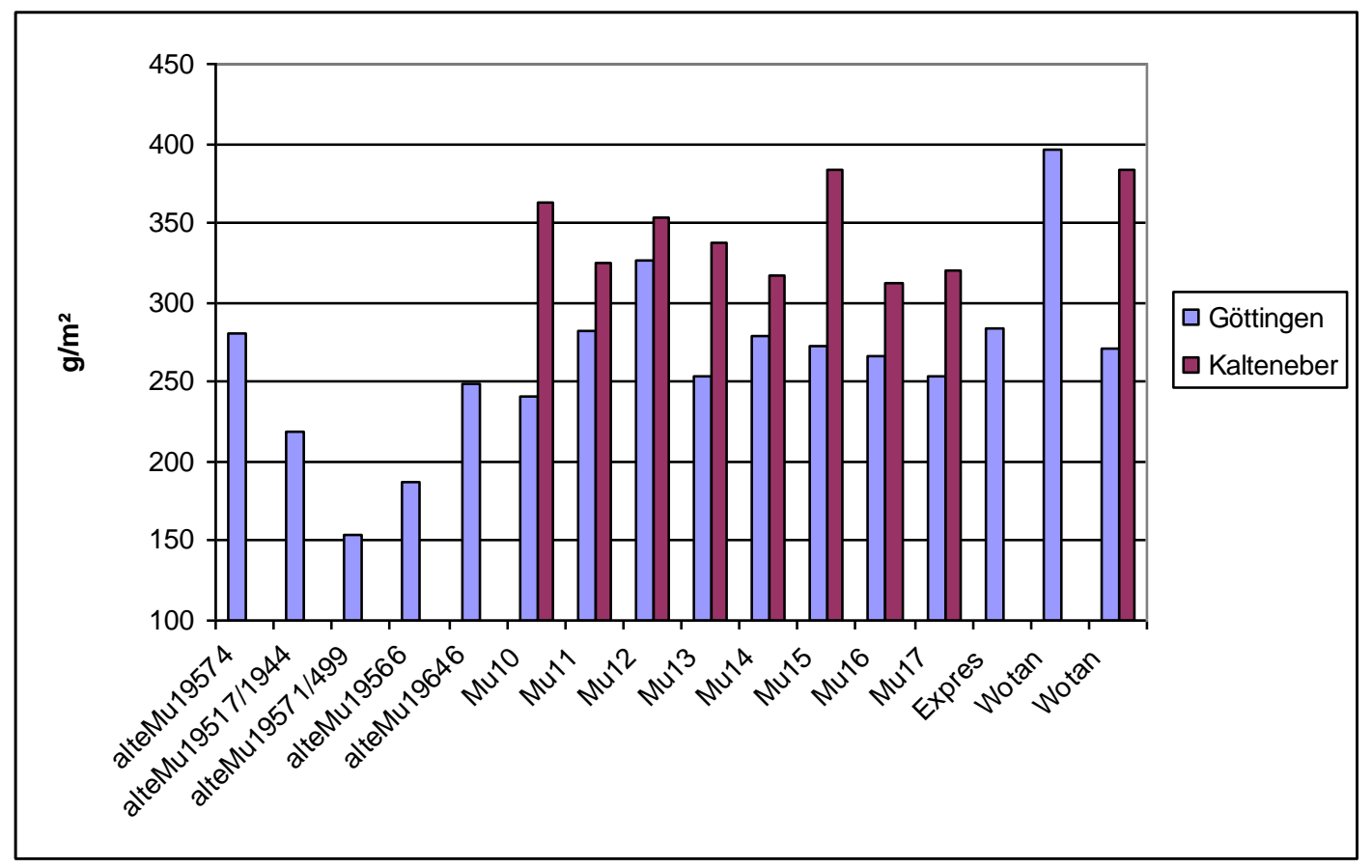

Abb. 2.14: Parzellenerträge Leistungsprüfung 2007 beider Orte

\subsection{Diskussion}

Wie in der Einführung zu diesem Abschnitt dargestellt, ging es uns zunächst um die Suche nach neuen Genotypen im Raps, nachdem das Saatgut mit einer mutagenen Substanz behandelt wurde. Im ersten Jahr wurden mehrere Merkmale, wie z.B. Protein-, Glucosinolat-, Sinapin-, Phytingehalt und Fettsäurezusammensetzung erfasst und ausgewertet. Es zeigten sich interessante Veränderungen bei der Fettsäurezusammensetzung der Samen. Diese sollten bezüglich des Ölsäuregehaltes in der Größenordnung der von Rücker und Schierholt im Jahre 
2000 beschriebenen Mutanten liegen, hinsichtlich der agronomischen Merkmale aber bessere Werte aufweisen.

Die Ergebnisse zeigen, dass diese Zielsetzung erreicht wurde. Mithilfe der NIRS- und vor allem der GC-Messtechnik konnten acht neue Mutanten (Mu10 bis Mu17) mit verändertem Fettsäuremuster selektiert werden, deren Ölsäuregehalt gegenüber der Ausgangssorte Wotan signifikant erhöht ist.

Der in den Jahren 2002 bis 2007 an zwei verschiedenen Orten durchgeführte Anbau dieser neuen Mutanten in Parzellen bestätigte, dass die induzierten Veränderungen stabil sind. Von den zunächst 8 selektierten Genotypen bestätigte sich für 6 (Mu10, Mu11, Mu12, Mu13, Mu16 und Mu17) über mehrere Generationen hinweg die höheren Ölsäuregehalte gegenüber der Ausgangssorte Wotan, wobei die Mutanten 12 und 13 über alle Jahre hinweg die höchsten Werte aufweisen. Die Mutanten 14 und 15 zeigten gegenüber dem Wotan leicht erhöhte Werte, die nicht in jedem Jahr signifikant waren. Darüber hinaus konnten wir auch die Stabilität der Veränderungen in den neuen Mutanten belegen (Tab.2.12).

Tab. 2.12 Ölsäuregehalte der neuen Mutanten von 2004 bis 2007 mittels GC-Messung

\begin{tabular}{|c|c|c|c|}
\hline & $\mathbf{2 0 0 4}$ & $\mathbf{2 0 0 6}$ & $\mathbf{2 0 0 7}$ \\
\hline Mu10 & 70,4 & 69,3 & 70,6 \\
\hline Mu11 & 66,6 & 67,6 & 66,9 \\
\hline Mu12 & 68,4 & 74,2 & 73 \\
\hline Mu13 & 69,2 & 73,2 & 70.9 \\
\hline Mu14 & 61 & 66,1 & 63,7 \\
\hline Mu15 & 66,4 & 64,1 & 63,6 \\
\hline Mu16 & 63,3 & 70,6 & 70,9 \\
\hline Mu17 & 63,9 & 74,2 & 68,1 \\
\hline Wotan & 58,4 & 65,2 & 60,9 \\
\hline GD 5\% & 8,1 & 2,8 & 2,92 \\
F-Test & 1,36 & $19,99 * *$ & $20,07 * *$ \\
\hline
\end{tabular}

Bezüglich des Fettsäuremusters ist als weiterer Befund hervorzuheben, dass alle Pflanzen mit erhöhten Ölsäuregehalten einen reduzierten Linolsäuregehalt aufweisen, während die Linolensäure unverändert blieb.

Die über zwei Jahre hinweg und ebenfalls an zwei verschiedenen Standorten vorgenommenen Prüfungen agronomischer Merkmale ergaben keine Unterschiede bezüglich des Blühbeginns 
zwischen dem ohnehin spät blühenden Wotan und den aus ihm hervorgegangenen neuen Mutanten. Die alten Mutanten hingegen ließen einen verzögerten Blühbeginn erkennen.

Auch hinsichtlich der Pflanzenlänge lagen die neuen Mutanten im Bereich von Wotan, während die alten Mutanten deutlich kürzer waren.

Bereits im ersten Jahr der Ertragsermittlung (Abb. 2.10) zeigte sich, dass die Parzellenerträge der neuen Mutanten im Bereich von Wotan lagen. Die Mu12 lag sogar darüber und zeigte die höchsten Parzellenerträge. Die alten Mutanten brachten bis auf eine Ausnahme (Mu 19782/7531) geringere Erträge hervor. Bei der Bewertung der Erträge durch die ,alten Mutanten“ muss für dieses Jahr allerdings berücksichtigt werden, dass das Saatgut bereits einige Jahre alt war und eine geringere Ertragsleistung dadurch zumindest mit bedingt sein könnte. In den folgenden Jahren wurde jeweils Saatgut von geselbsteten Pflanzen des Vorjahres verwendet, um einen Saatguteffekt auszuschließen.

Die Leistungsprüfung der Rapspflanzen im Jahre 2006 erbrachte am Standort Göttingen insgesamt bessere und der Sorte Wotan vergleichbare Resultate durch die neuen Mutanten. Von den „alten Mutanten“ lag lediglich die Variante 19646 im Ertrag ähnlich hoch. Am Standort Kalteneber erwiesen sich lediglich die Mu10 und die Mu15 besser im Ertrag. Eine mögliche Ursache für das schlechte Abschneiden könnte wie bereits erwähnt im Befall mit Phoma lingam liegen.

Die Leistungsprüfung im Jahr 2007 ergab sehr unterschiedliche Werte an den beiden Standorten. Die Erträge in Kalteneber waren durchweg höher als in Göttingen. Am Standort Göttingen variierten die Erträge innerhalb der alten und der neuen Mutanten sehr stark. Es gab so wohl gute als auch schlechte Erträge bei den alten und den neuen Genotypen.

Trotz der Ertragsunterschiede in den einzelnen Jahren und an den beiden Standorten kann doch festgehalten werden, dass die Erträge der neuen Mutanten fast immer auf der Ebene der Ausgangssorte Wotan und stets signifikant über denen der ,alten Mutanten“ lagen (Abb.2.15). 


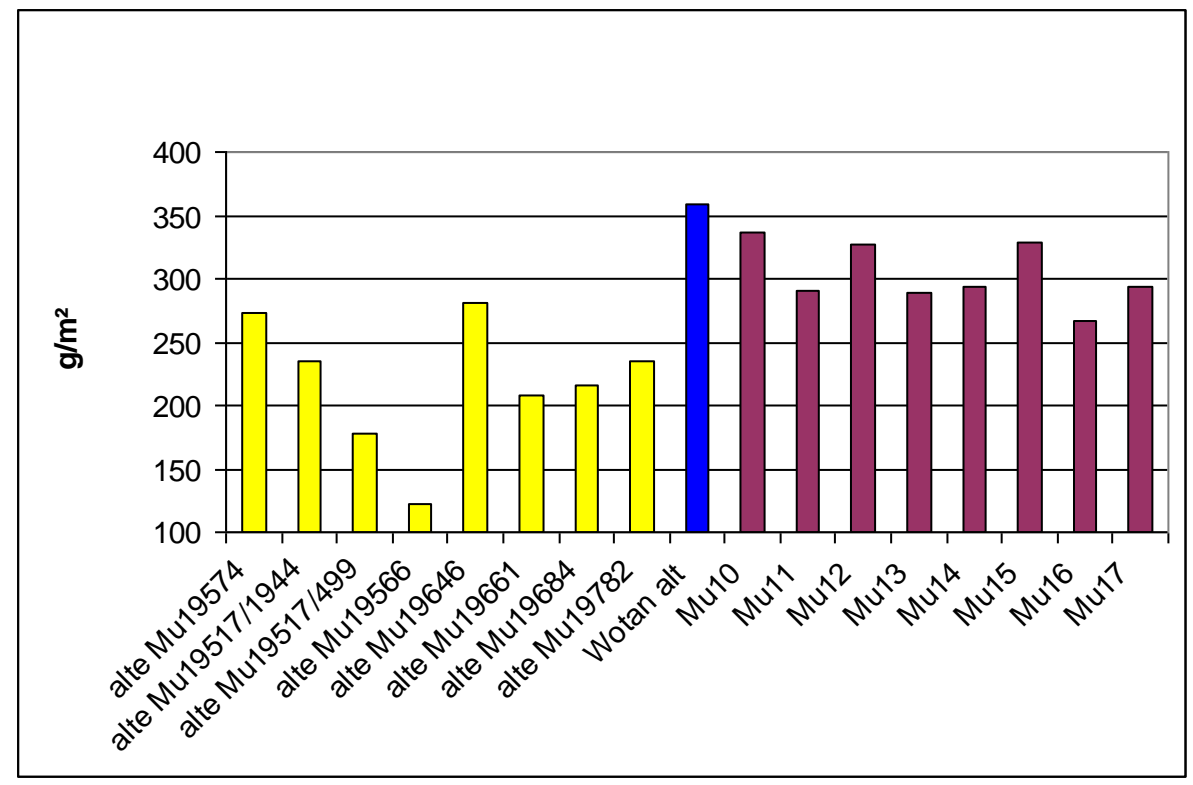

Abb. 2.15 Parzellenerträge aller Leistungsprüfungen über 2 Jahre und 2 Orte

Eine mögliche Erklärung für die besseren Erträge der neuen Mutanten ist auch das Ernteverfahren im ersten Jahr. Während bei dem ersten Versuch, aus dem die ,alten Mutanten“ hervorgingen, alle 20000 Pflanzen geerntet und analysiert wurden, wurden bei den Versuch auf dem diese Arbeit basiert, aus den Pflanzen der über 40000 ausgesäten Samen nur 4000 einzelne Haupttriebe der Pflanzen geerntet. Die Auswahl dieser Pflanzen erfolgte willkürlich, so dass bereits eine Selektion stattgefunden hat, da nur normal große und gut gewachsene Pflanzen geerntet wurden. Diese unbewusste Selektion bei der Ernte vernachlässigte kleine sehr schwachwüchsige Pflanzen, die aber auch möglicherweise mutiert sein konnten.

Die Ergebnisse dieses Versuchskomplexes zusammenfassend darf festgestellt werden, dass es gelungen ist, neue Mutanten der Rapssorte Wotan zu selektieren, die neben einem signifikant erhöhten Ölsäuregehalt auch über wünschenswerte agronomische Merkmale verfügen. $\mathrm{Ob}$ diese Werte auf eine Mutation in einem anderen Gen als bei den ,alten“ Mutanten zurückzuführen sind, muss durch weitere Untersuchungen wie z.B. Kreuzungen und genetische Analysen geklärt werden. 


\section{Genetische Analyse der Mutanten in Kreuzungen}

\subsection{Einleitung}

Wie im vorigen Abschnitt beschrieben, konnten verschiedenen Genotypen mit einem gegenüber der Ausgangssorte Wotan signifikant erhöhten Ölsäuregehalt gefunden werden. Um zu testen, ob diese Genotypen auf eine Mutation in einem anderen Gen als bei der bekannten Mutante 19661 (Schierholt et al 2000) zurückzuführen sind, wurden Kreuzungen dieser Genotypen mit 19661 durchgeführt. Beim Vorliegen von Mutationen an unterschiedlichen Loci müsste es in der $\mathrm{F}_{2}$-Generation $\mathrm{zu}$ Aufspaltungen bei den Ölsäuregehalten kommen, und es müssten Genotypen auftreten, bei denen der Ölsäuregehalt nicht erhöht ist, sondern im Bereich der Ausgangsform Wotan liegt. Bei einer Mutation am selben Genort sollten alle Pflanzen der $F_{2}$-Generation einen erhöhten Ölsäuregehalt aufweisen. Darüber hinaus wurden Kreuzungen der neuen Mutanten mit der Linie DH 009 durchgeführt. Die DH009 ist eine Doppel-Haploide Linie mit niedrigen Linolensäuregehalten und hohen Ölsäuregehalten. Ziel dieser Kreuzungen war es, maximale Ölsäuregehalte zu erreichen.

Des Weiteren erfolgten Kreuzungen der neuen Mutanten untereinander, um zu analysieren, ob die einzelnen Mutanten an verschieden Genorten mutiert sind.

Bereits in dem früheren Versuch (Schierholt et al. 2000) wurden genaue Vererbungsstudien mit den „,alten Mutanten“ (u.a. 19661) durchgeführt. Es wurde die Mutante19661 mit der konventionellen Sorte Lisbeth gekreuzt und die Elternlinien mit den Kreuzungsgenerationen im Feld geprüft. Die Spaltungsverhältnisse in den Folgegenerationen zeigten das Muster einer monogenen Vererbung. Daraus konnte die Schlussfolgerung gezogen werden, dass die gefundene Mutation an einem Genort, HO1 genannt, lokalisiert sein muss. Alle Mutanten waren bezüglich des ausschließlich samenspezifisch exprimierten HO1-Locus allel (Schierholt 2000).

Weiterhin wurden auch Kreuzungen der einzelnen Mutanten untereinander durchgeführt und die $\mathrm{F}_{2}$-Einzelsamen untersucht (Schierholt 2000), um zu testen, ob in allen Mutanten der 
gleiche Locus von der Mutation betroffen ist. Beim Vorliegen verschiedener Loci hätten in der spaltenden $\mathrm{F}_{2}$-Population Genotypen mit niedrigen (im Bereich Wotan) oder mit hohen Ölsäuregehalten auftreten müssen. In den dort untersuchten Kreuzungskombinationen konnten jedoch keine Aufspaltungen für das Merkmal Ölsäuregehalt beobachtet werden.

\subsection{Material und Methoden}

Im Frühjahr 2005 wurden am Standort Göttingen Kreuzungen zwischen den neuen Mutanten mit erhöhtem Ölsäuregehalt (Mu10 bis Mu17, siehe Abschnitt 2) vorgenommen. Außerdem wurden die Mutanten 10 bis 17 mit der alten Mutante 19661 sowie mit der DH-Linie 009 gekreuzt.

Für die Kreuzungen wurde die Mutante 19661 gewählt, die bereits im EMS-MutageneseProgramm (Rücker und Röbbelen 1995) als hochölsäurehaltig selektiert werden konnte. Darüber hinaus wurde diese Mutante verwendet, um sie näher zu charakterisieren und zu lokalisieren und um Untersuchungen zur Erblichkeit der Mutation durchzuführen (Schierholt et al. 2001).

Die DH009 Linie stammt aus folgender Kreuzung:

GÖ 9 (niedrig Linolensäure) x 3543-2640 (hoch Ölsäure)

Der Elter 3543-2640 mit dem hohen Ölsäuregehalt wurde aus einem Kreuzungsprogramm (Ernte 1998) selektiert, bei dem NPZ-Material 7065/94 mit der „alte Mutante“ M453 gekreuzt wurde. Letztere hat in ihrer Abstammung eine andere Mutation für Hochölsäure als die 19661 und stammt aus einem früheren Mutationsprogramm.

Des Weiteren wurden einige von den neuen Mutanten, die die höchsten Ölsäuregehalte aufwiesen, untereinander gekreuzt. Siehe dazu Tabelle 3.1. Da der Umfang der Kreuzungen aller neuen Mutanten miteinander zu groß geworden wäre, wurden die Mu14, Mu16 und Mu17 nicht einbezogen. Bei ihnen ist die Erhöhung des Ölsäuregehaltes ohnehin nicht so stark ausgeprägt. 
Tab 3.1: Kreuzungen neuer Mutanten untereinander

\begin{tabular}{|l|l|l|l|l|}
\hline & Mu11 & Mu12 & Mu13 & Mu15 \\
\hline Mu10 & x & x & x & x \\
\hline Mu11 & & x & x & x \\
\hline Mu12 & & & x & x \\
\hline Mu13 & & & & x \\
\hline
\end{tabular}

Das aus den in der Tabelle 3.1 dargestellten Kreuzungen gewonnene $F_{1}$-Saatgut wurde im August 2005 auf dem Reinshof bei Göttingen ausgesät und im Juli 2006 geerntet. Ebenso wurden die Eltern (19661, DH009 und die neuen Mutanten) in Parzellen angebaut und geselbstet. Von den Kreuzungen mit 19661 wurden mit GC Einzelkörner $\left(\mathrm{F}_{2}\right)$ analysiert und das Fettsäuremuster bestimmt. Da die GC-Einzelkörner-Untersuchung sehr aufwendig ist, wurden nur die $\mathrm{F}_{2}$-Samen der Kreuzungen mit 19661 untersucht, um erste Ergebnisse zur Aufspaltung zu erhalten.

Das im Juli 2006 geerntete $F_{2}$-Saatgut wurde im August 2006 erneut ausgesät. Im Juli 2007 erfolgte die Ernte. Siehe dazu auch das folgende Schema.

Frühjahr 2005 Bsp. $\quad$ : Kreuzung 19661 x Mu10 (jeweils 3 Pflanzen gekreuzt)

Ernte $2005 \quad F_{1}$ Saatgut

August 2005 Aussaat

$F_{1}$ Saatgut (3 Beobachtungsparzellen)

Ernte 2006

$\mathrm{F}_{2}$ Saatgut (geselbstet)

August 2006

Aussaat $F_{2}$ Saatgut

Ernte 2007

$F_{3}$ Saatgut (geselbstet)

Das bei der Ernte 2007 gewonnene $\mathrm{F}_{3}$-Saatgut wurde zunächst mit NIRS und später mit GC untersucht und die Fettsäurezusammensetzung bestimmt. 


\subsection{Ergebnisse}

\subsubsection{Untersuchung von $F_{2}$-Einzelsamen}

In den folgenden Abbildungen sind die Ölsäuregehalte von einzelnen $\mathrm{F}_{2}$-Samen der Kreuzung mit 19661 dargestellt. Die Abbildung 3.1 zeigt die Werte für den Elter HO-Mutante 19661. Wenn die neuen Mutanten, wie vermutet, auf einer anderen Mutation beruhen, dann muss in der $\mathrm{F}_{2}$-Generation eine Aufspaltung der Ölsäuregehalte zu erkennen sein.

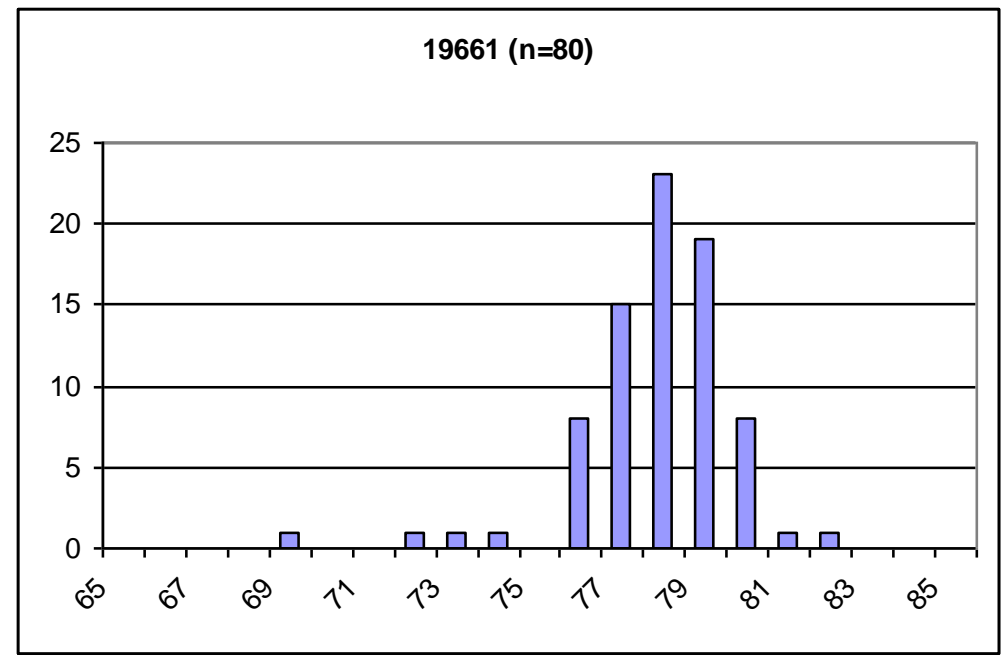

Abb. 3.1: Ölsäuregehalte von Samen der 19661 (GC-Messung)

Die Ölsäuregehalte von Samen der Linie 19661 liegen zwischen $69 \%$ und $82 \%$; nur vier Samen von insgesamt 80 zeigen Werte unter $75 \%$. Der Mittelwert beträgt $78 \%$. Die Ölsäuregehalte der $\mathrm{F}_{2}$-Samen weiterer Kreuzungen mit 19661 sind in den folgenden Diagrammen wiedergegeben (Abb.3.2.- Abb.3.5).

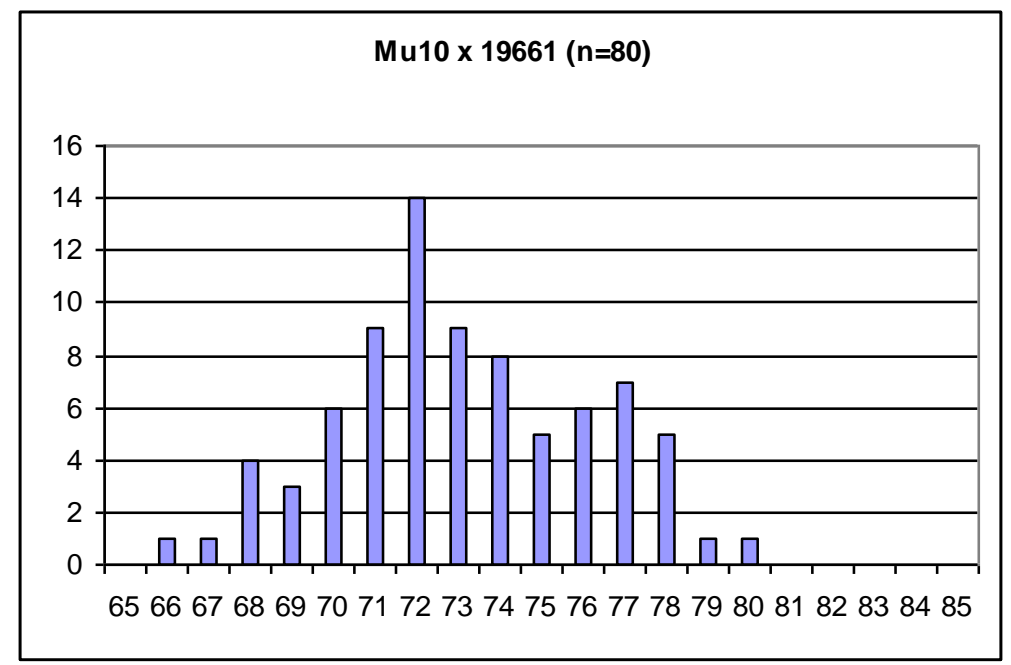

Abb.3.2: Ölsäuregehalte von $\mathrm{F}_{2}$-Samen der Kreuzung Mu10 x 19661 (GC-Messung) 


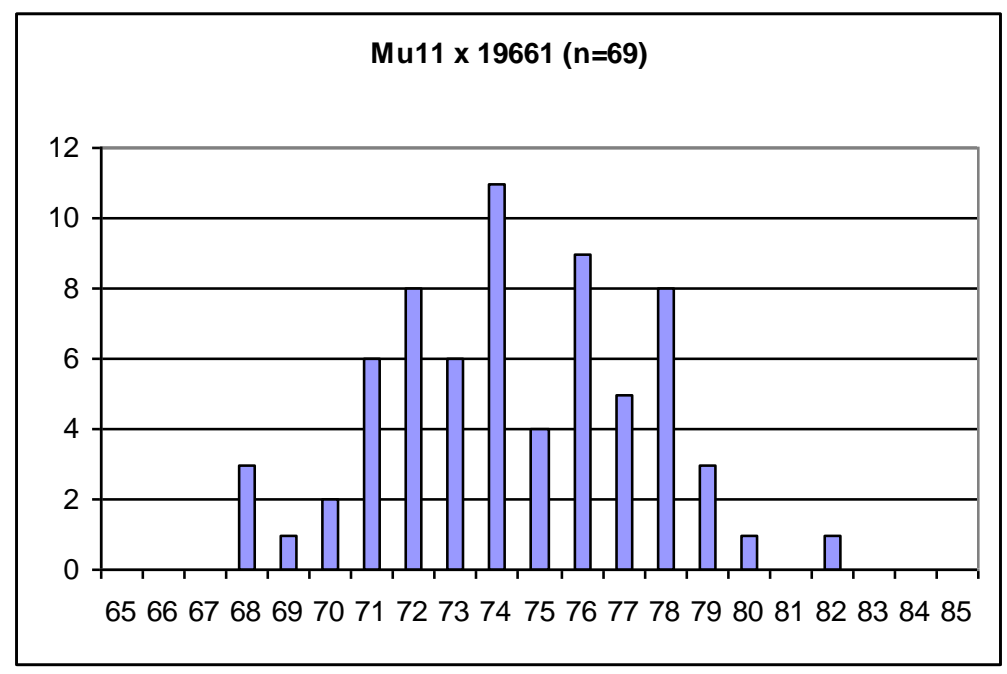

Abb.3.3: Ölsäuregehalte von $\mathrm{F}_{2}$-Samen der Kreuzung Mu11 x 19661 (GC-Messung)

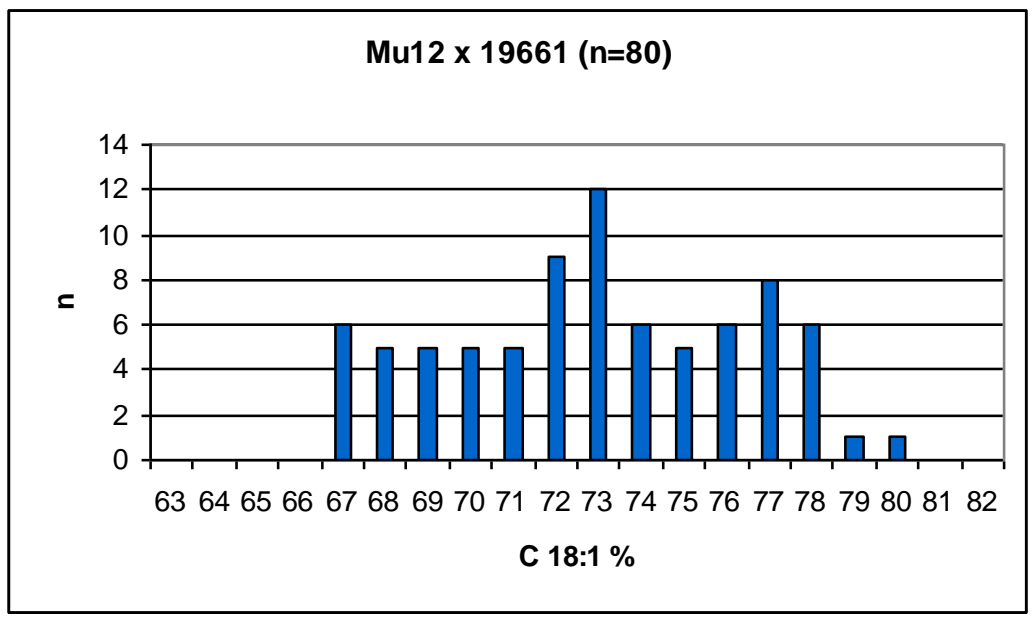

Abb.3.4: Ölsäuregehalte von $F_{2}-$ Samen der Kreuzung Mu12 x 19661 (GC-Messung)

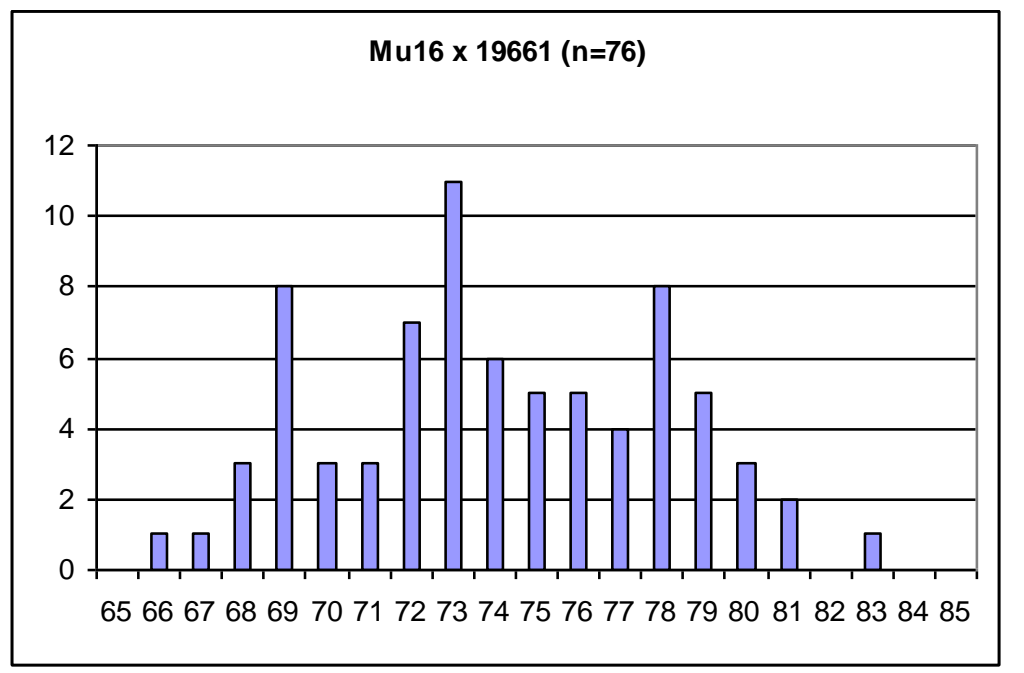

Abb.3.5: Ölsäuregehalte von $\mathrm{F}_{2}-$ Samen der Kreuzung Mu16 x 19661 (GC-Messung) 
In den vier Kreuzungen Mu10 x 19661, Mu11 x 19661, Mu12 x 19661 und Mu16 x 19661 ist eine Variation der Ölsäuregehalte zwischen $63 \%$ und $83 \%$ zu beobachten. Das Ausgangsmaterial der Mutanten (Sorte Wotan, siehe Abschnitt 1) hat Ölsäuregehalte um die $60 \%$. Bei einer Kreuzung Wotan x 19661 würde man in der $F_{2}$-Generation 25\% Samen mit Werten im Bereich von Wotan erwarten. Da bei den abgebildeten vier Kreuzungen auch die niedrigsten Werte einen Ölsäuregehalt von mindestens $63 \%$ aufweisen, wird die Vermutung bestätigt, dass es sich bei den Kreuzungen um Mutanten mit einem gegenüber Wotan höheren Ölsäuregehalt handelt.

Die Verteilung der Ölsäuregehalte in einem relativ weiten Bereich (63\% - $83 \%$; Abb. 3.2 3.5) deutet auf eine Aufspaltung hin. Eine solche Aufspaltung käme dann zustande, wenn zwei Eltern mit verschiedenen Mutanten gekreuzt werden.

Die Ergebnisse der Kreuzung Mu13 x 19661 sind im folgenden Diagramm (Abb.3.6) dargestellt.

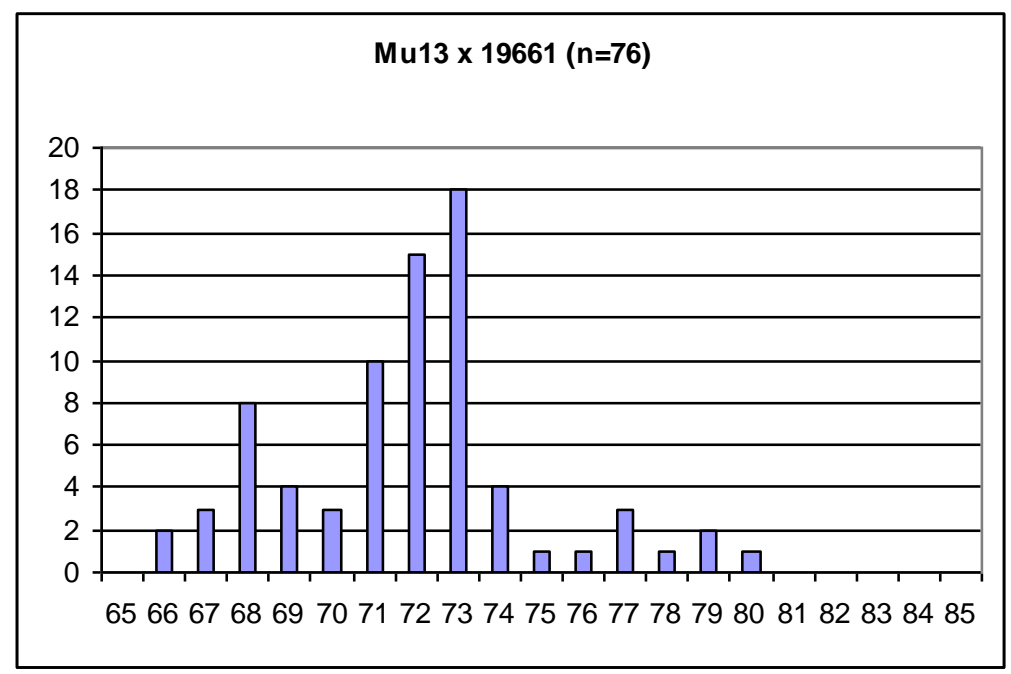

Abb.3.6: Ölsäuregehalte von F2-Samen der Kreuzung Mu13 x 19661 (GC-Messung)

In dieser Darstellung ist auffällig, dass nur sehr wenige Samen einen Gehalt an Ölsäure aufweisen, der höher als $73 \%$ beträgt. Eine Erklärung dafür ist schwierig. Wahrscheinlich ist diese Kreuzung nicht gelungen. 


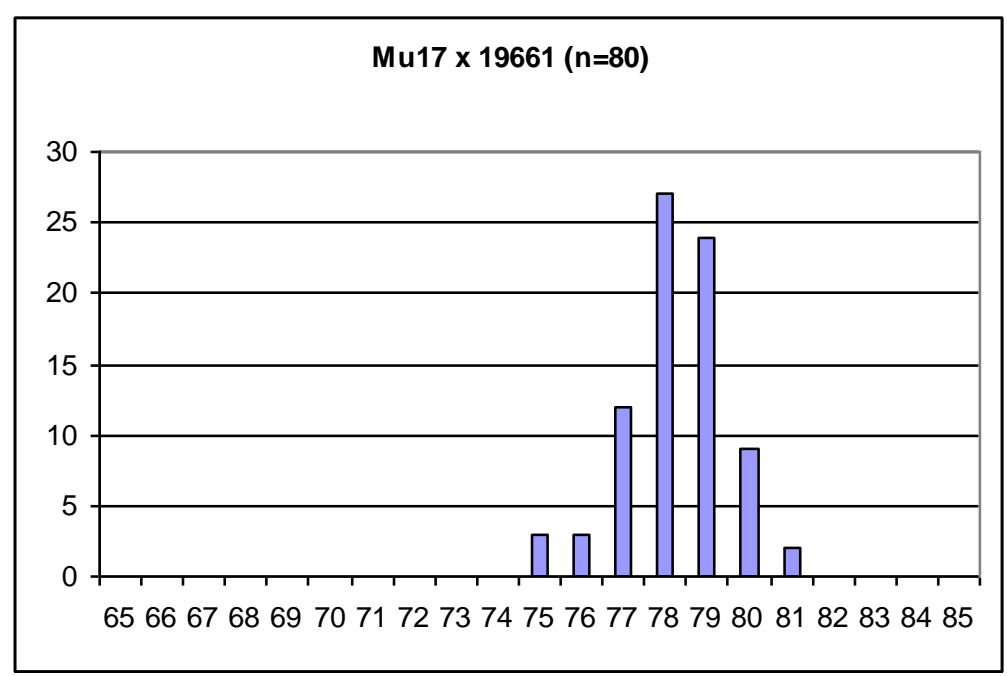

Abb.3.7: Ölsäuregehalte von $\mathrm{F}_{2}$-Samen der Kreuzung Mu17 x 19661 (GC-Messung)

Im Abb. 3.7 sind die Ölsäuregehalte der Kreuzung 19661 x Mu17 dargestellt. Die Werte liegen alle zwischen $75 \%$ und $81 \%$. und damit im gleichen Bereich des einen Kreuzungselter 19661. Für diesen Befund gibt es zwei mögliche Erklärungen:

Erstens: Die Kreuzung ist fehlgeschlagen, d.h. wenn 19661 die Mutterpflanze war und der Pollen vom Mu17 Vater stammt, ist es möglich, dass es nicht zur Befruchtung gekommen ist, weil die Pflanze bereits vorher vom eigenen Pollen bestäubt wurde.

Zweitens: Es muss auch in Betracht gezogen werden, dass es sich bei Mu17 um die gleiche Mutation handelt wie bei 19661. In diesem Fall wäre auch keine Aufspaltung zu erwarten.

\subsubsection{Fettsäuremuster vom Erntegut der F2-Pflanzen}

In diesem Kapitel werden die GC-Ergebnisse der geselbsteten $\mathrm{F}_{2}$-Pflanzen der Ernte 2007 vorgestellt. In der Tabelle 3.2 werden zunächst die Ölsäure-, Linol- und Linolensäuregehalte der Eltern und der $\mathrm{F}_{2}$-Generation der Kreuzungen wiedergegeben.

Anhand der Ölsäuregehalte lassen sich die Eltern in 3 Gruppen einteilen. Zunächst haben wir die Gruppe mit einem normalen bzw. leicht erhöhtem Ölsäuregehalt (Werte bis 65 \% C18:1). $\mathrm{Zu}$ ihr gehören Wotan, Mu11 und Mu16. Diese Genotypen weisen auch höhere Linolsäuregehalte $(18,0 \%-19,6 \%)$ auf. 
Die zweite Gruppe umfasst die Genotypen mit hohen Ölsäuregehalten, wie 19661 (75,2 \%), Mu10 (71,7 \%), Mu12 (72,7 \%) und Mu13 (71,8\%). In dieser Gruppe liegen die Linolsäuregehalte zwischen $9 \%$ und $11,5 \%$.

Tab.3.2: Ölsäure-, Linol-, Linolensäuregehalte der Eltern und der $\mathrm{F}_{2}$-Generation der Kreuzungen, bestimmt mittels GC

\begin{tabular}{|c|c|cc|c|c|}
\hline & N & & C 18:1 & C 18:2 & C 18:3 \\
\hline 19661 & 46 & 75,2 & & 9,0 & 7,4 \\
DH009 & 36 & 83,9 & & 6,3 & 2,5 \\
Mu10 & 98 & 71,7 & & 10,0 & 8,7 \\
Mu11 & 78 & 64,9 & & 18,0 & 8,2 \\
Mu12 & 74 & 72,7 & & 10,7 & 8,5 \\
Mu13 & 110 & 71,8 & & 11,5 & 7,1 \\
Mu16 & 68 & 64,7 & & 18,0 & 8,4 \\
Wotan & & 59,3 & & 19,6 & 8,4 \\
& & & Mittel der & & \\
Mu10 x 19661 & 95 & 69,5 & 73,5 & 12,8 & 8,0 \\
Mu11 x 19661 & 91 & 67,9 & 70,1 & 15,1 & 8,4 \\
Mu12 x 19661 & 51 & 67,8 & 73,9 & 15,4 & 8,2 \\
Mu10 x DH009 & 104 & 74,4 & 77,8 & 11,9 & 5,0 \\
Mu11 x DH009 & 96 & 73,5 & 74,4 & 13,0 & 4,8 \\
Mu12 x DH009 & 60 & 66,8 & 78,3 & 14,7 & 7,6 \\
Mu10 x Mu11 & 111 & 62,7 & 68,3 & 19,4 & 8,9 \\
Mu10 x Mu12 & 50 & 63,7 & 72,2 & 18,6 & 9,3 \\
Mu10 x Mu13 & 52 & 69,9 & 71,7 & 13,7 & 8,8 \\
Mu11 x Mu12 & 37 & 64,2 & 68,8 & 18,8 & 8,8 \\
Mu11 x Mu13 & 99 & 61,6 & 68,4 & 20,0 & 9,1 \\
Mu12 x Mu13 & 78 & 69,8 & 72,3 & 12,4 & 8,8 \\
& & & & & \\
\hline
\end{tabular}

${ }^{1}$ Wert aus Leistungsprüfung, siehe Kapitel 1

Die Linie DH009 zählt mit einem Ölsäuregehalt von 83,9 \% zur Gruppe der „,very high“Ölsäuregehalte. Dass die DH009 nicht nur ein hochölsäurehaltiger sondern auch ein niedriglinolenhaltiger Genotyp ist, wird durch den geringen Linolensäuregehalt von 2,5 \% bestätigt. Die Linolensäuregehalte aller anderen Genotypen liegen zwischen 7,0 \% und 9,0\%.

Weiterhin fällt in der Tabelle auf, dass die Ölsäuregehalte der einzelnen Kreuzungen immer unter den Mittelwerten der jeweiligen Eltern liegen.

\section{Kreuzung Mu10 x 19661}

In den folgenden drei Diagrammen (Abb.3.8 - Abb.3.10) sind zunächst die Ölsäuregehalte der beiden Eltern und der $\mathrm{F}_{2}$-Population der Kreuzung dargestellt. 


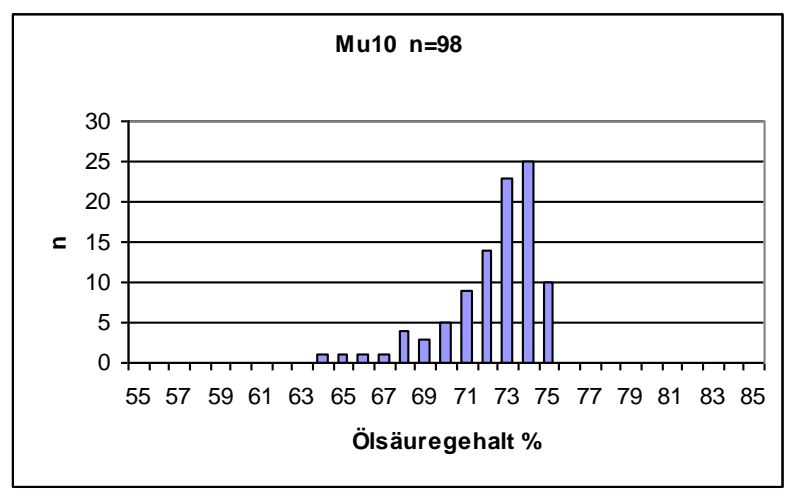

Abb. 3.8: Ölsäuregehalte bei Mu10 ( $\mathrm{F}_{2}$-Population), bestimmt mittels GC-Analyse

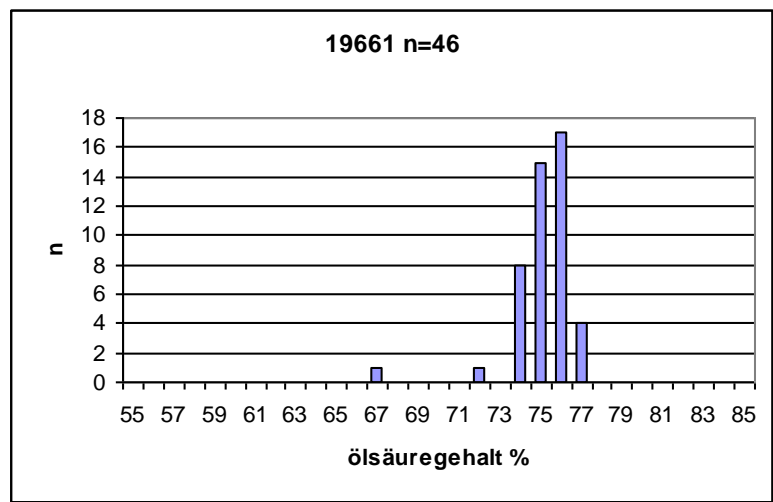

Abb. 3.9: Ölsäuregehalte bei 19661 ( $\mathrm{F}_{2}$-Population), bestimmt mittels GC-Analyse

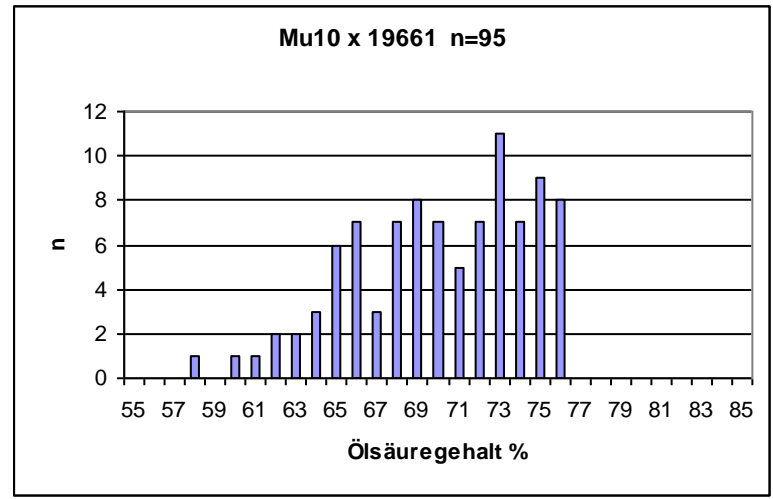

Abb. 3.10: Ölsäuregehalte bei Mu10 x 19661 (F2-Population) mittels GC-Analyse

Die Ölsäuregehalte der $\mathrm{F}_{2}$-Population dieser Kreuzung zeigen eine Aufspaltung. Die Werte der Kreuzung reichen von $58 \%$ bis $76 \%$. Der niedrigste Wert der Eltern beträgt $64 \%$, d.h. es gibt innerhalb der Kreuzung eine Gruppe von Genotypen, die eindeutig geringere Ölsäuregehalte aufweist als die Eltern. Dies ist ein Indiz für das Vorhandensein von zwei verschiedenen Mutationen, denn bei einer Rekombination müssten Genotypen mit einem 
„,normalen“ Ölsäuregehalt, also Werten zwischen $58 \%$ und $63 \%$, auftreten. Weiterhin fällt in der Abb.3.10 auf, dass es keine Genotypen mit Ölsäuregehalten, die über denen der Eltern liegen, gibt.

\section{Mu11 x 19661}

In den folgenden Diagrammen (Abb.3.11 - Abb.3.12) sind die Ölsäuregehalte der zwei Eltern Mu11 und 19661 dargestellt und in der Abbildung 3.13 die Ölsäuregehalte der $F_{2}$-Population der Kreuzung Mu11 x 19661.

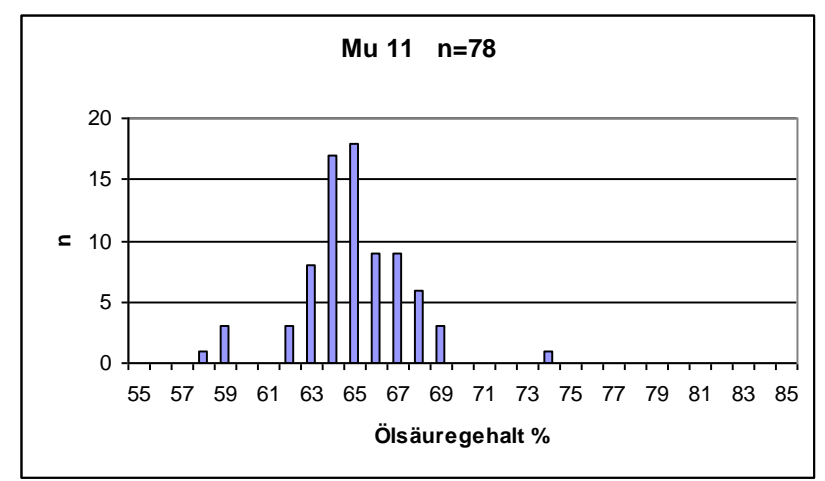

Abb. 3.11: Ölsäuregehalte bei Mu11 ( $\mathrm{F}_{2}$ geselbstet), bestimmt mittels GC-Analyse

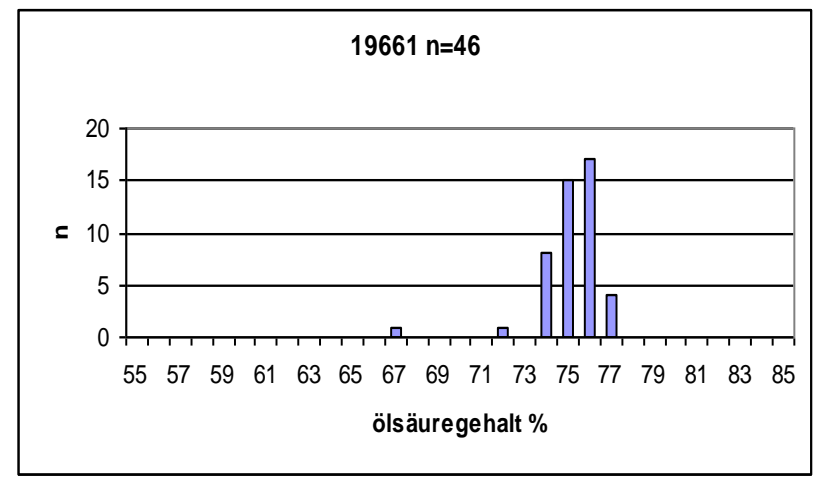

Abb. 3.12: Ölsäuregehalte bei 19661 ( $\mathrm{F}_{2}$ geselbstet), bestimmt mittels GC-Analyse

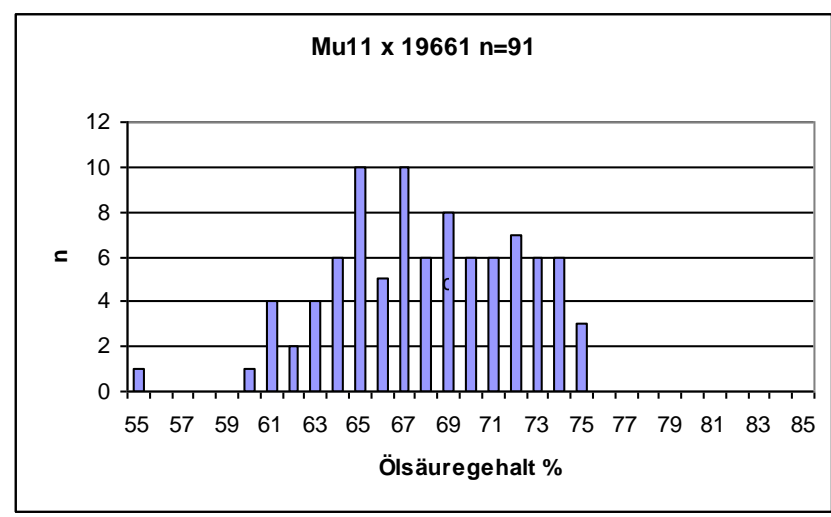

Abb. 3.13: Ölsäuregehalte bei Mu11 x 19661 ( $\mathrm{F}_{2}$-Population), bestimmt mittels GC-Analyse 
Die Ergebnisse der Ölsäuregehalte der Kreuzung Mu11 x 19661 (Abb.2.16) liegen weitgehend im Bereich der Werte der beiden Eltern (Abb.3.11 und Abb.3.12). Hier ist eine eindeutige Aussage, ob es sich bei der Mu11 um eine Mutation an einem anderen Genort handelt, nicht möglich. Die Ölsäuregehalte des Elternteils Mu11 liegen mit Werten von 59 \% bis $70 \%$ Ölsäure auch nur gering über den Vergleichswerten vom Wotan. Deshalb ist die Frage, ob es sich bei der Mu11 um einen neue Mutante handelt, nicht eindeutig zu beantworten.

\section{Mu12 x 19661}

In den folgenden Diagrammen (Abb. 3.14 - Abb.3.15) sind die Ölsäuregehalte der zwei Eltern Mu12 und 19661 dargestellt und in der Abbildung 3.16 die Ölsäuregehalte der $F_{2}$ Population der Kreuzung Mu12 x 19661.

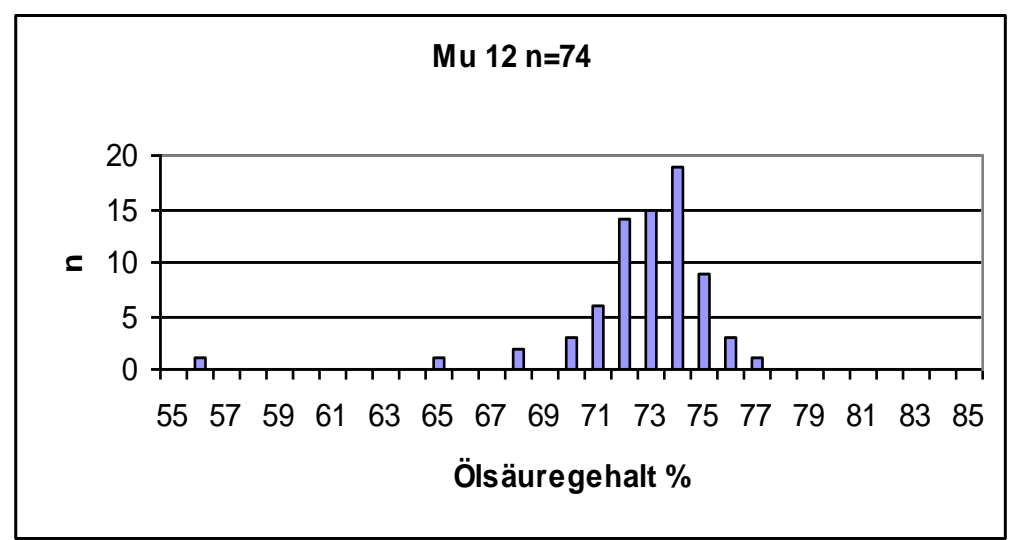

Abb. 3.14: Ölsäuregehalte bei Mu12 ( $\mathrm{F}_{2}$ geselbstet), bestimmt mittels GC-Analyse

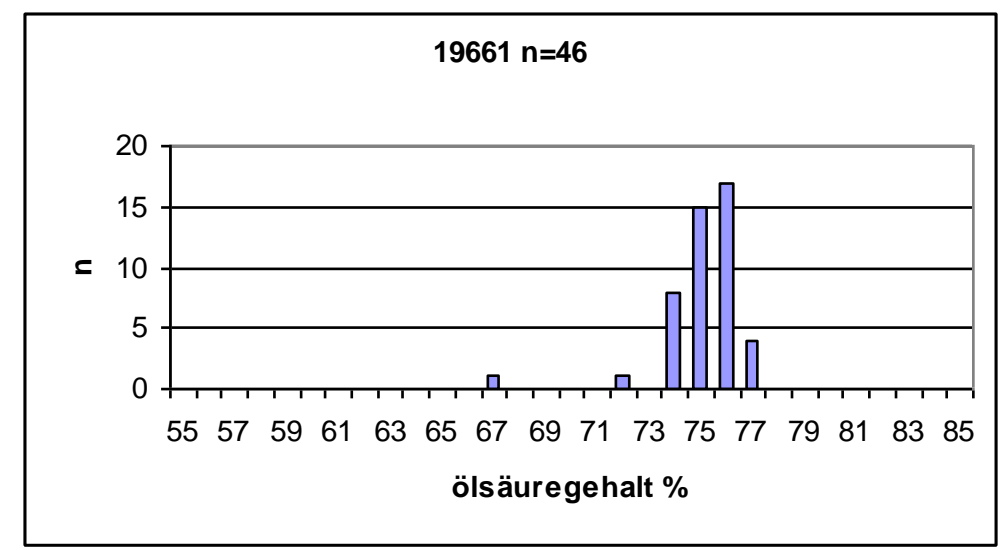

Abb. 3.15: Ölsäuregehalte bei 19661 ( $\mathrm{F}_{2}$ geselbstet), bestimmt mittels GC-Analyse 


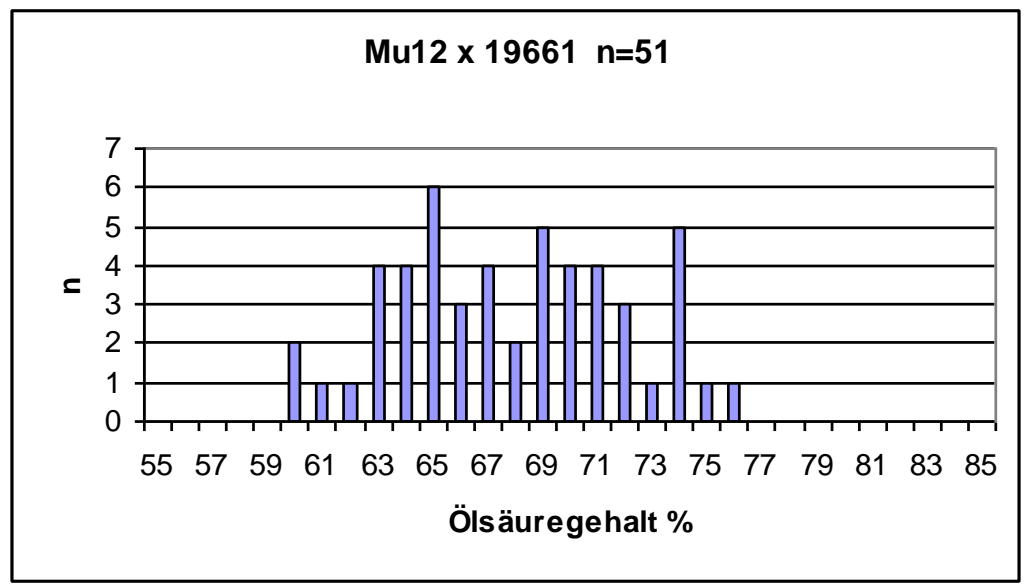

Abb.3.16: Ölsäuregehalte bei Mu12 x 19661 ( $\mathrm{F}_{2}$-Population), bestimmt mittels GC-Analyse

Bei der Kreuzung Mu12 x 19661 zeigt sich ein ähnliches Bild wie bei der Kreuzung Mu10 x 19661. Das heißt, die $F_{2}$-Population spaltet auf, da es auch viele Genotypen mit Ölsäuregehalten unterhalb der Eltern gibt, die im Bereich des Wotan (um $60 \%$ Ölsäure) liegen. Die Variation ist mit Werten zwischen $60 \%$ und $76 \%$ allerdings recht breit gestreut. Andererseits gibt es nur wenige Genotypen mit besonders hohen und an den Bereich der 19661 heranreichenden Ölsäuregehalten.

\section{Mu10 x DH009, Mu11 x DH009 und Mu12 x DH009}

In der folgenden Abbildung 3.17 sind in der oberen Reihe die Ölsäuregehalte der Kreuzungseltern Mu10, Mu11, Mu12 dargestellt. Die zweite Reihe zeigt die Ölsäuregehalte des 2. Elters DH009 und die untere Reihe die Ergebnisse der $\mathrm{F}_{2}$-Populationen der Kreuzung.

Die Kreuzungen der drei Genotypen Mu10, Mu11 und Mu12 mit der DH-Linie DH009 weisen ähnliche Ergebnisse auf. Die Ölsäuregehalte der Kreuzungsprodukte zeigen eine große Variation und befinden sich im Bereich der Werte der Eltern. Bei keiner der Kreuzungen gab es Genotypen in der $\mathrm{F}_{2}$, die niedrigere Werte als die Eltern zeigten. 

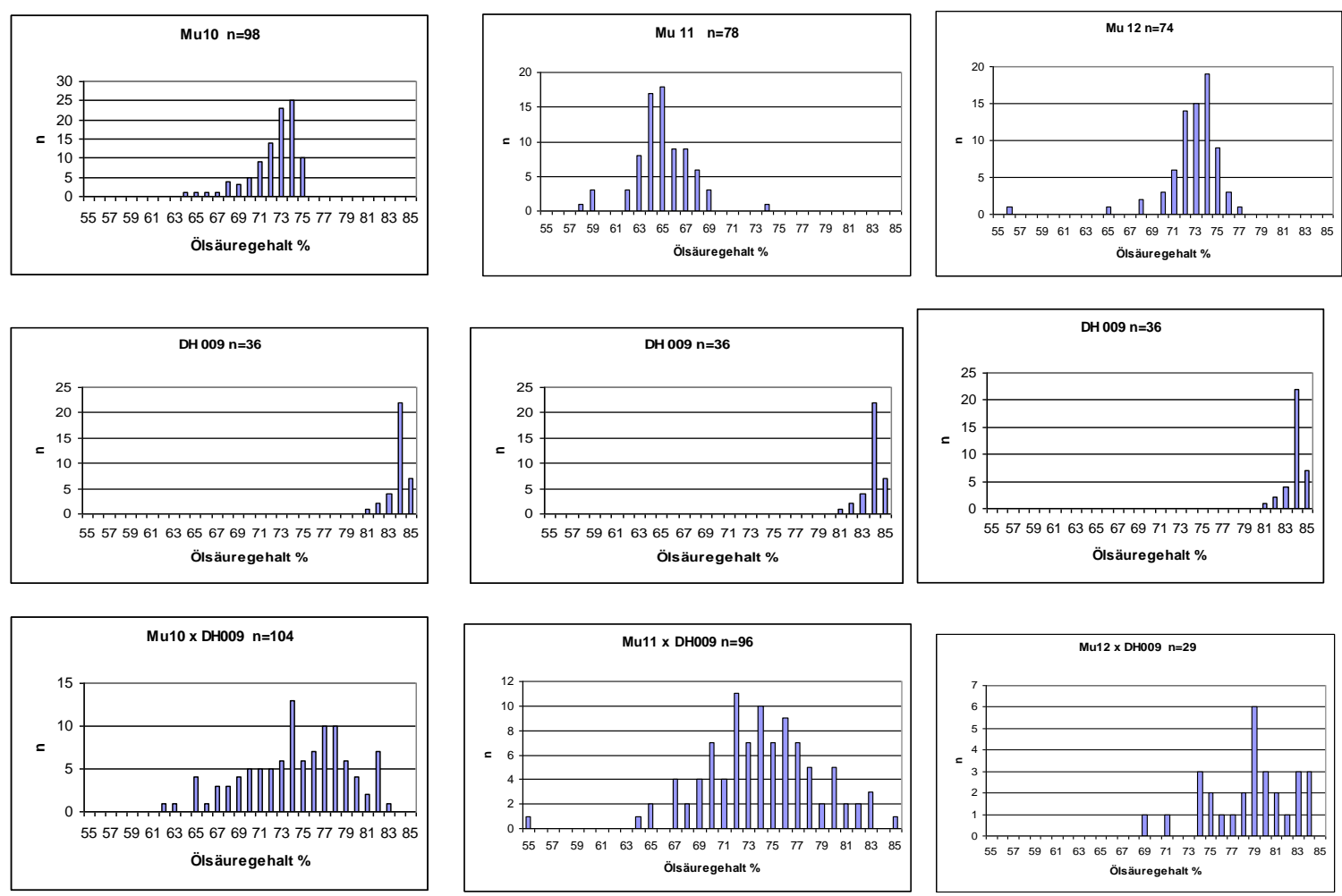

Abb. 3.17: Ölsäuregehalte der Eltern Mu10, Mu11, Mu12 und DH009 und Ölsäuregehalte der Kreuzungen Mu10xDH009, Mu11xDH009 und Mu12xDH009 ( $\mathrm{F}_{2}$-Population), bestimmt mittels GC-Analyse

Die DH-Linie DH009 wurde auf Hoch-Ölsäure-Gehalt selektiert. Die hohen Werte beruhen auf Veränderungen in mehreren Genen. Weiterhin wurde diese Linie auf einen niedrigen Linolensäure-Wert hin selektiert, und auch diese Eigenschaft basiert auf der Veränderung von mindestens zwei Genen. Somit darf festgestellt werden, dass mehrere Genorte betroffen sind und eine klare Aufspaltung der einzelnen Eigenschaften nicht zu erwarten ist. Der Einfluss der geringeren Linolensäuregehalte der DH-Linie zeigt sich in den deutlich niedrigeren Mittelwerten der Kreuzungspopulation mit Werten von 4,8 \% - 7,6 \% Linolensäure (Tab.3.2) im Vergleich zu Linolensäuregehalten von $8,0 \%$ - 9,3 \% bei allen anderen Kreuzungspopulationen.

\section{Mu10 x Mu11}

In den Diagrammen (Abb.3.18 - Abb.3.19) sind die Ölsäuregehalte der beiden Eltern Mu10 und Mu11 dargestellt und in der Abbildung 3.20 die Ölsäuregehalte der $F_{2}$-Population der Kreuzung Mu10 x Mu11. 


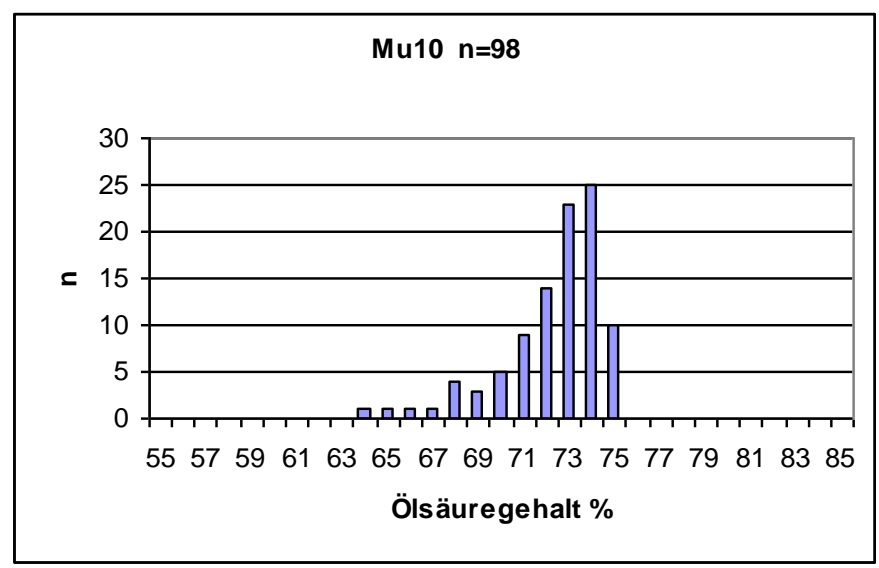

Abb. 3.18: Ölsäuregehalte bei Mu10 ( $\mathrm{F}_{2}$ geselbstet), bestimmt mittels GC-Analyse

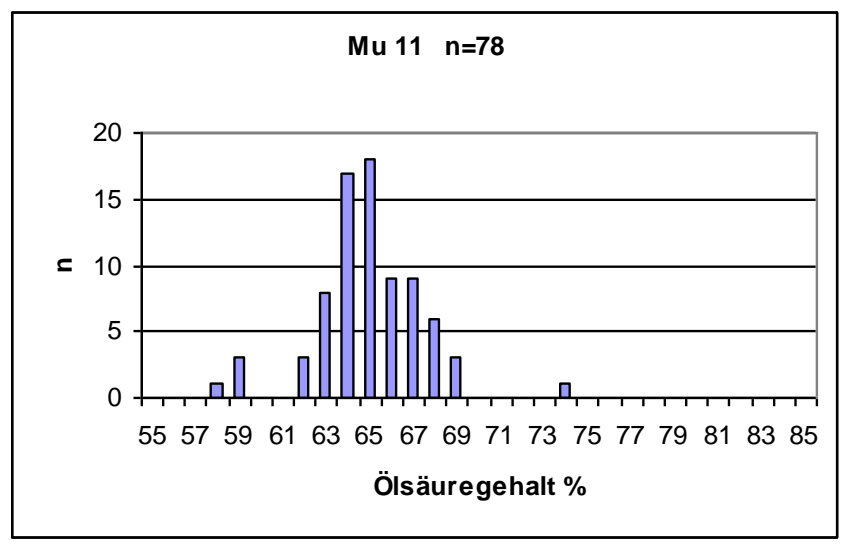

Abb. 3.19: Ölsäuregehalte bei Mu11 ( $\mathrm{F}_{2}$ geselbstet), bestimmt mittels GC-Analyse

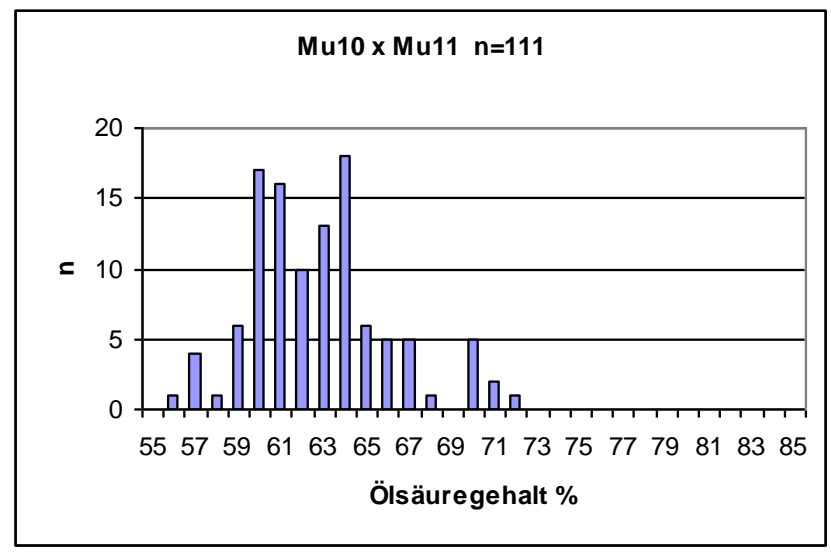

Abb. 3.20: Ölsäuregehalte bei Mu10 x Mu11 ( $\mathrm{F}_{2}$-Population), bestimmt mittels GC-Analyse

Die Ölsäuregehalte der $\mathrm{F}_{2}$-Generation der Kreuzung Mu10 x Mu11 bewegen sich zwischen $57 \%$ und $73 \%$ Ölsäure, wobei die Mehrzahl der Werte zwischen $59 \%$ und $67 \%$ liegt, d.h. sehr viele Genotypen liegen noch niedriger als die beiden Kreuzungseltern (Bereich Wotan). 


\section{Mu10 x Mu12}

In den Diagrammen (Abb.3.21 - Abb.3.22) sind die Ölsäuregehalte der beiden Eltern Mu10 und Mu12 dargestellt und in der Abbildung 3.23 die Ölsäuregehalte der $F_{2}$-Population der Kreuzung Mu10 x Mu12.

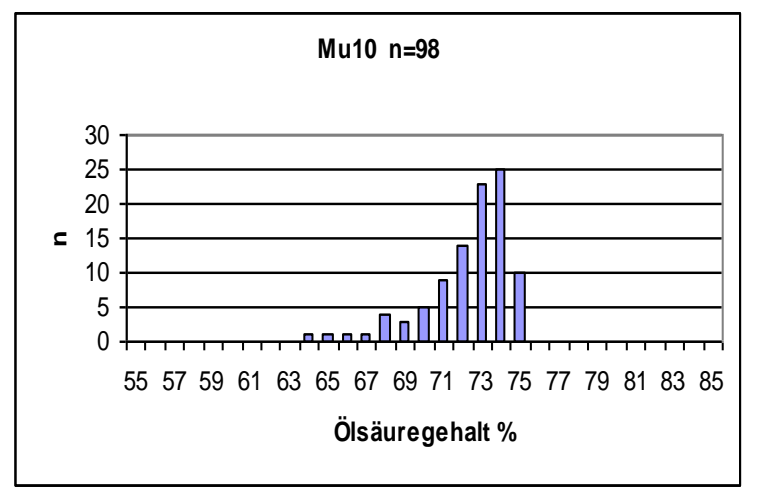

Abb.3.21: Ölsäuregehalte bei Mu10 ( $\mathrm{F}_{2}$ geselbstet), bestimmt mittels GC-Analyse

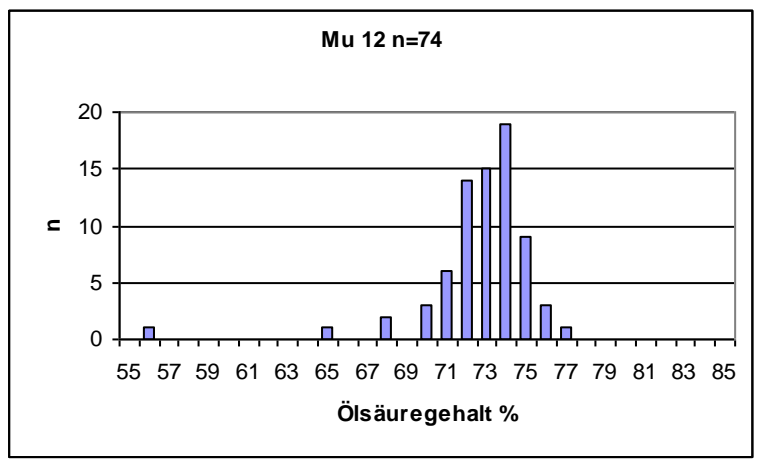

Abb.3.22: Ölsäuregehalte bei Mu12 ( $\mathrm{F}_{2}$ geselbstet), bestimmt mittels GC-Analyse

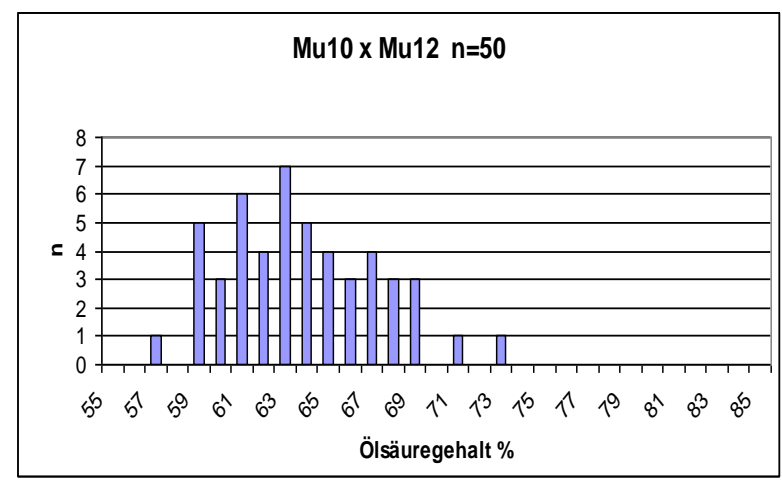

Abb. 3.23: Ölsäuregehalte bei Mu10 x Mu12 ( $\mathrm{F}_{2}$-Population), bestimmt mittels GC-Analyse 
Die Ölsäuregehalte der $\mathrm{F}_{2}$-Generation der Kreuzung Mu10 x Mu12 liegen ebenfalls wie bei der Kreuzung Mu10 x Mu 11 zwischen $57 \%$ und $73 \%$ Ölsäure, wobei auch hier die Mehrzahl der Werte zwischen $59 \%$ und $67 \%$ zu finden sind. Das bedeutet, fast alle Genotypen der $\mathrm{F}_{2}$-Population liegen im Bereich des Wotan oder nur leicht darüber.

\section{Mu10 x Mu13}

In den Diagrammen (Abb.3.24 - Abb.3.25) sind die Ölsäuregehalte der zwei Eltern Mu10 und Mu13 dargestellt und in der Abb.3.26 die Ölsäuregehalte der $F_{2}$-Population der Kreuzung Mu10 x Mu13.

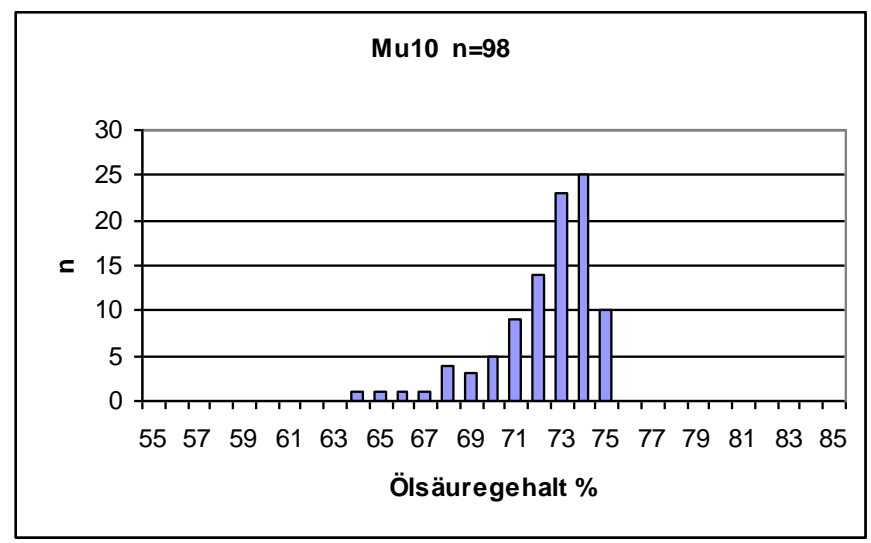

Abb. 3.24: Ölsäuregehalte bei Mu10 ( $\mathrm{F}_{2}$ geselbstet), bestimmt mittels GC-Analyse

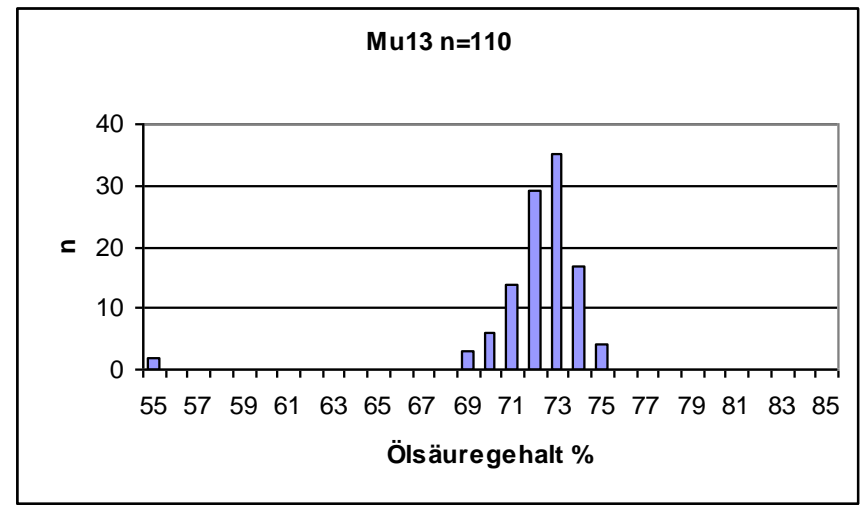

Abb. 3.25: Ölsäuregehalte bei Mu13 ( $\mathrm{F}_{2}$ geselbstet), bestimmt mittels GC-Analyse 


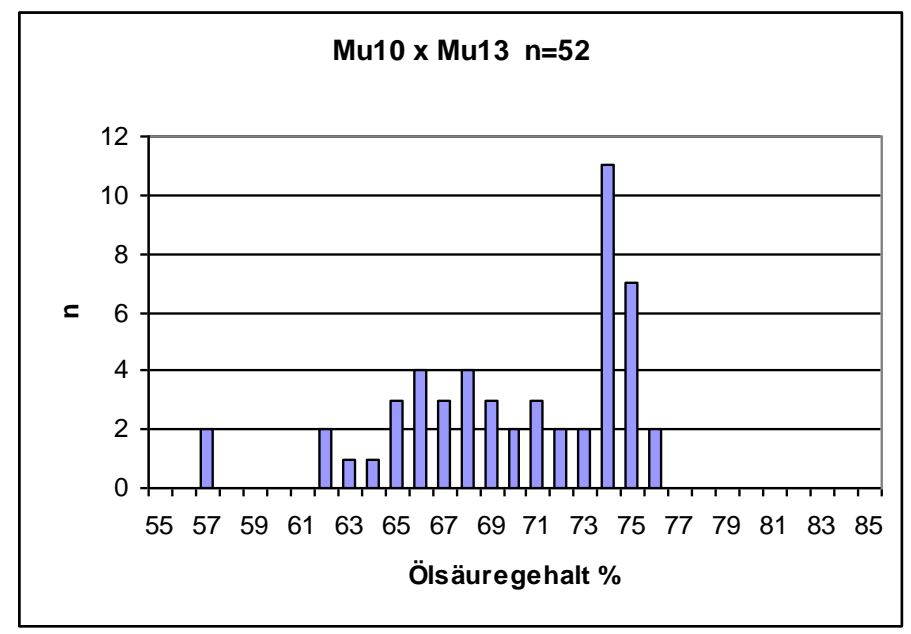

Abb. 3.26: Ölsäuregehalte bei Mu10 x Mu13 ( $\mathrm{F}_{2}$-Population), bestimmt mittels GC-Analyse

Die Ölsäuregehalte der $\mathrm{F}_{2}$-Population der Kreuzung Mu10 x Mu13 zeigen mit Werten zwischen 57 und 76 Prozent eine breitere Variation als die Ausgangspopulationen. Die niedrigsten Ölsäuregehalte der Eltern liegen bei $64 \%$. Die Aufspaltung der Werte lässt vermuten, dass zwei Mutationen an unterschiedlichen Loci vorliegen.

\section{Mu 11 x Mu12}

In den Diagrammen (Abb.3.27 - Abb.3.28) sind die Ölsäuregehalte der zwei Eltern Mu11 und Mu12 dargestellt und in der Abb.3.29 die Ölsäuregehalte der $F_{2}$-Population der Kreuzung Mu11 x Mu12.

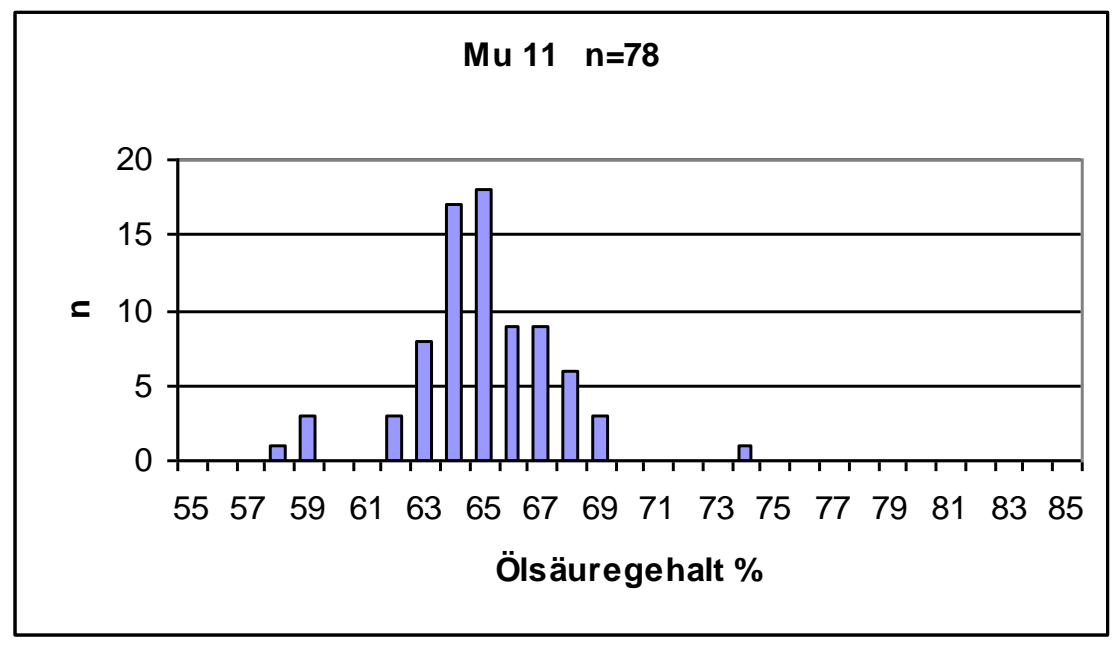

Abb. 3.27: Ölsäuregehalte bei Mu11 ( $\mathrm{F}_{2}$ geselbstet), bestimmt mittels GC-Analyse 


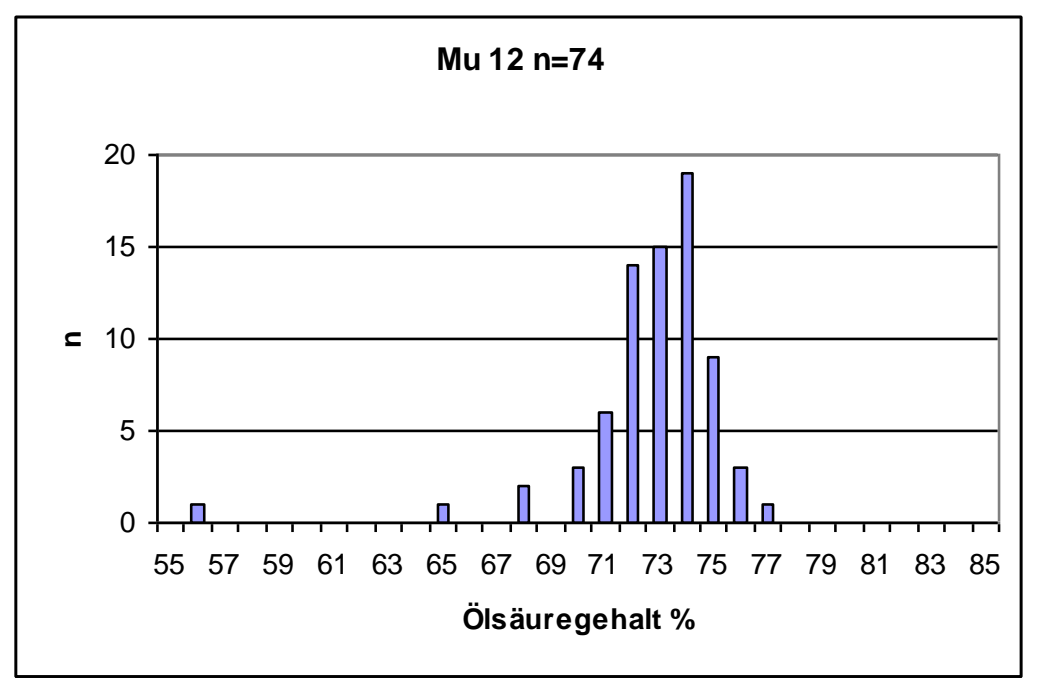

Abb.3.28: Ölsäuregehalte bei Mu11 ( $\mathrm{F}_{2}$ geselbstet), bestimmt mittels GC-Analyse

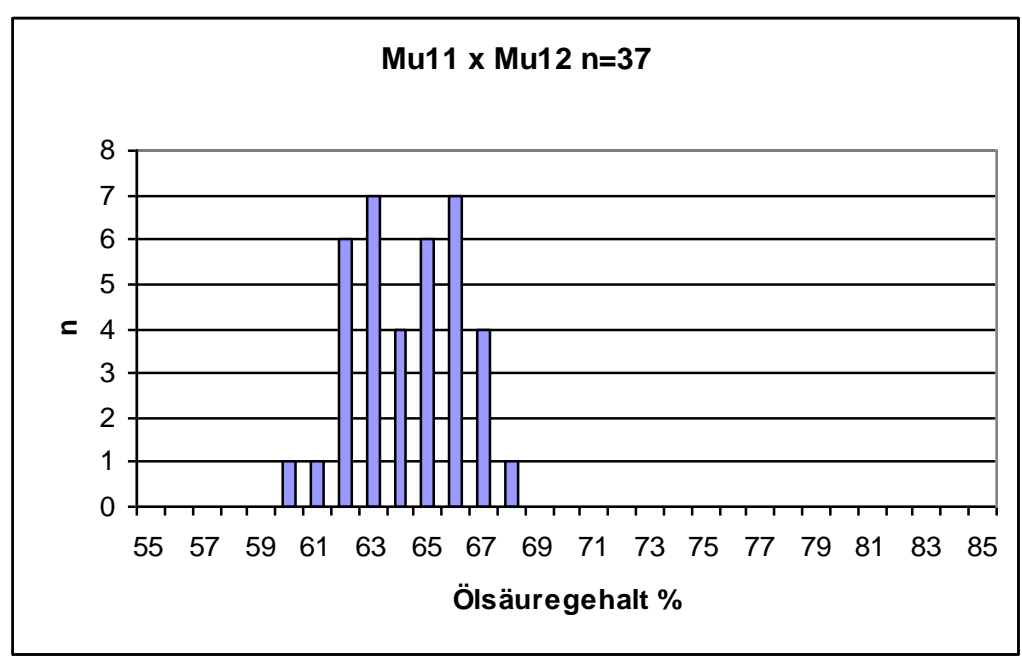

Abb. 3.29: Ölsäuregehalte bei Mu11 x Mu12 ( $\mathrm{F}_{2}$-Population), bestimmt mittels GC-Analyse

Der Ölsäuregehalt in der $\mathrm{F}_{2}$-Population der Kreuzung Mu11 x Mu12 zeigt Ergebnisse, die ausschließlich im Bereich des einen der beiden Eltern (Mu11) angesiedelt sind. Diese Resultate legen die Vermutung nahe, dass die $\mathrm{F}_{2}$-Population nicht auf eine Kreuzung der Eltern Mu 11 und Mu12 zurückgeht, sondern nur eine Folge der Selbstung von Mu11 sein kann. 


\section{Mu11 x Mu13}

In den Diagrammen (Abb.3.30 - Abb.3.31) sind die Ölsäuregehalte der zwei Eltern Mu11 und Mu13 dargestellt und in der Abbildung 3.32 die Ölsäuregehalte der $F_{2}$-Population der Kreuzung Mu11 x Mu13.

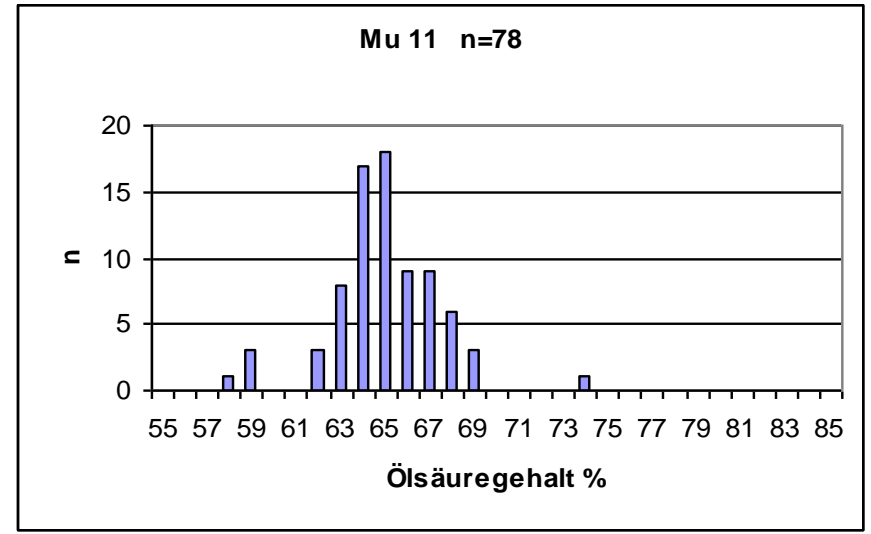

Abb.3.30: Ölsäuregehalte bei Mu11 ( $\mathrm{F}_{2}$ geselbstet), bestimmt mittels GC-Analyse

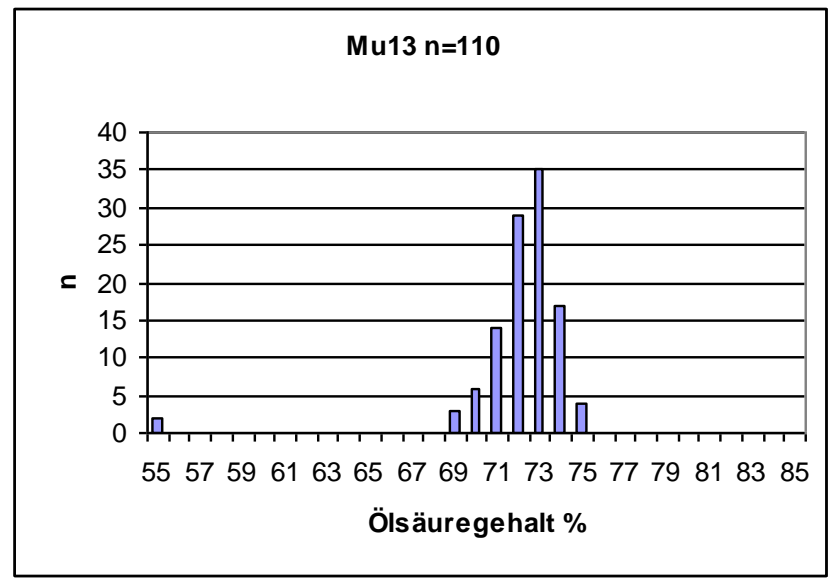

Abb.3.31: Ölsäuregehalte bei Mu13 ( $\mathrm{F}_{2}$ geselbstet), bestimmt mittels GC-Analyse

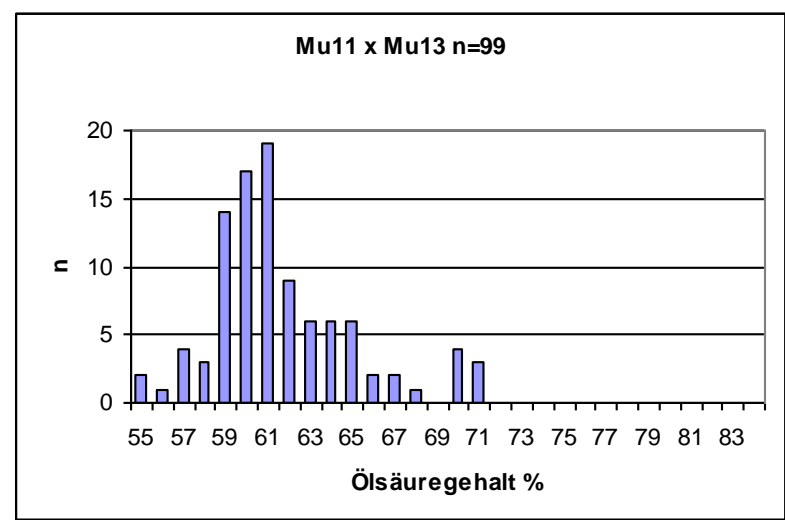

Abb. 3.32 Ölsäuregehalte bei Mu11 x Mu13 ( $\mathrm{F}_{2}$ Population), bestimmt mittels GC-Analyse 
Die Resultate der Kreuzung Mu11 mal Mu13 weisen Ölsäuregehalte von $55 \%$ bis $71 \%$ aus. Es gibt zahlreiche Kreuzungsnachkommen deren Werte zwischen $55 \%$ und $65 \%$, d.h. unterhalb der Werte der Kreuzungseltern liegen. Eine eindeutige Aussage, ob es sich um Mutationen an verschiedenen Loci handelt, ist anhand der vorliegenden Ergebnisse nicht möglich.

\section{Mu 12 x Mu 13}

In den Diagrammen (Abb.3.33 - Abb.3.34) sind die Ölsäuregehalte der zwei Eltern Mu12 und Mu13 dargestellt und in der Abbildung 3.35 die Ölsäuregehalte der $F_{2}$-Population der Kreuzung Mu12 x Mu13.

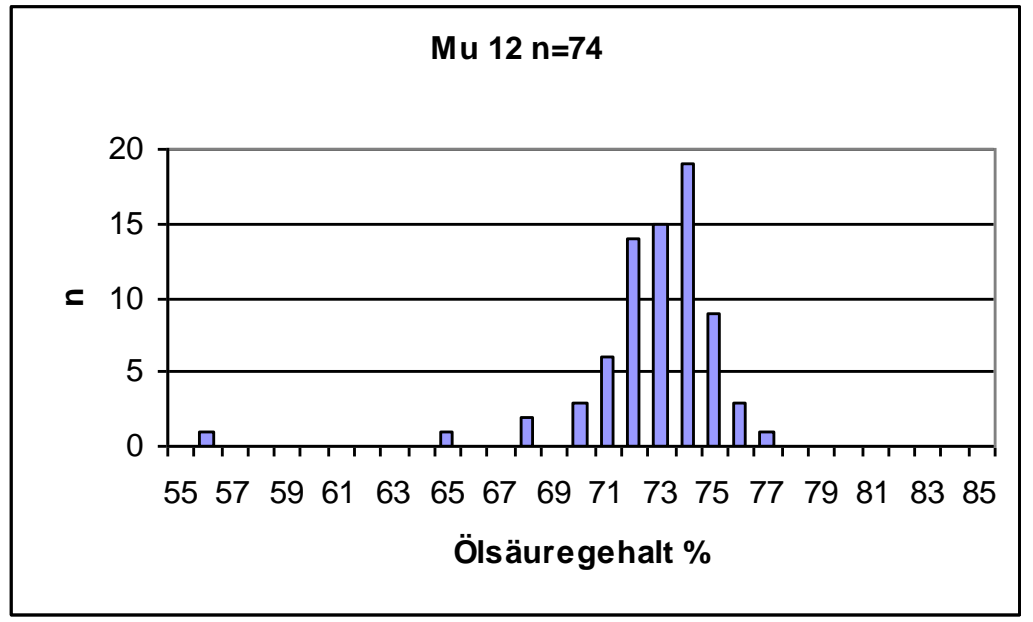

Abb. 3.33: Ölsäuregehalte bei Mu12 ( $\mathrm{F}_{2}$ geselbstet), bestimmt mittels GC-Analyse

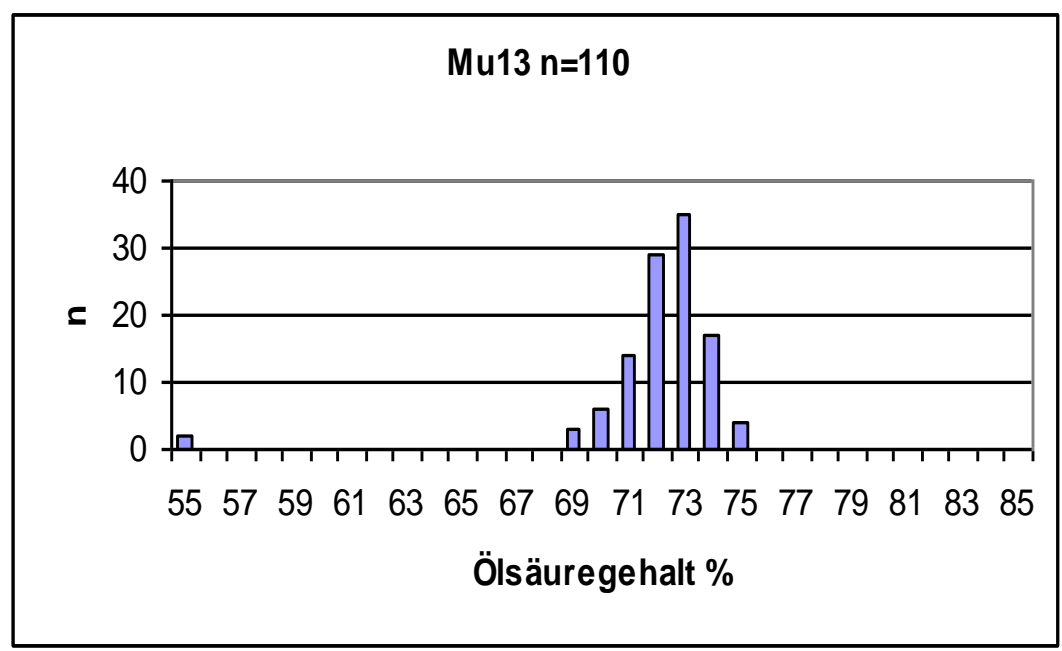

Abb.3.34: Ölsäuregehalte bei Mu13 ( $\mathrm{F}_{2}$ geselbstet), bestimmt mittels GC-Analyse 


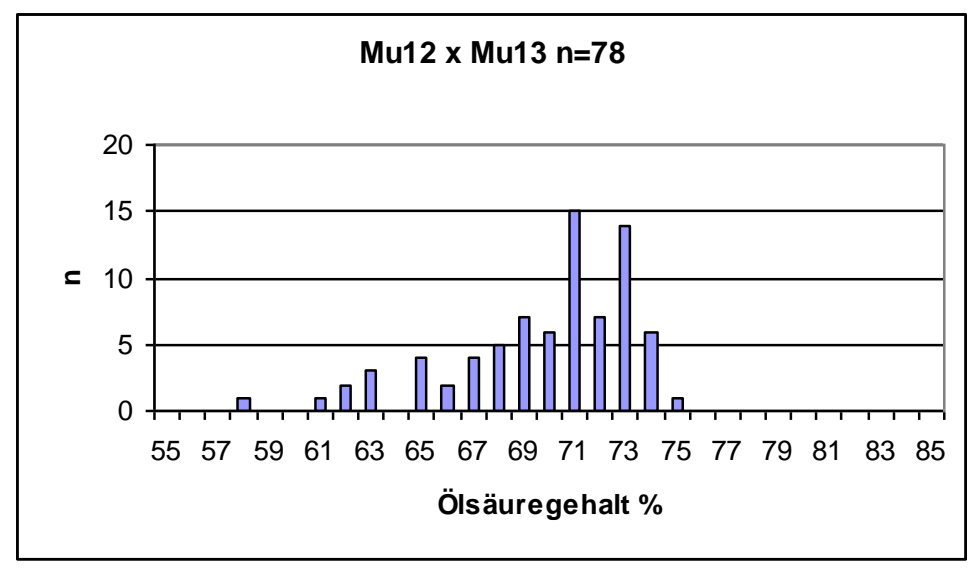

Abb.3.35: Ölsäuregehalte bei Mu12 x Mu13 ( $\mathrm{F}_{2}$-Population), bestimmt mittels GC-Analyse

Die $\mathrm{F}_{2}$-Population der Kreuzung Mu12 x Mu13 lässt eine breite Variation der Ölsäuregehalte erkennen. Die $\mathrm{F}_{2}$-Population weist Werte zwischen $58 \%$ und $75 \%$ Ölsäuregehalt auf. Es gibt viele Werte, die denen der beiden Eltern entsprechen, aber es gibt auch Genotypen, deren Werte deutlich niedriger sind. Diese Verteilung deutet auf Mutationen an verschiedenen Loci hin.

\subsection{Diskussion}

Der besseren Übersichtlichkeit wegen sind die Ölsäuregehalte der $F_{2}$-Samen und der $F_{3}$ Samen von drei Kreuzungen in der folgenden Tabelle (Tab.3.3) noch einmal zusammenfassend dargestellt.

Tab.3.3: Ölsäuregehalte von $\mathrm{F}_{2}-$ und $\mathrm{F}_{3}$-Samen der Kreuzungen Mu10, Mu11, Mu12 x 19661

\begin{tabular}{|c|c|c|c|}
\hline $\begin{array}{c}\text { Ölsäuregehalte } \\
\text { \% }\end{array}$ & $\begin{array}{c}\text { Kreuzung 10 } \\
\mathbf{x ~ 1 9 6 6 1}\end{array}$ & $\begin{array}{c}\text { Kreuzung 11 } \\
\mathbf{x ~ 1 9 6 6 1}\end{array}$ & $\begin{array}{c}\text { Kreuzung 12 } \\
\mathbf{x 1 9 6 6 1}\end{array}$ \\
\hline $\mathrm{F}_{2}$-Samen & $67-81$ & $63-82$ & $67-80$ \\
\hline $\mathrm{F}_{3}$-Samen & $58-76$ & $60-75$ & $60-76$ \\
& & & \\
\hline
\end{tabular}

Aus der Gegenüberstellung geht eindeutig hervor, dass alle Ölsäuregehalte der $\mathrm{F}_{2}$-Samen dieser Kreuzungen mit $63 \%$ bis $82 \%$ über den Werten von Wotan, die mit $60 \%$ bestimmt wurden, liegen. Erst in der nächsten Generation sind Genotypen zu finden, die dem Wotan entsprechende Werte aufweisen. Darüber hinaus ist augenfällig, dass die Ölsäuregehalte der 
$\mathrm{F}_{2}$-Samen bei allen drei Kreuzungen über denen der $\mathrm{F}_{3}$-Samen liegen. Die Erklärung für diesen Befund könnte ein Jahreseffekt sein. Dafür spricht, dass auch in der Leistungsprüfung zur Ernte 2006 höhere Werte ermittelt wurden als zur Ernte 2007.

Weiterhin ist zu beobachten, dass es keine Kreuzungsprodukte gibt, mit Ölsäuregehalten, die höher sind als die der Eltern. Eine mögliche Erklärung dafür ist, dass die Mutationen in der Regel nicht additiv wirken und somit eine stärkere Erhöhung des Ölsäuregehaltes als die der Eltern nicht erreicht wird. Es wäre auch möglich, dass Pflanzen, die für die betreffende Mutation doppelt homozygot sind, nicht lebensfähig sind. Das wäre insbesondere der Fall, wenn die Mutation eine völlige Ausschaltung des entsprechenden Enzyms bewirken würde.

In der Tabelle 3.2 fällt ins Auge, dass die mittleren Ölsäuregehalte der dargestellten Kreuzungen stets unter den Mittelwerten der dazugehörenden Eltern rangieren. Ein solches Ergebnis ist dann zu erwarten, wenn es bei der Kreuzung von zwei unterschiedlichen Mutanten zur Rekombination der Gene kommt und dabei Genotypen mit „,normalen“ Ölsäuregehalten (im Bereich von Wotan) und Genotypen mit erhöhten Ölsäuregehalten (im Bereich der Eltern) entstehen. In diesen Fällen liegen die Mittelwerte der Kreuzungsnachkommen niedriger als die der Eltern.

Die Auswertung der Nachkommen aller von uns vorgenommenen Kreuzungen brachte unterschiedliche Ergebnisse. Bei den Kreuzungen

$$
\begin{array}{ll}
\text { Mu11 x } 19661 & \text { Mu10 x Mu11 } \\
\text { Mu11 x Mu12 } & \text { Mu11 x Mu13 }
\end{array}
$$

sind anhand der Ölsäuregehalte der $\mathrm{F}_{2}$-Population keine eindeutigen Aussagen bezüglich der Aufspaltung und somit unterschiedlicher Mutationen zu treffen. Die Ölsäuregehalte der Nachkommen liegen alle im Bereich der Eltern. Hervorzuheben ist dabei, dass Mu11 als Elter auch nur einen gegenüber Wotan geringfügig erhöhten Ölsäuregehalt aufweist. Als Grund dafür könnte vermutet werden, dass die $\mathrm{M}_{2}$-Generation der Mu11 noch heterozygot war (was auch den nur leicht gegenüber Wotan erhöhten Ölsäuregehalt erklären könnte) und es durch weitere Selbstungen zu Aufspaltungen gekommen ist. In diesem Fall wären die Kreuzungen mit bereits aufgespalteten Pflanzen der Mu11- Population vorgenommen worden, die keine 
Erhöhung des Ölsäuregehaltes mehr aufwiesen und somit in der Nachkommenschaft auch nur normale Ölsäurewerte zeigen.

Die Ergebnisse der Kreuzung Mu10 x Mu12 (Abb.3.23) lassen sich nur unzureichend interpretieren. Es liegen sehr viele Werte im niedrigen Bereich. Denkbar wäre es, dass bei der Kreuzung eine Durchwuchspflanze mitgekreuzt wurde. Da die Kreuzungen im offenen Feld und nicht im geschlossenen Gewächshaus durchgeführt wurden, kann man eine mögliche „Verunreinigung“ nicht völlig ausschließen.

Eine deutliche Aufspaltung konnte bei den folgenden Kreuzungen beobachtet werden:

$$
\begin{array}{ll}
\text { Mu 10 x } 19661 & \text { Mu12 x } 19661 \\
\text { Mu 10 x Mu13 } & \text { Mu 12 x Mu13 }
\end{array}
$$

Die bei diesen Kreuzungen, die zwischen den neuen Mutanten und der alten Mutante 19661 sowie zwischen den neuen Mutanten untereinander durchgeführt wurden, entstandenen $\mathrm{F}_{3^{-}}$ Populationen, zeigen Ölsäuregehalte, die im Bereich der Eltern liegen, aber auch darunter und damit im Bereich von Wotan. Diese Ergebnisse lassen vermuten, dass die Mutationen an unterschiedlichen Genorten zu finden sind, da es erst zu Aufspaltungen in den späteren Generationen kommt.

$\mathrm{Ob}$ es sich tatsächlich um andere als die bereits bekannten Mutationen handelt, muss in einem weiteren Abschnitt der Arbeit und anhand genetischer Analysen geklärt werden. 


\section{Charakterisierung der Mutanten durch DNA-Analysen}

\subsection{Einleitung}

Die in den ersten beiden Abschnitten dieser Arbeit vorgestellten Untersuchungsergebnisse lassen vermuten, dass unsere Kreuzungsexperimente zu neuen Rapsmutanten mit einem erhöhten Ölsäuregehalt geführt haben. Diese Vermutung soll im nun folgenden Kapitel anhand genetischer Analysen verifiziert werden. Dazu sollen für zwei Gene die DNASequenzen von neu identifizierten Mutanten verglichen werden mit der publizierten Sequenz einer älteren Mutante.

Im Winterraps der 00-Qualität macht die Ölsäure (C18:1) mit ca. $60 \%$ die Hauptspeicherfettsäure aus. Sie liegt dabei deutlich über dem Anteil der Linolsäure (C18:2) mit ca. $20 \%$ und dem der Linolensäure (C18:3) mit ca. $10 \%$. Die Ölsäure wird in den Plastiden der Pflanzenzellen synthetisiert und anschließend in das Cytosol verlagert, wo sie teilweise zu Linol- und Linolensäure desaturiert wird. Der Anteil der Ölsäure an den Gesamtfettsäuren wird so über die Intensität der Desaturierung geregelt. Bei HORapspflanzen ist sie herabgesetzt. Da für die Aktivität der beteiligten Desaturasen die spontane genetische Variation sehr gering ist, wurde in der Vergangenheit immer wieder versucht, die Variabilität durch chemische Mutationsauslösung zu erhöhen (Rücker und Röbbelen 1995, Spasibionek 2006) bzw. durch Genmanipulation die Aktivität der Desaturasen gehemmt.

Die Desaturation der Ölsäure zu Linolsäure findet sowohl in den Plastiden als auch im endoplasmatischen Retikulum statt. Dementsprechend gibt es 2 Formen der Oleatdesaturase die 412 -Desaturase (FAD2), die im Cytosol am endoplasmatischem Reticulum gebunden vorliegt und die w6- Desaturase (FAD6), die in den Plastiden lokalisiert ist. Den quantitativ größeren Anteil (bis zu 90 \% der PUFA-Synthese, Okuley et al 1994) an der Desaturation der Ölsäure während der Samenreifung zu Linolsäure hat die FAD2. Sie ist somit das wichtigste Ziel-Enzym für eine Steigerung des Ölsäuregehaltes.

Für das Enzym FAD2 liegen im Genom des allotetraploiden Brassica napus vier Genkopien vor (Scheffler et al. 1997). Von diesen Genkopien isolierte und charakterisierte P. Spiekermann (2005) zwei funktionale Genkopien: FAD 2-I und FAD 2-II. Beide Genkopien sind zu $97 \%$ identisch und lassen sich dem A-Genom (B. rapa) und dem C-Genom (B. 
oleracea) zuordnen. Mit Hilfe dieser Sequenzinformationen charakterisierte P. Spiekermann die HO-Mutante 19661, die auch in der vorliegenden Arbeit zusammen mit den neuen Mutanten angebaut wurde. In der Mutante 19661 konnte in der Genkopie FAD2-I (AGenom) eine Punktmutation identifiziert werden, die zu einem Aminosäure-Austausch eines Glycin-Restes gegen einen Arginin-Rest führt. Diese Punktmutation ließ sich dem Locus HO1 zuordnen, der für den HO-Phänotyp der Mutante verantwortlich zeichnet.

Auf diesen Erkenntnissen bauten die in diesem Abschnitt der Arbeit vorgelegten Untersuchungen auf. Es ging darum, die Sequenzen der FAD2-I (A-Genom) und der FAD2II (C-Genom) der gefundenen Mutanten mit hohem Ölsäuregehalt zu ermitteln und sie mit den bekannten Sequenzen der Sorte Wotan und der Mutante 19661 zu vergleichen, um so zu einer besseren Charakterisierung der neuen Genotypen zu gelangen. 


\subsection{Literaturübersicht}

Lipide sind essentiell wichtige Verbindungen in höheren Pflanzen. Sie setzen sich aus verschiedenen Verbindungsgruppen mit jeweils charakteristischen Funktionen zusammen.

Die zwei größten Gruppen bilden:

(1) Die Speicherlipide, die vorwiegend als Triacylglycerin (TAG) z.B. in fettspeichernden Samen als Hauptspeicher für organisch gebundenen Kohlenstoff dienen. TAGs sind Ester von drei Fettsäuren mit Glycerin. In den pflanzlichen TAGs findet man als häufigste Fettsäuren die gesättigte Palmitin- und Stearinsäure, sowie die ungesättigte Öl-, Linolund Linolensäure. Diese Speicherlipide sind nicht nur als Energielieferanten wertvoll sondern auch als Träger für Mensch und Tier essentieller Fettsäuren. Die Fettspeicherung erfolgt in den höheren Pflanzen vorwiegend im Samen. Die Zellen sind dann von zahlreichen Fetttröpfchen = Oleosomen im Cytoplasma oder als Plastoglobuli in den Plastiden ausgefüllt. Die Speicherung der Lipide variiert stark zwischen den einzelnen Pflanzenarten. Bei den Ölpflanzen kann die Speicherung bis zu $80 \quad \%$ des Trockengewichtes des Samens betragen. (Voelker und Kinney, 2001), während in anderen Pflanzenarten Stärke und Proteine die Hauptspeicherformen sind.

(2) Die Strukturlipide. Sie sind essentiell für den Aufbau von Biomembranen. Im Unterschied $\mathrm{zu}$ den unpolaren Speicherlipiden sind die am Aufbau biologischer Membranen beteiligten Strukturlipide amphipolar, d.h. sie besitzen hydrophobe und hydrophile Bereiche. In der Regel sind zwei benachbarte Hydroxylgruppen des Glycerins mit Fettsäuren verestert und die 3. Hydroxylgruppe trägt eine polare Kopfgruppe. Ist diese Kopfgruppe über einen Phoshorsäurerest mit dem Glycerin verestert, spricht man von Phospholipiden, bildet sie ein Glykosid mit einem Zucker, so erhält man Glykolipide (Strasburger 2008).

Aufgrund dieser aphipolaren Eigenschaft können die Lipide im wässrigen Milieu flächige Strukturen bilden. Im Blattgewebe kann der Anteil der Lipide, die hauptsächlich in den Membranen lokalisiert sind, 5-10 \% der Trockenmasse betragen (Ohlrogge und Browse, 1995). Außer diesen beiden Hauptgruppen können Lipiden auch als Wachse schützende Oberflächenschichten bilden oder als Signalmoleküle und Botenstoffe in Form von Vitaminen und Hormonen vorkommen. 


\section{Synthese von Fettsäuren (Lipide)}

Die Fettsäure-Biosynthese ist ein primärer metabolischer Prozess, der in jeder Pflanzenzelle in den Plastiden zu finden ist. In den grünen Pflanzenzellen demnach in den Chloroplasten, ansonsten in den Chromoplasten, Leucoplasten oder Proplastiden. Eine komplette Blockade der Fettsäuresynthese ist tödlich für die Zelle. Der Lipidstoffwechsel insgesamt ist ein komplexes Reaktionsgefüge, an dem Plastiden, Zytoplasma und endoplasmatisches Retikulum beteiligt sind.

Die wichtigsten Fettsäuren (über $90 \%$ ), die in den Plastiden gebildet werden, sind Fettsäuren mit 16 und 18 C-Atomen und 1-3 Doppelbindungen. Um diese C16- bzw. C18-Fettsäuren zu produzieren sind ca. 30 enzymatische Reaktionen notwendig (Ohlrogge und Browse, 1995).

Das wichtigste Enzym der de novo-Synthese von Fettsäuren in Pflanzen ist ein Multienzymkomplex, die Fettsäure-Synthetase. Dieser besteht aus einzelnen Enzymen und einem freien, löslichen Acylträgerprotein (ACP). Die Fettsäuresynthetase akzeptiert nur ACPgebundene Metabolite. Ein wichtiger regulierender Bestandteil dieses Komplexes ist die ACCase (Acetyl-CoA Caboxylase), die die 1. Reaktion im Fettsäuresyntheseweg katalysiert. Beim diesem Schritt entsteht Malonyl-CoA als zentraler C-Spender, durch Carboxylierung von Acetyl-CoA (Abb.4.1). Die Aktivität der ACCase ist lichtabhängig. Als Ergebnis entsteht eine C-C Verbindung. Weitere wichtige regulierende Enzyme sind die Ketoacyl-ACPSynthasen I-III (KAS), sie katalysieren die Kettenverlängerung bis zu einer C16 bzw. C18Kette. Die erste Kondensation von Acetyl-CoA und Malonyl-ACP zu einem C4-Produkt wird durch die KASIII katalysiert. Weitere Kondensationen von C6 bis C16 werden durch die KASII katalysiert. Der letzte Schritt vom C16- Palmitoyl-ACP zu C18-Stearoyl-ACP wird durch die KASII erreicht (Ohlrogge und Browse 1995). 


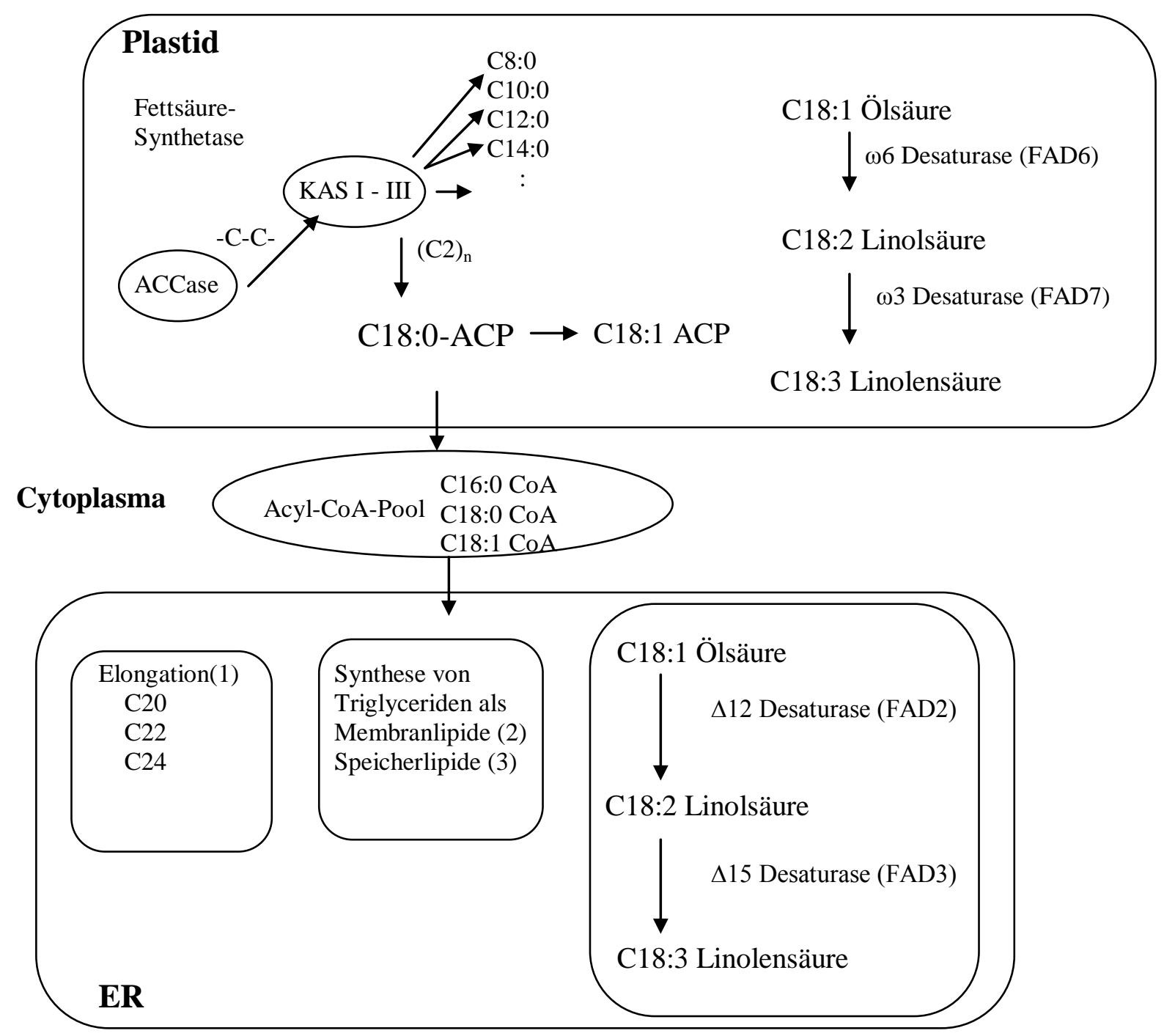

Abb.4.1 Vereinfachte Darstellung der Biosynthese von Fettsäuren in den Plastiden und im endoplasmatischen Retikulum (ER) (verändert nach Strasburger 2008 und Friedt 2006)

Dieser Fettsäure-Synthetase-Komplex produziert gesättigte Fettsäuren, aber in Blättern liegen über $75 \%$ der Fettsäuren in ungesättigter Form vor. Die 1. Doppelbindung wird noch im Stroma der Plastiden durch die lösliche Stearoyl-ACP-Desaturase eingeführt (Abb.4.1). Die bei der Fettsäuresynthese entstandenen Produkte dienen einerseits zum Aufbau der Membranlipide der Plastiden, oder sie werden in das Zytoplasma exportiert. Dabei wird vor dem Transport durch die Hüllmembran das ACP durch eine Acyl-ACP-Thioesterase abgespalten. Nach dem Austritt aus den Plastiden bildet die an der äußeren Hüllmembran lokalisierte Acyl-CoA-Synthetase unter ATP-Verbrauch Acyl-CoA (C16:0-CoA, C18:0-CoA, C18:1-CoA). Die nun vorliegenden Acyl-CoAs können auf unterschiedliche Weise weiter reagieren. 
(1) Ein Teil der Acyl-CoAs werden am ER durch membrangebundene Elongasen zu Fettsäuren mit 20 und mehr C-Atomen verlängert.

(2) Das Endoplasmatische Reticulum ist ebenfalls Syntheseort der Phospholipide als Membranlipide. Die Synthese der TAGs und der Phospholipide läuft über den Kennedy-Pathway. Die Membranlipide entstehen, indem im Plastidenstroma durch Reduktion von Dihydroxyacetonphosphat ein Glycerinbaustein gewonnen wird und als Glycerin-3-phosphat anfällt. Die Acylreste werden vom Acyl-CoA durch spezielle Acyl-Transferasen übertragen. Die am ER gebildeten Glycerolipide tragen an der sn2Position immer einen C18-Acylrest, während bei den plastidären Glycerolipiden an dieser Position stets ein C16-Acylrest zu finden ist (Strasburger 2008 ; Sommerville und Browse, 1991).

(3) Die Biosynthese der Triacylglyceride als Speicherlipide (TAGs) bei der Samenreifung verläuft ebenfalls am Endoplasmatischen Retikulum, ausgehend von verschiedenen CoAs und Glycerin-3-phoshat. Dabei werden zwei verschiedene Wege beschritten: Beim ersten Weg wird eine Phosphatidsäure dephosphoryliert zum Diacylglycerin, und anschließend wird auf die frei gewordene Hydroxylgruppe ein dritter Acylrest transferiert. Der zweite Weg führt über Phosphatidcholin zu Diacylglycerin und schließlich zum Triglycerid. Über diesen Weg entstehen bevorzugt Speicherlipide mit mehrfach ungesättigten Fettsäuren (Strasburger 2008).

\section{Genetische Kontrolle des Ölsäuregehaltes}

Desaturasen sind Enzyme, die Elektronen von einem Molekül auf ein anderes übertragen können. Das Zielsubstrat wird dabei „entsättigt“ und eine Mehrfachbindung eingebaut. Bei den Pflanzen unterscheidet man 2 Arten von Desaturasen:

(1) Acyl-ACP-Desaturasen sind als lösliche Enzyme im Plastiden-Stroma lokalisiert und führen ausschließlich die 1. Doppelbindung in gesättigte und mit ACP veresterte Fettsäuren ein.

(2) Zur zweiten Gruppe gehören die membrangebundenen Acyl-Lipid-Desaturasen, die mit der Plastidenmembran oder dem ER assoziiert sind und mit Glycerolipiden veresterte Fettsäuren als Substrate nutzen. 
Der Mechanismus und die Regulation der plastidären und der ER - Desaturasen wurde genau untersucht an Mutanten von Arabidopsis (Browse and Sommerville, 1991). Die Loci bekamen die Namen FAD (fatty acid desaturation). Die Mutationen an den 2 Loci FAD2 und FAD3 konnten der Desaturation am endoplasmatischen Reticulum zugeordnet werden, während die anderen Mutanten FAD4 - FAD8 der Lipid Desaturierung den Chloroplasten zugeordnet wurden (Ohlrogge und Browse 1995)

Die cytoplasmatische Desaturation am ER (FAD2) ist dominant gegenüber der plastidären Oleatdesaturase (FAD6) (Browse et al 1989). Das Substrat für die spezifische ER $\Delta 12$ Ölsäure Desaturase (FAD2) ist das Oleoylphosphatidcholin (mit cis-Doppelbindung in $\Delta 9$ Position) an dem eine weitere Doppelbindung in $\Delta 12$ Position eingefügt wird (Heinz 1993).

Der Gehalt an Ölsäure in den Pflanzenzellen ist abhängig von der Existenz der mikrosomalen Oleatdesaturasen (FAD2), die den größten Teil an 18:1-Substraten während der Samenreifung desaturiert. Spiekermann (2005) untersuchte das Genom des allotetraploiden Rapses, von dem bekannt war, dass vier Genkopien des Enzyms existierten (Scheffler et al 1997). Sie isolierte und charakterisierte die funktionalen FAD2-Kopien und konnte durch Sequenzvergleiche die gefundenen FAD2-I und FAD2-II Kopien dem A-Genom bzw. dem C-Genom des Rapses zuordnen und sie stammen somit offenbar von den Vorfahren B. rapa bzw. B. oleracea ab. Mit Hilfe dieser Sequenzinformationen charakterisierte Spiekermann ebenfalls die in Göttingen erzeugte Mutante 19661, die auch in der vorliegenden Arbeit mit einbezogen wurde. In der Genkopie FAD2-I der Mutante 19661 konnte eine Punktmutation identifiziert werden, die zu einem Aminosäure-Austausch führte. Hierbei wurde ein konservierter Glycin-Rest gegen ein Arginin ausgetauscht (Spiekermann 2005). Um die Wirksamkeit dieser Mutation zu überprüfen wurde eine heterologe Expression der mutierten Genkopie in Saccharomyces cerevisiae durchgeführt und die Desaturase zeigte einen um 90 $\%$ reduzierten Substratumsatz im Vergleich zum unveränderten Protein FAD2-I. Die gefundene Punktmutation konnte somit dem locus HO1 der Mutante 19661 zugeordnet werden. Die Bezeichnung HO1 stammt von A.Schierholt (2000). Sie fand durch Kreuzungsanalysen mit der Mutante 19661 heraus, dass in dieser Mutante ein Locus für das Merkmal ,hoher Ölsäuregehalt im Samen’ verantwortlich ist und bezeichnet diesen locus mit HO1. 


\section{Allel-spezifische Marker zur Selektion von Hochölsäure-Raps}

Bei der Bestimmung der Fettsäuremuster wurde mit den bisher beschriebenen Methoden (GC bzw. NIRS) nur der phänotypische Wert ermittelt. Umwelteffekte, wie Temperatur und Feuchtigkeit (Deng und Scarth 1998) oder Lichtverhältnisse während der Abreife (Pleines und Friedt 1989) können einen Einfluss auf das Fettsäuremuster von Rapssamen haben und somit die phänotypische Selektion erschweren. Von besonderem Interesse ist daher die Anwendung von molekularen Markern auf DNA-Basis zur Genotypisierung von Pflanzen und zur markergestützten Selektion bestimmter Eigenschaften. So können molekulare Marker die eng mit den Genen verbunden sind, die den Ölsäuregehalt kontrollieren, in Rapszüchtungsprogrammen genutzt werden, um Genotypen mit erhöhtem Ölsäuregehalt zu finden. Es wurden verschiedene Typen von molekularen Markern entwickelt um Genotypen mit hohem Ölsäuregehalt zu selektieren. So identifizierte Schierholt (2000) 3 AFLP (amplified fragment length polymorphism) Marker die mit dem HO1-locus der Mutante 19661 gekoppelt waren.

Tanhuanpäa et al. (1998) entwickelten einen allel-spezifischen PCR-Marker für den Ölsäuregehalt durch Vergleiche von Wild-Typ und Hoch-Ölsäure Allelen der FAD2 Gene in Sommerraps (B.rapa ssp. oleifera).

Auch eine Arbeitsgruppe um $\mathrm{Hu}(\mathrm{Hu}$ et al. 2006) sequenzierte Klone von FAD2-Genen einer EMS-induzierten Hoch-Ölsäure-Mutante und verglichen sie mit Wild-Typ Allelen der Sorte Quantum. Sie identifizierten ebenfalls einen einfachen Nucleotid-Austausch von $\mathrm{C}$ zu $\mathrm{T}$ in allen Mutanten. Diese Mutation auf der Nucleotid-Ebene führte zu einem Stop-Codon in der Aminosäuresequenz und somit zu einem verfrühten Ende des Polypeptids nach bereits 185 Aminosäuen anstatt 384 Aminosäuren. Dieses verkürzte Polypeptid kann nicht als aktive Desaturase von C18:1 zu C18:2 funktionieren und somit kommt es zur Akkumulation von C18:1. Auf Grund dieser Sequenzdifferenz entwickelte Hu einen SNP-Marker (single nucleotid polymorphism marker), mit dessen Hilfe eine direkte Selektion der mutierten FAD2-Allele durch eine markegestützte Selektion möglich ist. Der Vorteil dieser neuartigen SNP-Marker ist die direkte Kopplung mit der mutierten Stelle im Genom im Gegensatz zu den bisherigen gekoppelten Markern. Diese Marker sind informativer in der Untersuchung der Beziehung zwischen Genotyp und Phänotyp (Rafalski 2002). 
In den bisher beschriebene Arbeiten wurden ausschließlich Mutationen in der FAD2-I aus dem B.rapa-Genom (A-Genom) beschrieben. Bei einem Forschungsprojekt in Frankreich (Falentin et al. 2007) wurden ebenfalls in einem EMS-Mutagenese-Programm Hoch-ÖlsäureMutanten gefunden und charakterisiert. Sie konnten für eine Hochölsäure-Linie NucleotidMutationen in beiden Genen FAD2-I (B.rapa A-Genom) und FAD2-II (B.oleracea C-Genom) identifizieren. Beide Mutationen resultierten auch in einem Aminosäure-Austausch. Für zwei weitere Linien wurden einfache Nucleotid-Mutationen gefunden, die zu einem Stopp-Codon führten und somit zu einer früheren Beendigung der Polypeptidbildung. Auf der Grundlage dieser Sequenzdifferenzen zwischen den Mutanten und dem Wild-Typ wurden 2 SNP-Marker (single nucleotide polymorphism) entwickelt. Diese neuen molekularen Marker die die Punktmutation direkt selektieren sind sehr hilfreich bei der Selektion der mutierten FAD2 Allele.

\subsection{Material und Methoden}

\subsubsection{Planzenmaterial}

Saatgut der Mutanten Mu10, Mu11, Mu12, Mu13, Mu16 und Mu17, die über die Jahre erhöhte Ölsäuregehalte aufwiesen, wurde am 24.11.08 ausgelegt. Nach der Keimung wurde von den Keimlingen am 27. und 28.11.08 jeweils 1 Keimblatt abpräpariert und mittels GC nach Thies (1971) der Ölsäuregehalt untersucht. Der restliche Keimling wurde eingepflanzt und weiterkultiviert. Anhand der Ergebnisse der GC-Untersuchung der Keimblätter wurden von jeder Mutante 2 Proben mit den höchsten Ölsäuregehalten ausgewählt und von den entsprechenden weiterkultivierten Pflanzen Blattmaterial zur DNA-Analyse entnommen.

\subsubsection{DNA-Isolation}

Die DNA-Extraktion aus dem Blattmaterial erfolgte mittels des DNeasy ${ }^{\circledR}$ Plant mini Kit von QIAGEN. Die genaue Anleitung ist im DNeasy ${ }^{\circledR}$ Plant mini Kit Handbuch (2006) zu finden. 


\subsubsection{PCR}

Die Polymerasekettenreaktion (PCR) ermöglicht die gezielte Vermehrung oder Amplifikation von bestimmten DNA-Fragmenten mit Hilfe einer thermostabilen DNA-Polymerase. In dieser Arbeit wurde die DNA-Polymerase (FIREPol) verwendet. Als Primer wurden die bekannten Primer FAD2-I (A-Genom) und FAD2-II (C-Genom) verwendet (Spiekermann 2005).

FAD2-I A-Genom: Sequenz 5' $\rightarrow$ 3'

ATGGGTGCAGGTGGAAGAATG (forward primer)

CAGTTTCTTCTTTGCTTCATAAC (reverse primer)

FAD2-II C-Genom: Sequenz 5' $\rightarrow$ 3'

ATGGGTGCAGGTGGAAGAATG (forward primer) TTCTTTCACCATCATCATATCC (reverse primer)

Eine PCR mit der Tag DNA-Polymerase wurde im entsprechenden Puffer wie folgt angesetzt:

$\underline{\text { PCR-Ansatz }}$

50nM DNA

auf $25 \mu \mathrm{l}$ bidest HPLC $\mathrm{H}_{2} \mathrm{O}$

1x PCR-buffer (Solis Biodyne, Tallinn, Estland)

$1 \mathrm{mM} \quad \mathrm{MgCl}_{2} \quad$ (Solis Biodyne, Tallinn, Estland)

0,2 mM dNTPs (Bio-Budget Technologies GmbH, Krefeld)

$0,4 \mu \mathrm{M} \quad$ Primer F (Invitrogen)

$0,4 \mu \mathrm{M} \quad$ Primer $\mathrm{R} \quad$ (Invitrogen)

1,25 U Tag Polymerase (FIREPol DNA Polymerase/Solis Biodyne, Tallinn, Estland)

PCR-Temperaturprofil

\begin{tabular}{|c|c|c|c|}
\hline & $\begin{array}{c}\text { FAD2-I(A-Genom) } \\
{ }^{\circ} \mathrm{C}\end{array}$ & $\begin{array}{c}\text { FAD2-II(C-Genom) } \\
{ }^{\circ} \mathrm{C}\end{array}$ & Min \\
\hline 1. Denaturation & 94 & 94 & 3 \\
\hline 2. Denaturation & 94 & 94 & 0,5 \\
\hline 3. Annealing & 57 & 55 & 0,5 \\
\hline 4. Extension & 72 & 72 & 2 \\
\hline 5. Elongation & 72 & 72 & 5 \\
\hline
\end{tabular}

Die Schritte 2-4 wurden 30 mal wiederholt. 
Nach Beendigung des Amplifikationsvorgangs wurden die PCR-Produkte in einer Agarosegel-Elektrophorese überprüft. Die PCR-Produkte wurden mit einem AufreinigungsKit (My-Budget Double Pure Kit von Bio-Budget) aufgereinigt.

\subsubsection{DNA-Sequenzierung}

Die DNA wurde mit den entsprechenden Primern zu Sequenzierung zu MWG-Eurofins versandt.

\subsubsection{Sequenzanalyse}

Die erhaltenen Sequenzdaten wurden mit Hilfe folgender Programme ausgewertet und die entsprechenden Aminosäuresequenzen ermittelt.

DIALIGN-Submission (http://bibiserv.techfak.uni-bielefeld.de/dialign/submission.html)

ExPASy (http://www.expasy.ch/tools/dna.html) 


\subsection{Ergebnisse}

Ein wichtiges Ziel dieser Arbeit war die Charakterisierung der gefundenen Hoch-ÖlsäureMutanten. Eine Akkumulation der Ölsäure basiert auf einer Reduzierung der Aktivität der mikrosomalen Oleatdesaturase FAD2. Als Ursache für eine verringerte Aktivität kann eine Mutation in der DNA-Sequenz des entsprechenden Gens vermutete werden. Um dies zu überprüfen wurden die DNA-Sequenzen der gefundenen neuen Mutanten mit der bekannten von Spiekermann (2005) beschriebenen Sequenz der funktionalen FAD2-Genkopien aus Wotan verglichen. Spiekermann (2005) klonierte und charakterisierte zwei funktionale FAD2-Genkopien, FAD2-I konnte dem A-Genom (B.rapa) zugeordnet werden und FAD2-II dem C-Genom (B.oleracea). Sie entwickelte ebenfalls Genkopie-spezifische PCR- Primer.

Aus genomischer DNA der neuen Mutanten konnte mit Hilfe der für die Genkopien FAD2-I und FAD2-II spezifischen Primer, die offenen Leserahmen amplifiziert und sequenziert werden. Die so erhaltenen FAD2-I und FAD2-II Sequenzen wurden mit den von Spiekermann (2005) beschrieben Sequenzen aus Wotan verglichen. Bei diesem Vergleich konnten für 2 neue Mutanten, die Mu12 und Mu13, Punktmutationen in dem FAD2-I (A-Genom) identifiziert werden (Abb.4.2 und Abb.4.3).

Wotan FAD2-I .... TGC CAT TTC CAC CCC AAC GCT CCC ATC .... Mu12 FAD2-I .....TGC CAT TTC CAC CTC AAC GCT CCC ATC ....

Abb. 4.2: Ausschnitte aus der Nukleotid-Sequenz der Genkopie FAD2-I aus B.napus var. Wotan (Spiekermann 2005) und der Mutante Mu12. Die durch den Sequenzvergleich identifizierte Punktmutation ist grau unterlegt.

Bei der Mutante 12 liegt an der Stelle 638 statt des Cytosin ein Thymin vor (Abb.4.2), dies führt zu einer Änderung des Tripletts CCC in CTC.

476

Wotan FAD2-I ....GAA GTG TTT GTC CCC AAG AAG AAG TCA...

Mu13 FAD2-I .....GAA GTG TTT GTC CTC AAG AAG AAG TCA...

Abb. 4.3: Ausschnitte aus der Nukleotid-Sequenz der Genkopie FAD2-I aus B.napus var. Wotan und der Mutante Mu13. Die durch den Sequenzvergleich identifizierten Punktmutation ist grau unterlegt 
Ebenso wie bei der Mutante 12 wurde ein Cytosin durch ein Thymin ausgetauscht und auch das Triplett CCC ist durch ein CTC ersetzt wurden.

Von jedem Genotyp wurden 2 Wiederholungen sequenziert und die Sequenzierung erfolgte vom 3' und vom 5' Ende der DNA. Bei jeder Mutante konnte in allen Wiederholungen und Sequenzier-Richtungen die gleiche Punktmutation festgestellt werden. Die komplette Sequenz ist im Anhang 1 zu finden.

Aufgrund dieser Punktmutation kommt es auf der Proteinebene bei beiden Mutanten zu einem Aminosäureaustausch (Abb.4.4).

\begin{tabular}{|c|c|c|c|c|c|}
\hline & 1 & & & & \\
\hline Wotan & MGAGGRMQVS & PPSKKSETDN & IKRVPCETPP & FTVGELKKAI & PPHCEKRSIP \\
\hline Mutante12 & MGAGGRMQVS & PPSKKSETDN & IKRVPCETPP & FTVGELKKAI & PPHCEKRSIP \\
\hline \multirow[t]{2}{*}{ Mutante13 } & MGAGGRMQVS & PPSKKSETDN & IKRVPCETPP & FTVGELKKAI & PPHCFKRS I \\
\hline & 51 & & & & \\
\hline Wotan & RSESYLIWDI & IIASCFYYVA & TTYFPLLPHP & LSYFAWPLYW & ACQGCVLTG \\
\hline Mutante12 & RSFSYLIWDI & IIASCFYYVA & TTYFPLLPHP & LSYFAWPLYW & ACQGCVLTG \\
\hline \multirow[t]{2}{*}{ Mutante13 } & RSFSYLIWDI & IIASCFYYVA & TTYFPLLPHP & LSYFAWPLYW & ACQGCVLTC \\
\hline & 101 & & & & \\
\hline Wotan & WVIAHECGHH & AFSDYQWLDD & TVGLIFHSFL & LVPYFSWKYS & HRRHHSNTC \\
\hline Mutante12 & WVIAHECGHH & AFSDYQWLDD & TVGLIFHSFL & LVPYFSWKYS & HRRHHSNTC \\
\hline \multirow[t]{2}{*}{ Mutante13 } & WVIAHECGHH & AFSDYQWLDD & TVGLIFHSEL & LVPYFSWKYS & HRRHHSNTC \\
\hline & 159 & & & & \\
\hline Wotan & LERDEVFVPK & KKSDIKWYGK & YLNNPLGRTV & MLTVQFTLGW & PLYLAFNVS \\
\hline Mutante12 & LERDEVFVPK & KKSDIKWYGK & YLNNPLGRTV & MLTVQFTLGW & PLYLAFNVS \\
\hline \multirow[t]{2}{*}{ Mutante13 } & LERDEVFVLK & KKSDIKWYGK & YLNNPLGRTV & MLTVQFTLGW & PLYLAFNVS \\
\hline & 201 & 21 & & & \\
\hline Wotan & RPYDGGFACH & FHPNAPIYND & RERLQIYISD & AGILAVCYGL & YRYAAVQGV \\
\hline Mutante12 & RPYDGGFACH & FHLNAP I YND & RERLQIYISD & AGILAVCYGL & YRYAAVQG \\
\hline \multirow[t]{2}{*}{ Mutante13 } & RPYDGGFACH & FHPNAPIYND & RERLQIYISD & AGILAVCYGL & YRYAAVQG \\
\hline & 251 & & & & \\
\hline Wotan & SMVCFYGVPL & LIVNGFLVLI & TYLQHTHPSL & PHYDSSEWDW & LRGALATVD \\
\hline Mutante12 & SMVCFYGVPL & LIVNGFLVLI & TYLQHTHPSL & PHYDSSEWDW & LRGALATVI \\
\hline \multirow[t]{2}{*}{ Mutante13 } & SMVCFYGVPL & LIVNGFLVLI & TYLQHTHPSL & PHYDSSEWDW & LRGALATVI \\
\hline & 301 & & & & \\
\hline Wotan & DYGILNKVFH & NITDTHVAHH & LFSTMPHYHA & MEATKAIKPI & LGEYYQFDC \\
\hline Mutante12 & DYGILNKVFH & NITDTHVAHH & LFSTMPHYHA & MEATKAIKPI & LGEYYQFDC \\
\hline \multirow[t]{2}{*}{ Mutante13 } & DYGILNKVFH & NITDTHVAHH & LFSTMPHYHA & MEATKAIKPI & LGEYYQFDC \\
\hline & 351 & & & 384 & \\
\hline Wotan & PVVKAMWREA & KECIYVEPDR & QGEKKGVFWY & NNKL & \\
\hline Mutante12 & PVVKAMWREA & KECIYVEPDR & QGEKKGVFWY & NNKL & \\
\hline Mutante13 & PVVKAMWREA & KECIYVEPDR & QGEKKGVFWY & NNKL & \\
\hline
\end{tabular}

Abb.4.4 Vergleich der Aminosäuresequenz der FAD2-I Gene von Wotan (Spiekermann 2005), Mutante12 und Mutante13. Der AS-Austausch von Mutante13 und Mutante 12 ist grau unterlegt 
Bei der Mutante 12 kommt es an der Position 213 des Genoms FAD2-I zu einem Austausch der Aminosäure Prolin (P) durch die Aminosäure Leucin (L). Ebenfalls ein Austausch Prolin durch Leucin ist bei Mutante 13 zu finden und zwar an der Position 159.

Ein Vergleich der FAD2-II (C-Genom) Sequenzen wurde auch durchgeführt, es konnten aber keine Mutationen festgestellt werden.

\subsection{Diskussion}

Die mikrosomale Oleatdesaturase FAD 2 hat den größten Anteil an der Produktion von mehrfach ungesättigten C18-Produkten bei der Synthese von Speicherlipiden. Scheffler et al. (1997) fanden heraus, dass im haploiden Genom vier bis sechs Genkopien des FAD2-Gens vorliegen. Durch RFLP-Mapping konnten für FAD2 vier Loci ermittelt und vier verschiedenen Kopplungsgruppen zugeordnet werden, von denen zwei dem A-Genom (B.rapa) und zwei dem C-Genom (B. oleracea) angehören. In weiteren Untersuchungen konnte Spiekermann (2005) aber nur jeweils eine funktionelle Genkopie von FAD2-I und FAD2-II isolieren und charakterisieren. Sie sind zu $97 \%$ identisch und konnten durch Sequenzvergleiche dem A-Genom bzw. dem C-Genom zugeordnet werden. Offensichtlich werden die beiden anderen mittels RFLP-analyse identifizierten Genkopien nicht exprimiert (Spiekermann 2005).

Mit den Sequenzinformationen der beiden isolierten funktionalen FAD2-Genkopien sequenzierte Spiekermann (2005) die FAD2-I (A-Genom) und FAD2-II (C-Genom) von B.napus var. Wotan und vom Genom der Mutante 19661. Beim Vergleich der Sequenzen konnte Sie eine Punktmutation bei der Mutante 19661 an der Position 598 feststellen (Anlage 1). Diese Punktmutation resultierte in einem Aminosäureaustausch von Glycin zum Arginin. Zur Kontrolle führte sie eine Expression des mutierten Gens in Hefe (Saccharomyces cerevisiae) durch und konnte eine Reduktion der Oleatdesaturaseaktivität um 90\% feststellen.

Mit Hilfe der bekannten FAD2-I und FAD2-II Sequenzen (Spiekermann 2005) wurden in der vorliegenden Arbeit Vergleiche mit den Sequenzen der neu gefundenen Mutanten vorgenommen. Ebenfalls wie bei der „alten“ Mutante 19661 konnten Punktmutationen im Genom der FAD2-I Genotypen identifiziert werden. Bei den Mutanten 12 und 13 wurde 
jeweils ein Cytosin durch Thymin ersetzt und zwar an Position 476 bei der Mu13 und an Position 638 bei Mu12 (Anlage 1). Hu et al. (2006) konnten in ihrer Mutante DMS100 (eine hoch-Ölsäure-Mutante aus einem EMS-Programm) ebenfalls den Austausch eines Cytosin durch ein Thymin in der FAD2-I Sequenz beobachten. Die zur Auslösung der Mutationen eingesetzte Substanz EMS (Ethylmethansulfonat) ruft zufällige Mutationen in der DNA hervor, indem es die Nukleotide verändert, zum Beispiel durch Alkylierung von Guanin. Bei der DNA-Replikation wird dann häufig statt einem dem Guanin gegenüberliegenden Cytosin ein Thymin eingebaut. Bei Versuchen an Arabidopsis thaliana wurde festgestellt, das über 99\% der Punktmutationen von G/C nach A/T stattfanden (Greene et al. 2003).

Die Sequenz der FAD2-II aus dem C-Genom des Rapses war bei allen Mutanten identisch mit der entsprechenden Sequenz aus Wotan. Bisher ist in der Literatur auch nur eine Mutation im C-Genom beschrieben worden (Falentin et al. 2007), alle anderen Mutationen betrafen die FAD2-I aus dem A-Genom. Es ist durchaus denkbar, dass die FAD2-II Genkopie in einer weniger mutationsanfälligen Region liegt. Baranczewski et al. (1997) beobachteten bei Vicia faba dass durch alkylierende Agenzien ausgelöste Mutationen nicht gleichmäßig im Genom verteilt waren. Sie stellten fest, dass $70 \%$ aller Mutationen in sechs Genombereichen, sogenannten ,hot spots' (Genomregionen mit erhöhter Mutationsanfälligkeit) auftraten. Dieser Befund konnte von Greene et al. (2003) nicht bestätigt werden. Bei ihren Untersuchungen zur Mutationsauslösung mit EMS an Arabidopsis thaliana konnten sie solche ,hot spots'nicht feststellen.

Darüber hinaus sollte auch in Betracht gezogen werden, dass möglicherweise aufgetretene Mutationen in dem FAD2-II Genom beim Screening der heterozygoten $\mathrm{M}_{2}$-Samenramsche unentdeckt geblieben sind, da das Fettsäuremuster im Samen nicht ausreichend auffällig verändert war.

Die Punktmutationen in beiden Mutanten Mu12 und Mu13 führte über eine Triplett-Änderung zu einem Austausch einer Aminosäure (Abb. 4.5). Im Gegensatz dazu führte bei den Arbeiten von $\mathrm{Hu}$ et al. (2006) der Austausch von C zu T zu einem Stopp-Codon und somit zum frühzeitigen Ende der Enzymbildung. 


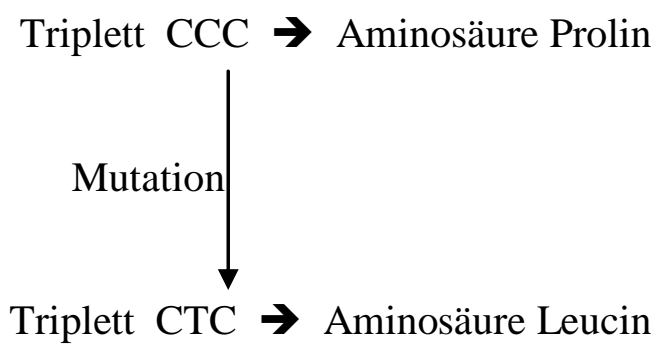

Abb 4.5: Punktmutation und der daraus resultierende Aminosäureaustausch

Das neue Triplett codiert eine andere Aminosäure. Die Funktion des Polypeptids der Mutante kann nach einem Aminosäureaustausch in der Effektivität zwischen $0<100 \%$ liegen (Vogel und Angermann 1990). In beiden Mutanten wird ein Prolin durch ein Leucin ersetzt. Beide Aminosäuren sind unpolar und neutral, aber im Gegensatz zum heterozyklischen Prolin ist das Leucin aliphatisch (Abb. 4.6).
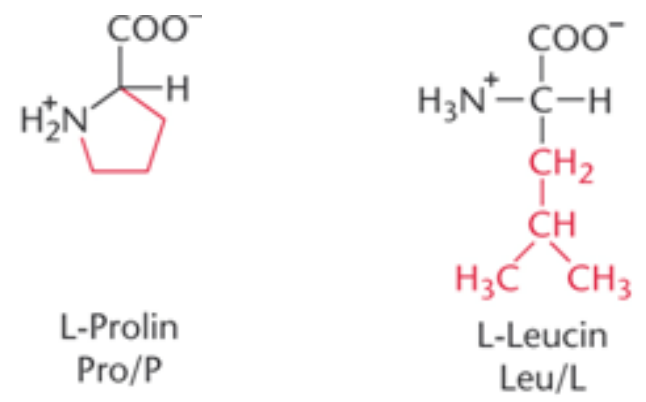

Abb. 4.6 Strukturformeln der Aminosäuren Prolin und Leucin (Strasburger 2008)

Auch Prolin besitzt eine aliphatische Seitenkette, unterscheidet sich jedoch von der anderen Aminosäure dadurch, dass seine Seitenkette sowohl mit dem $\alpha$-Kohlenstoffatom als auch mit dem Stickstoffatom verbunden ist (heterozyklisch). Prolin beeinflusst die Architektur eines Proteins in hohem Maße, da es durch seine Ringstruktur in seiner Konformation stärker eingeschränkt wird (Stryer et al. 2007).

Schwartz und Dayhoff (1978) teilten die Aminosäuren in 5 Gruppen auf. Die Aminosäuren innerhalb einer Gruppe verhalten sich funktionell konservativ. Liegt ein Aminosäureaustausch vor, bei dem eine Aminosäure der einem Gruppe durch einen Aminosäure einer anderen Gruppe ersetzt wird, handelt es sich um einem nicht konservativen Austausch, was bedeutet, 
dass die Aminosäuren funktionell unterschiedlich sind. Im vorliegenden Fall wurde das Prolin aus der Gruppe 1 ausgetauscht durch ein Leucin aus der Gruppe 4.

Aufgrund dieser beiden Betrachtungen ist es wahrscheinlich, dass der Austausch des Prolin durch ein Leucin in den Mutanten zu einer veränderten Struktur des Enzymes FAD2-I geführt hat und somit auch in einer Veränderung der Aktivität des Enzyms resultierte.

Um den Grad der Konservierung des ausgetauschten Glycin-Restes einschätzen zu können, ist in der folgenden Abbildung (Abb. 4.7) ein Vergleich von 10 bekannten FAD2 Proteinen mit unseren zwei Mutanten dargestellt.

211

LERDEVFVPK KKSDIKWYGK YLNNPLGRTV MLTVQFTLGW PLYLAFNVSG RPYDGGFACH FHPNAPIYND WOTAN

LERDEVFVPK KKSDIKWYGK YLNNPLGRTV MLTVQFTLGW PLYLAFNVSG RPYDGGFACH FHINAPIYND MUTANTE12

LERDEVFVIK KKSDIKWYGK YLNNPLGRTV MLTVQFTLGW PLYLAFNVSG RPYDGGFACH FHPNAPIYND MUTANTE13

LERDEVFVPK KKSDIKWYGK YLNNPLGRTV MLTVQFTLGW PLYLAFNVSR RPYDGGFACH FHPNAPIYND MUTANTE 19661

LERDEVFVPK KKSDIKWYGK YLNNPLGRTV MLTVQFTLGW PLYLAFNVSG RPYDGGFACH FHPNAPIYND Brassica napus

LERDGVFVPK KKSDIKWYGK YLNNPLGRTV MLTVQFTLGW PLCLAFNVSG RPYDGGFACH FHPNAPIYND Brassica junCea

LERDEVFVPK KKSDIKWYGK YLNNPLGRTV MLTVQFTLGW PLYLAFNVSG RPYPEGFACH FHPNAPIYND BrasSica Carinata

LERDEVFVPK QKSAIKWYGK YLNNPLGRIM MLTVQFVLGW PLYLAFNVSG RPYDG-FACH FFPNAPIYND Arabidopsis thali

LERDEVFVPK KKSDIKWYGK YLNNPLGRTV MLTVQFTLGW PLYLAFNVSG RPYDGGFACH FHPNAPIYND BrasSiCa rapa

LERDEVFVPK KKSDIKWYGK YLNNPLGRTV MLTVQFTLGW PLYLAFNVSG RPYDGGFACH FHPNAPIYND Brassica oleracea MERDEVFVPK PKSKLSCFAK YLNNPPGRVL SLVVTLTLGW PMYLAFNVSG RYYDRLASHY N PYGPIYSD GosSYPiUm hirSUt.

IEHDEVFVPK LKSGVRSTAR LLNNPPGRIL TLLVTLTMGW PLYLMFNVSG RYYDRFACH FDPNSPIYSN Helianthus annuus

Abb. 4.7 Ausschnitt eines Aminosäure-Sequenzvergleiches von FAD2-Proteinen. Die ausgetauschten Aminosäuren der Mutanten 12 und 13 sind eingerahmt. Die Sequenzen stammen aus der „Genbank“ des NCBI (National Center of Biotechnology Information) mit den Accessions-Nummern: Brassica napus BnFAD2, AAF78778; Brassica juncea BjFAD2, CAA62578; Brassica carinata BcFAD2, AAD19742; Arabidopsis thaliana AtFAD2,

AAA32782; Brassica rapa BrFAD2, CAD30827; Brassica oleracea BoFAD2,AAF14564; Gossypium hirsutum GhFAD2-1, CAA65744; Helianthus annuus HaFAD2-2, AAL68982; Die Sequenzen von Wotan und der Mutante 19661 stammen von Spiekermann (2005) und die Sequenzen der Mutanten 12 und 13 aus dieser Arbeit.

Der Konservierungsgrad der ausgetauschten Aminosäuren ist ein weiterer Hinweis auf die Auswirkung des Austausches der Aminosäure auf die Funktion des Enzyms. Um allerdings die genaue Funktionalität des Enzyms zu überprüfen, müssten noch weiterführende Arbeiten, wie z.B. eine heterologe Expression in Saccharomyces cerevisiae durchgeführt werden. 


\section{Zusammenfassung}

Neben den üblichen Zuchtzielen bei Raps, wie Ertrag, Ertragstabilität, Erhöhung der Widerstandsfähigkeit gegenüber Krankheiten und Schädlingen hat vor allem in den letzten Jahren ein weiteres Zuchtziel zunehmend an Bedeutung gewonnen. Hierbei handelt es sich um das Fettsäuremuster vom Rapsöl. Ziel ist es Sorten mit einem hohen Anteil an einfach ungesättigten Fettsäuren (Ölsäure) und geringerem Anteil an mehrfach ungesättigten Fettsäuren (Linol-, Linolensäure) zu erhalten. Rapsöle mit hohem Anteil an Ölsäure (Zuchtziel bis über $80 \%$ Ölsäure) sind für die Nahrungsmittelindustrie und die chemische Industrie von Interesse, da Öle mit hohem Gehalt an Ölsäure eine höhere Temperaturstabilität und geringere Oxidationsanfälligkeit aufweisen.

Um eine Veränderung des Fettsäuremusters zu erreichen wurde im Jahr 1991 in Göttingen ein Versuch gestartet, bei dem Raps der Sorte Wotan mit der Mutationen auslösenden Substanz EMS (Ethylmethansulfonat) behandelt wurde. Im Rahmen dieses Versuches konnten bereits Mutanten mit gesteigertem Ölsäuregehalt identifiziert werden. Allerdings wiesen die Mutanten schlechte agronomische Merkmale auf. Ziel der vorliegenden Arbeit war es daher, Mutanten mit erhöhtem Ölsäuregehalt und gleichzeitig besseren agronomischen Merkmalen zu finden. Dabei sollte auch untersucht werden, ob bei diesen Mutanten der gleiche Genort mutiert war, wie bei früheren Mutanten. Außerdem sollten die Mutanten molekular durch DNA-Sequenzierung charakterisiert werden.

Samen von mutagen behandelten Pflanzen ( $\mathrm{M}_{1}$-Generation) wurden als Ausgangsmaterial für die vorliegende Arbeit verwendet. Die $\mathbf{M}_{2}$-Generation wurde im Feld angebaut und die geernteten Samen auf ihren Ölsäuregehalt untersucht. Es konnten dabei einige vermutliche Mutanten mit erhöhtem Ölsäuregehalt identifiziert werden. Der in den Jahren 2002 bis 2007 an zwei verschiedenen Orten durchgeführte Anbau bestätigte für 6 Mutanten über mehrere Generationen hinweg höhere Ölsäuregehalte. In den Jahren 2006 und 2007 wurden Leistungsprüfungen im Feld durchgeführt, bei denen die neuen Mutanten, Wotan und die aus früheren Arbeiten bekannte ,alten Mutanten“ miteinander im Feld verglichen wurden. Als Ergebnis über 2 Jahre und 2 Orte konnte festgestellt werden, das die neuen Mutanten im Ertrag signifikant besser waren als die alten Mutanten aber nicht ganz das Niveau der Ausgangssorte Wotan erreichten. 
Von den älteren Mutanten ist bekannt, dass eine monogene Vererbung an einem Genort HO1 vorliegt. Ein weiteres Ziel dieser Arbeit war es, festzustellen ob die neu gefundenen Mutanten am gleichen Genort mutiert waren. Dazu wurden Kreuzungen der neuen Mutanten untereinander und mit der alten Mutante 19661 durchgeführt. Bei einer Mutation an unterschiedlichen Genorten müsste es in der spaltenden $\mathrm{F}_{2}$-Generation zu Aufspaltungen im Merkmal Ölsäuregehalt kommen. Als Ergebnis der Kreuzungsexperimente konnte bei 4 Kreuzungen eine eindeutige Aufspaltung in der $\mathrm{F}_{2}$-Generation festgestellt werden Diese Ergebnisse ließen vermuten, dass die untersuchten Mutanten mit erhöhtem Ölsäuregehalt an zwei verschiedenen Genorten lokalisiert sind. Diese Vermutung sollte mit genetischen Analysen untermauert werden. Ein weiteres Ziel der Kreuzungen war es, herauszufinden, ob in den Nachkommenschaften Genotypen mit höheren Ölsäuregehalten als die der Eltern zu erreichen sind. Solche Genotypen wurden bei den Kreuzungen nicht gefunden.

Das wichtigste Enzym für die Steigerung des Ölsäuregehaltes in der Fettsäure-Biosynthese ist die mikrosomale Oleatdesaturase FAD2. Für dieses Enzym liegen im Genom des allotetraploiden B. napus vier Genkopien vor. Die beiden Genkopien: FAD 2-I und FAD 2-II sind bereits in der Literatur beschrieben wurden. Diese Genkopien sind zu $97 \%$ identisch und lassen sich dem A-Genom (B. rapa) und dem C-Genom (B. oleracea) zuordnen. Mit Hilfe dieser Sequenzinformationen wurde bereits früher die HO-Mutante 19661 charakterisiert, die auch in der vorliegenden Arbeit zusammen mit den neuen Mutanten angebaut wurde. In der Mutante 19661 konnte in der Genkopie FAD2-I (A-Genom) eine Punktmutation identifiziert werden, die zu einem Aminosäure-Austausch eines Glycin-Restes gegen ein Arginin führt. Diese Punktmutation konnte dem Locus HO1 zugeordnet werden, der den HO-Phänotyp der Mutante verursacht. Ziel der vorliegenden Arbeit war es, die Sequenzen der FAD2-I (AGenom) und der FAD2-II (C-Genom) der gefundenen neuen Mutanten mit hohem Ölsäuregehalt zu ermitteln und mit der bekannten Sequenz von Wotan und der Mutante 19661 zu vergleichen, um die Mutation genauer beschreiben zu können. Dabei konnte bei zwei der neuen Mutanten ebenfalls eine Punktmutation im Genom der FAD2-I Genotypen festgestellt werden, die auch in einem Aminosäure-Austausch von Prolin durch Leucin resultierten.

Zusammenfassend kann also festgestellt werden, dass neue Mutanten mit erhöhtem Ölsäuregehalt identifiziert und charakterisiert werden konnten. Im Vergleich zu bisher 
bekannten HO-Mutanten haben die neuen Mutanten deutlich bessere agronomische Eigenschaften und sind daher ein wertvoller Ausgangspunkt für die Rapszüchtung. 


\section{Literatur}

Agrarmärkte 2007: Ölsaaten, www.lfl.bayern.de/iem/agrarmarktpolittik/28943 (Bayrische Landesanstalt für Landwirtschaft) (Seite besucht August 2009)

AID(Hrsg.)(1997): Speisefette. AID-Broschüre Nr. 1012, Bonn

Baranczewski P., Nehls P., Rieger R., Pich U., Rajewsky M.F., Schubert I. (1997): Formation and repair of O6-Methylguanine in recombination hot spots of plant chromosomes. Environmental and molecular mutagenesis 29: 394-399

Becker H. (1993): Pflanzenzüchtung. Ulmer Stuttgart

Biodiesel (2008): www.biodiesel.org/pdf_files/fuelfactssheets/BDSpec.pdf (Seite besucht August 2009)

bioSicherheit. Nachwachsende Rohstoffe. Mehr Rapsanbau durch Biodiesel. (2008): www.biosicherheit.de/de/raps/landwirtschaft/50.doku.html (Seite besucht August 2009)

Browse J., Kunst L., Anderson S., Hugly S., Somerville C.R. (1989): A mutant of Arabidopsis deficient in the chloroplast 16:1/18:1 desaturase. Plant Physiol. 90: 522-529

Browse J., Sommerville C. (1991): Glycerolipid synthesis: biochemistry and regulation. Annu Rev Plant Physiol Plant Mol Biol 42: 467-506

Colombani P., Keller U., Moser U., Müller M. (2008): Fette in der Ernährung; ein EEKBericht, S. 1 - 50

Colton B. and Potter T. (1999): History, Chapter 1, In: Canola in Australia: The first thirty years, P.A. Salisbury, T. Potter, G. McDonald, A. G. Green (eds), pp 1 - 4

Dehesh K. (2004): Nucleic acid sequences encoding beta-ketoacyl-ACP synthase and uses thereof. United States Patent Applikation 20040132189.

Deng X., Scarth R. (1998): Temperature effects on fatty acid composition during development of low linolenic oilseed rape (Brassica napus L.). J. Am Oil Chem. Soc. 75: 759-766

DNeasy® Plant Mini and DNeasy Plant Maxi Handbook (2006): For Isolation of DNA from plant tissue. Patented or patent-pending technology and/or registered or registration-pending trademarks of the QIAGEN Group, www.QIAGEN.com

Downey R.K., Craig B.M. and Youngs C.G. (1969): Breeding rapeseed for oil and meal quality J. Am. Oil Chem. Soc. 46: 121 - 123

Falentin C., Bregeon M., Lucas M.O., Deschamps M., Leprince F., Fournier M-T., Delourme R., Renard M. (2007) : Identification of fad2 mutations and development of Allel-Specific Markers for High Oleic acid content in rapeseed (Brassica napus L.). Proc. $12^{\text {th }}$ Intern Rapeseed Congress Wuhan, China, Vol. 2 
Fried W. and Lühs W.W. (1999): Breeding of rapeseed (Brassica napus) for modified seed quality - synergy of conventional and modern approaches. In: Proc. $10^{\text {th }}$ Rapeseed Cong., Canberra, Australia

Friedt W. (2006): Ressource Pflanze: Vom Genom zum Nachwachsenden Rohstoff. 49. Jahrestagung der Gesellschaft Für Pflanzenbauwissenschaften e.V., Rostock

Gerlach F. (2007): Rape cake, more than just a by-product. New Energy, pp 25 - 27

Green J. (2009) Evolution of glyphosate-resistant crop technology. Weed Science 57: 108 117

Greene E.A., Codomo C.A., Taylor N., Henikoff J.G., Till B.J., Reynolds S.H., Enns L.C., Burtner C., Johnson J.E., Odden A.R., Comai L. Henikoff S. (2003): Spectrum of Chemically Induced mutations From a Large-Scale Reverse-Genetic Screen in Arabidopsis. Genetics 164: $731-740$

Hahn A. und Ströhl A.(2004): Omega-3-Fettsäuren. In: Chemie in unserer Zeit. 38: 310 - 318

Harberberger GmbH (2009), www.pro-oleic.de/rapsoel.htm (Seite besucht August 2009)

Heinz E. (1993): Biosynthesis of polyunsaturated fatty acids. In: Lipid Metabolism in Plants. Ed. Moore T. CRC Press

Heyland K.-U., Hanus H. und Keller E.R.(2006): Ölfrüchte, Faserpflanzen, Arzneipflanzen und Sonderkulturen. Handbuch des Pflanzenbaus, Band 4, Eugen Ulmer KG, Stuttgart, S. 41 $-148$

Hu X., Sullivan-Gilbert M., Gupta M., Thompson St. (2006): Mapping of the loci controlling oleic and linolenic acid contents and development of fad 2 and fad 3 allele-specific markers in canola (Brassica napus L.). Theor. Appl. Genet. 113:497-507

Hugly S., Kunst L., Browse J. and Somerville C. (1989) Enhanced thermal tolerance of photosynthesis and altered chloroplast ultrastructure in a mutant of Arabidopsis deficient in lipid desaturation. Plant Physiol. 90: 1134 - 1142

Jentsch U. (2009): Züchtung und Züchtungsfortschritt bei Winterraps, Anforderungen an moderne Sorten. TLL 5: 20 - 43

Kempken F. und Kempken R. (2006): Gentechnik bei Pflanzen, S. 2, 3. Auflage

Kleber H.-P. und Schlee D.(1991): Biochemie, Teil 1. Allgemeine und funktionelle Biochemie, Jena: Fischer, S. 150

Kuhn E. (2008) www.biotechpflanzen.de/HTML/Raps/Biotechraps/html (Seite besucht August 2009)

Kunau W.H. (1976): Chemie und Biochemie ungesättigter Fettsäuren. Angewandte Chemie 88: 97 
Lauridsen C., Nielsen J. H., Henckel P. and Sörensen M.T. (1999): Antioxidative and oxidative status in muscles of pigsfed on rapeseed oil, vitamin E and copper. J. Anim. Sci. 77: $105-115$

Lehmann L., Hamann M., Stelling D. und Busch H. (2008): Vistive ${ }^{\mathrm{R}}$ Holli-Winterraps. Ein erfolgreiches Beispiel innovativer, vorausschauender Pflanzenzüchtung. Raps 4: 1 - 4

Mensink, R. P. (2005): Metabolic and health effect of isomeric fatty acids. Curr. Opin. Lipidol. 16 (1): $27-30$

Mietkiewska E., Giblin E.M., Wang S., Barton D.L., Dirpaul J., Brost J.M., Katavic V. and Taylor D.C. (2004): Seed-specific heterologous expression of a nasturtium FAE gene in Arabidopsis results in a dramatic increase in the proportion of erucic acid. Plant Physiol. 136: $2665-26775$

Müller M. (2008): Transfettsäuren. SZE 4/08: 1 - 50

Ohlrogge J., Browse J., (1995): Lipid biosynthesis. Plant Cell 7: 957-970

Okuley J., Lightner J., Feldmann K., Yadav N., Lark E., Browse J. (1994): Arabidopsis fad2 gene encodes the enzyme that is essential for polyunsaturated lipid synthesis. Plant cell 6: $147-158$

Pleines S., Friedt W. (1989): Genetic control of linolenic acid concentration in seed oil of rapeseed (Brassica napus L.). Theor. Appl. Genetics 78: 793-797

Rafalski A. (2002): Applications of single nucleotide polymorphisms in crop genetics. Curr. Op. Plant. Boil. 5: 94-100

Rakow G. (1973): Selektion auf Linol- und Linolensäuregehalt in Rapssamen nach mutagener Behandlung. Z.Pflanzenzüchtung 69: 62-82

Rapsmagazin: 2009/1, www.ufop.de/2088.php (Seite besucht August 2009)

Raymer P.L.(2002): Canola: An emerging oilseed crop. In: J. Janick and A. Wipkey (eds), Trends in new crops and new use, ASHS Press, Alexandria, VA, pp 122-126

Rücker B. and Röbbelen G. (1995): Development of high oleic acid winter rapeseed. In: Proc. $9^{\text {th }}$ Int. Rapeseed Cong., Cambridge, UK, pp. 389 - 391

Saedler H. (2004): Gentechnik in der Pflanzenzüchtung - was ist heute machbar? http://www.mpiz.koeln.mpg.de/ saedler/hsaedl01.htm (Seite besucht August 2009)

Scarth R. and Tang J. (2006): Modification of Brassica oil using conventional and transgenic approaches. Crop Sci. 46: 1225 - 1236

Scarth R., McVetty P.B.E., Rimmer S.A. and Stefansson B.R. (1988): Stellar low linolenic, high linoleic summer rape. Can. J. Plant Sci. 68: 509 - 511 
Scheffler J.A., Sharpe A.G., Sperling P., Parkin I.A.P., Lühs W., Lydiate D.J., Heinz E. (1997): Desaturase multigene families of Brassica napus arose through genome duplication. Theor. Appl. Genet. 94: 583-591

Schierholt A. (2000): Hoher Ölsäuregehalt im Samenöl: Genetische Charakterisierung von Mutanten im Winterraps (Brassica napus L.). Dissertation. Cuvillier Verlag Göttingen

Schierholt A. and Becker H.C. (1999): Genetic and environmental variability of high oleic acid content in winter oilseed rape. In: Proc. $10^{\text {th }}$ Int.Rapeseed Cong. Canberra, Australia

Schierholt A. and Becker H.C. (2001): Environmental variability and heritability of oleic acid content in winter oilseed rape. Plant. Breed.120: 63-66

Schierholt A., Ecke W., Becker H.C. (2000): Mapping a high oleic acid mutation in winter oilseed rape (Brassica napus L.). Theor. Appl. Genet. 101: 897-901

Schierholt A., Rücker B., Becker H.C. (2001): inheritance of high oleic mutations in winter oilseed rape (Brassica napus L.). Crop Sci 41: 1444-1449

Schröder-Pontoppidan M., Skarzhinskaya M., Dixelius C., Stymne S. and Glimelius K. (1999): Very long chain and hydroxylated fatty acids in offspring of somatic hybrids between Brassica napus and Lesquerella fendleri. Theor. Appl. Genet. 99: 108 - 114

Schwartz R.M., Dayhoff M.O.(1978): Atlas of Protein Sequence Structure. Vol.5, suppl.3 (ed. Dayhoff, M.O.) pp 353-358

Shahidi F. (1990): Rapeseed and Canola: Global production and distribution. In: F. Shahidi (ed.) Canola and rapeseed: Production, chemistry, nutrition and processing technology, Van Norstrand Reinhold, New York, pp 3 - 13

Sommer W. (2006): Rapskuchen - ein hochwertiges Futtermittel. www.landwirtschaftskammer.de/landwirtschaft/tierproduktion/schweinehaltung/fuetterung/ra pskuchenfutter.htm (Seite besucht August 2009)

Sommerville C., Browse J. (1991): Plant lipids: metabolism, mutants and membranes. Science 252: $80-87$

Spasibionek S. (2006): New mutants of winter repeseed (Brassica napus L.) with changed fatty acid composition. Plant Breeding 125: 259-267

Spiekermann P. (2005): Isolierung und Charakterisierung von Genkopien der mikrosomalen Oleatdesaturase FAD2 aus Brassica napus L. sowie Entwicklung transgener Rapspflanzen mit erhöhtem Ölsäuregehalt im Samen. Dissertation. Universität Hamburg

Spiekers H. und Südekum K.-H. (2004): Einsatz von 00-Raps-Extraktionsschrot bei Wiederkäuern, ufop, www.ufop.de/downloads/RZ_Praxisinfo_Raps_100604.pdf (Seite besucht August 2009)

Stefansson B.R., Hougen F.W. and Downey R.K. (1961): Note of the isolation of rape plants with seed oil free from erucic acid. Can. J. Plant Sci. 41: 218 - 219 
Strasburger (2008): Lehrbuch der Botanik. 36.Auflage, Spektrum Akademischer Verlag Heidelberg

Stringam G.R., Ripley V.L., Love H.K. and Mitchell A. (2003): Transgenic herbicide tolerant canola - the canadian experience. Crop Sci. 43: 1590 - 1593

Stryer L., Berg J.M., Tymoczko J.L. (2007): Stryer Biochemie. 6. Auflage. (C Elsevier Gmbh München. S.31

Tanhuanpäa P., Vilkki J., Vihinen M. (1998): Mapping and cloning of a fad2 gene to develop allele-specific PCR for oleic acid in sring turnip rape (Brassica rapa ssp.oleifera). molecular Breeding 4: 543-550

Thies W. (1971): Schnelle und einfache Analysen der Fettsäurezusammensetzung in einzelnen Rapskotyledonen I. Gaschromatografische und papierchromatographische Methoden. Z. Pflanzenzüchtung 65: 181-202

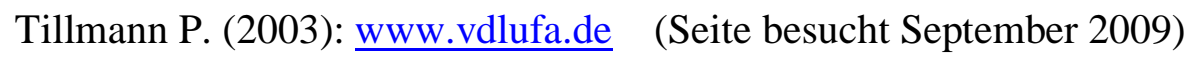

Töpfer R., Martini N. and Schell J. (1995): Modification of plant lipid synthesis. Science 268: $681-686$

Transgen (2009): www.transgen.de/anbau/eu_international/199.doku.html (Seite besucht August 2009)

Trautwein E.A., Erbersdobler H.F. (1998): Rapssorten mit verändertem Fettsäuremuster- eine ernährungswissenschaftliche Betrachtung. Ufop-Schriften „Rapsöl - ein wertvolles Speiseöl“, Heft 6: $27-36$

Treu R. and Emberlin J.(2000): Pollen dispersal in the crops Maize (Zea mays), Oil seed rape (Brassica napus), Potatoes (Solanum tuberosum), Sugar beet (Beta vulgaris) and Wheat (Triticum aestivum).Report for Soil Association, pp 1-54,

Utz H.F. (2001): Kurze Einführung in PLABSTAT-ANOVA. Version 2P, Institute of Plant Breeding, Seed Science and Population genetics, University of Hohenheim, Stuttgart, Germany,@ Copyright 2001 H.F.Utz

VDB, Pressemitteilung (2008): www.biokraftstoffverband.de/downloads/413/Soja.pdf (Seite besucht Sept 2009)

Velasco L., Möllers C., Becker H.C., (1999): Estimation of seed wight, oil content and fatty acid composition in intact single seeds of rapeseed (Brassica napus L.) by near infrared reflectance spectroscopy. Euphytica 106: 79-85

Vilkki J.P. and Tanhuanpää P.K. (1995): Breeding of high oleic acid spring turnib rape in Finland. In: Proc. $9^{\text {th }}$ Int.Rapeseed Cong., Cambridge, UK, pp. $386-388$

Vles R.O.(1974): Nutritional aspects of rapeseed oils. Proc. 4. Int. Rapeseed Conf., Giessen, Germany, $17-20$ 
Voelker T., Kinney A.J. (2001): Variation in the biosynthesis of seed-storage lipids. Annu.Rev.Plant Physiol. Plant Mol. Biol. 52: 335-361

Vogel G., Angermann H. (1990): dtv-Atlas zur Biologie, Band 3, 4. Auflage, Deutscher Taschenbuchverlag München, S. 475

Weiß J. und Schöne F. (2008): Rapsextraktionsschrot in der Schweinefütterung. Ufop, www.ufop.de/downloads/Prxisinfo_RES_131108.pdf (Seite besucht August 2009) 


\section{Anhang}

Anhang1: Vergleich der Nucleotid-Sequenzen der FAD2-I(A-Genome)vom Wotan und den neuen Mutanten Mu12 und Mu13 und der bereits bekannten Mutante 19661 (Spiekermann 2005). Gelb unterlegt sind die Stellen der Punktmutation

\begin{tabular}{|c|c|c|c|c|c|}
\hline & 1 & & & & 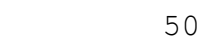 \\
\hline Wotan & ATGGGTGCAG & GTGGAAGAAT & GCAAGTGTCT & ССТСССТССА & AAAAGTCTGA \\
\hline Mutante12 & ATGGGTGCAG & GTGGAAGAAT & GCAAGTGTCT & ССТСССТССА & AAAAGTCTGA \\
\hline Mutante13 & ATGGGTGCAG & GTGGAAGAAT & GCAAGTGTCT & ССТСССТССА & AAAAGTCTGA \\
\hline \multirow[t]{2}{*}{19661} & ATGGGTGCAG & GTGGAAGAAT & GCAAGTGTCT & ССТСССТССА & AAAAGTCTGA \\
\hline & 51 & & & & \\
\hline Wotan & AACCGACAAC & ATCAAGCGCG & TACCCTGCGA & GACACCGCCC & TTCACTGTCG \\
\hline Mutante12 & AACCGACAAC & ATCAAGCGCG & TACCCTGCGA & GACACCGCCC & TTCACTGTCG \\
\hline Mutante13 & AACCGACAAC & ATCAAGCGCG & TACCCTGCGA & GACACCGCCC & TTCACTGTCG \\
\hline \multirow[t]{2}{*}{19661} & AACCGACAAC & ATCAAGCGCG & TACCCTGCGA & GACACCGCCC & TTCACTGTCG \\
\hline & 101 & & & & \\
\hline Wotan & GAGAACTCAA & GAAAGCAATC & CCACCGCACT & GTTTCAAACG & CTCGATCCCT \\
\hline Mutante12 & GAGAACTCAA & GAAAGCAATC & CCACCGCACT & GTTTCAAACG & CTCGATCCCT \\
\hline Mutante13 & GAGAACTCAA & GAAAGCAATC & CCACCGCACT & GTTTCAAACG & CTCGATCCCT \\
\hline \multirow[t]{2}{*}{19661} & GAGAACTCAA & GAAAGCAATC & CCACCGCACT & GTTTCAAACG & CTCGATCCC \\
\hline & 151 & & & & \\
\hline Wotan & CGCTCTTTCT & ССТАССТСАТ & CTGGGACATC & ATCATAGCCT & сCTGCTTCT \\
\hline Mutante12 & CGCTCTTTCT & ССТACCTCAT & CTGGGACATC & ATCATAGCCT & CCTGCTTCT \\
\hline Mutante13 & CGCTCTTTCT & ССТАССТСAT & CTGGGACATC & ATCATAGCCT & CCTGCTTCT \\
\hline \multirow[t]{2}{*}{19661} & CGCTCTTTCT & ССТАССТСАТ & CTGGGACATC & ATCATAGCCT & CCTGCTTCT \\
\hline & 201 & & & & \\
\hline Wotan & CTACGTCGCC & ACCACTTACT & ТСССТСТсCТ & СССТСАСССТ & СТСТССТАС \\
\hline Mutante 12 & CTACGTCGCC & ACCACTTACT & тСССТСТССТ & СССТСАСССТ & СТСТССТАС \\
\hline Mutante 13 & CTACGTCGCC & ACCACTTACT & TCССТСТССТ & СССТСACСCT & СТСТССТAC \\
\hline \multirow[t]{2}{*}{19661} & CTACGTCGCC & ACCACTTACT & ТСССТСТССТ & СССТСАСССТ & СТСТССТАC \\
\hline & 251 & & & & \\
\hline Wotan & TCGCCTGGCC & TCTCTACTGG & GCCTGCCAGG & GCTGCGTCCT & AACCGGCGT \\
\hline Mutant & TCGCCTGGCC & TCTCTACTGG & GCCTGCCAGG & GCTGCGTCCT & AACCGGCGI \\
\hline Mutante13 & TCGCCTGGCC & TCTCTACTGG & GCCTGCCAGG & GCTGCGTCCT & AACCGGCGI \\
\hline \multirow[t]{2}{*}{19661} & TCGCCTGGCC & TCTCTACTGG & GCCTGCCAGG & GCTGCGTCCT & AACCGGCGT \\
\hline & 301 & & & & \\
\hline Wotan & TGGGTCATAG & CCCACGAGTG & CGGCCACCAC & GCCTTCAGCG & ACTACCAGT \\
\hline Mutante12 & TGGGTCATAG & CCCACGAGTG & CGGCCACCAC & GCCTTCAGCG & ACTACCAGT \\
\hline Mutante13 & TGGGTCATAG & CCCACGAGTG & CGGCCACCAC & GCCTTCAGCG & ACTACCAGA \\
\hline \multirow[t]{2}{*}{19661} & TGGGTCATAG & CCCACGAGTG & CGGCCACCAC & GCCTTCAGCG & ACTACCAGA \\
\hline & 351 & & & & \\
\hline Wotan & GCTGGACGAC & ACCGTCGGCC & TCATСТTCCA & СтСстTССтС & CTCGTCCCTT \\
\hline Mutante12 & GCTGGACGAC & ACCGTCGGCC & TСАТСТTССА & стссттссте & CTCGTCCCT \\
\hline Mutante13 & GCTGGACGAC & ACCGTCGGCC & TCATCTTCCA & СТССТTССТC & CTCGTCCCT \\
\hline \multirow[t]{2}{*}{19661} & GCTGGACGAC & ACCGTCGGCC & TCATCTTCCA & стссттсстс & CTCGTCCCT \\
\hline & 401 & & & & \\
\hline Wotan & АСТTСТССТG & GAAGTACAGT & CATCGACGCC & ACCATTCCAA & САCTGGCT \\
\hline Mutante12 & АСТTCTCCTG & GAAGTACAGT & CATCGACGCC & АССАTTCCAA & CACTGGCTC \\
\hline Mutante13 & АсттстсстG & GAAGTACAGT & CATCGACGCC & ACCATTCCAA & CACTGGCTC \\
\hline 19661 & АстTстсстG & GAAGTACAGT & CATCGACGCC & АССАTTCCAA & CACTGGCT \\
\hline
\end{tabular}


Wotan

Mutante12

Mutante13

19661

Wotan

Mutante12

Mutante13

19661

Wotan

Mutante 12

Mutante13

19661

Wotan

Mutante12

Mutante13

19661

Wotan

Mutante12

Mutante13

19661

Wotan

Mutante12

Mutante13

19661

Wotan

Mutante12

Mutante13

19661

Wotan

Mutante12

Mutante13

19661

Wotan

Mutante 12

Mutante13

19661

Wotan

Mutante12

Mutante13

19661

Wotan

Mutante12

Mutante13

19661
451

476

500

CTCGAGAgA ACGAAGTGTT TGTCCCCAAG AAgAAgTCAg ACATCAAGTG CTCGAGAGA ACGAAGTGTT TGTCCCCAAG AAGAAGTCAG ACATCAAGTG CTCGAGAGA ACGAAGTGTT TGTCCTCAAG AAGAAGTCAG ACATCAAGTG CTCGAGAGA ACGAAGTGTT TGTCCCCAAG AAGAAGTCAG ACATCAAGTG

501

550

GTACGGCAAG TACCTCAACA ACCCTTTGGG ACGCACCGTG ATGTTAACGG GTACGGCAAG TACCTCAACA ACCCTTTGGG ACGCACCGTG ATGTTAACGG GTACGGCAAG TACCTCAACA ACCCTTTGGG ACGCACCGTG ATGTTAACGG GTACGGCAAG TACCTCAACA ACCCTTTGgG ACGCACCGTG ATGTTAACGg

551

600

TTCAGTTCAC TCTCGGCTGG CCTTTGTACT TAGCCTTCAA CGTCTCGGGG TTCAGTTCAC TCTCGGCTGG CCTTTGTACT TAGCCTTCAA CGTCTCGGGG TTCAGTTCAC TCTCGGCTGG CCTTTGTACT TAGCCTTCAA CGTCTCGGGG TTCAgTTCAC TCTCGgCTGg CCTTTGTACT TAgCCTTCAA CGTCTCGAgG

601 638

650

AGACCTTACG ACGGCGGCTT CGCTTGCCAT TTCCACCCCA ACGCTCCCAT AGACCTTACG ACGGCGGCTT CGCTTGCCAT TTCCACCTCA ACGCTCCCAT AGACCTTACG ACGGCGGCTT CGCTTGCCAT TTCCACCCCA ACGCTCCCAT AGACCTTACG ACGGCGGCTT CGCTTGCCAT TTCCACCCCA ACGCTCCCAT

\section{1}

700

CTACAACGAC CGTGAGCGTC TCCAGATATA CATCtCCGAC GCTGGCATCC CTACAACGAC CGTGAGCGTC TCCAGATATA CATCTCCGAC GCTGGCATCC CTACAACGAC CGTGAGCGTC TCCAGATATA CATCTCCGAC GCTGGCATCC CTACAACGAC CGTGAGCGTC TCCAGATATA CATCTCCGAC GCTGGCATCC

701 750

TCGCCGTCTG CTACGGTCTC TACCGCTACG CTGCTGTCCA AgGAgTTGCC TCGCCGTCTG CTACGGTCTC TACCGCTACG CTGCTGTCCA AGGAGTTGCC TCGCCGTCTG CTACGGTCTC TACCGCTACG CTGCTGTCCA AGGAGTTGCC tCGCCGTCTg CTACGgtCTC TACCGCtACG CtgCtgtCCA AgGAgttGCC

751

800

TCGATGGTCT GCTTCTACGG AGTTCCTCTT CTGATTGTCA ACGGGTTCTT TCGATGGTCT GCTTCTACGG AGTTCCTCTT CTGATTGTCA ACGGGTTCTT TCGATGGTCT GCTTCTACGG AGTTCCTCTT CTGATTGTCA ACGGGTTCTT TCGATGGTCT GCTTCTACGG AGTTCCTCtT CTGATtGTCA ACGGGTTCTt

801

850

AGTTTTGATC ACTTACTTGC AGCACACGCA TCCTTCCCTG CCTCACTATG AGTTTTGATC ACTTACTTGC AGCACACGCA TCCTTCCCTG CCTCACTATG AGTTTTGATC ACTTACTTGC AGCACACGCA TCCTTCCCTG CCTCACTATG AgtTtigatC ACTtACTTGC AgCACACGCA tCCTtCCCtg CCTCACTAtg

851

900

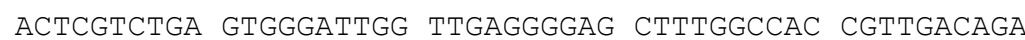
ACTCGTCTGA GTGGGATTG TTGAgGgGA CTTTGGCCAC CGTTGACAGA ACTCGTCTGA GTGGGATTGG TTGAGGGGAG CTTTGGCCAC CGTTGACAGA

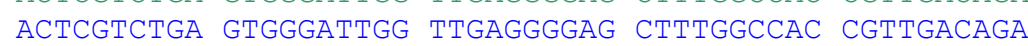

901 950

GACTACGGAA TCTTGAACAA GGTCTTCCAC AATATCACGG ACACGCACGT GACTACGGAA TCTTGAACAA GGTCTTCCAC AATATCACGG ACACGCACGT GACTACGGAA TCTTGAACAA GGTCTTCCAC AATATCACGG ACACGCACGT GACTACGGAA TCTTGAACAA GGTCTTCCAC AATATCACGg ACACGCACGT

951 1000

GGCGCAtCAC CTGTTCtCGA CCATGCCGCA tTAtCAtgCg AtgGAagctA GGCGCATCAC CTGTTCTCGA CCATGCCGCA tTATCATGCG ATGgAAgCtA GGCGCATCAC CTGTTCTCGA CCATGCCGCA TTATCATGCG ATGGAAGCTA GgCGCAtCAC CTGtTCtCGA CCAtgCCGCA tiAtCAtgCG AtgGAAgCtA 
Wotan

Mutante12

Mutante13

19661

Wotan

Mutante12

Mutante13

19661

\section{Wotan}

Mutante12

Mutante13

19661

Wotan

Mutante12

Mutante13

19661
1001

1050

CGAAGGCGAT AAAGCCGATA CTGGGAGAgT ATTATCAGTT CGATGGGACG

CGAAGGCGAT AAAGCCGATA CTGGGAGAGT ATTATCAGTT CGATGGGACG

CGAAGGCGAT AAAGCCGATA CTGGGAGAGT ATTATCAGTT CGATGGGACG

CGAAGGCGAT AAAGCCGATA CTGGGAGAgT AtTATCAGTT CGATGGGACG

1051

1100

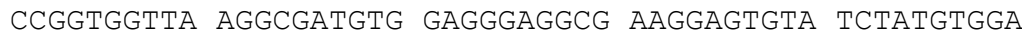

CCGGTGGTTA AgGCGATGTG GAgGgAgGCG AAgGAgTGTA TCTATGTGGA CCGGTGGTTA AgGCGATGTG GAgGgAgGCG AAgGAgtgTA TCTATGTGgA CCGgtggttA AggCGAtgtg GAgGgAggCg AAggAgtgtA tCtAtgtgGA

1101

1150

ACCGGACAgG CAAgGtgAgA AgAAAgGtgt GTtCTGGTAC AACAATAAgT ACCGGACAgG CAAGgTGAgA AgAAAgGtgT GTTCTGGTAC AACAATAAGt ACCGGACAGG CAAGGTGAGA AGAAAGGTGT GTTCTGGTAC AACAATAAGT

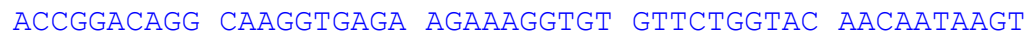

1151

1171

TATGAAGCAA AGAAGAAACT G

TATGAAGCAA AGAAGAAACT G

TATGAAGCAA AGAAGAAACT G

TATGAAGCAA AGAAGAAACT G 
Lebenslauf

Personalien: $\quad$ Maria Kahlmeyer

geboren am 16.01.1971 in Leinefelde

Familienstand: verheiratet

3 Kinder

\section{Ausbildung:}

1978-1988

Polytechnische Oberschule, Arenshausen

1988-1990

1990

Erweiterte Oberschule, Heiligenstadt

Abitur

1990-1993

1993-1998

1994-1995

Universität Göttingen, Studium der Biologie

Abschluss. Vordiplom

Universität Göttingen, Studium Agrarwissenschaft Abschluss Diplom-Agrar-Ingenieur

Praktikum in der Agrar-Gesellschaft mbH Kalteneber

1998-

Mitarbeiter der Agrar-Gesellschaft mbH Kalteneber

2008-

Promotionsstudium am Institut für Pflanzenbau und Pflanzenzüchtung der Georg-August Universität, Göttingen 


\section{Danksagung}

Herrn Prof. Dr. Heiko Becker danke ich für die Überlassung des Themas, für die wissenschaftliche Betreuung und das mir entgegengebrachte Vertrauen, ebenso möchte ich mich bei Dr. Christian Möllers für seine Unterstützung bedanken.

Frau Prof. Dr. Elke Pawelzik danke ich für die Übernahme des Korreferats.

Bei allen Mitarbeiterinnen und Mitarbeitern der Abteilungen Pflanzenzüchtung und Pflanzenbau des Departments für Nutzpflanzenwissenschaften bedanke ich mich für die gute Zusammenarbeit und die Hilfsbereitschaft. Besonders erwähnen möchte ich hier Gunda Asselmeyer, Uwe Ammermann und Rosi Clemens für die Unterstützung bei der Durchführung meiner Versuche.

Mein Dank gilt auch der Agrar-Gesellschaft mbH Kalteneber, die mich in all den Jahren bei der Durchführung der Versuche und dem Schreiben der Arbeit unterstützt hat.

Ein ganz besonderer Dank gebührt meiner Familie, die mich auf vielfältige Weise unterstützt hat und ohne deren Hilfe ich die Arbeit nicht hätte schreiben können. 